\title{
Thermal Analysis of LANL lon Exchange Column
}

by

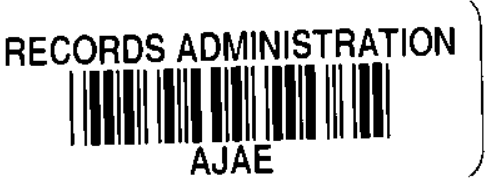

J. E. Laurinat

Westinghouse Savannah River Company

Savannah River Site

Aiken, South Carolina 29808

This paper was prepared in connection with work done under the above contract number with the U. $S$.

Department of Energy. By acceptance of this paper, the publisher and/or recipient acknowledges the U. S.

Government's right to retain a nonexclusive, royalty-free license in and to any copyright covering this paper, along with the right to reproduce and to authorize others to reproduce all or part of the copyrighted paper. 
May 20, 1999

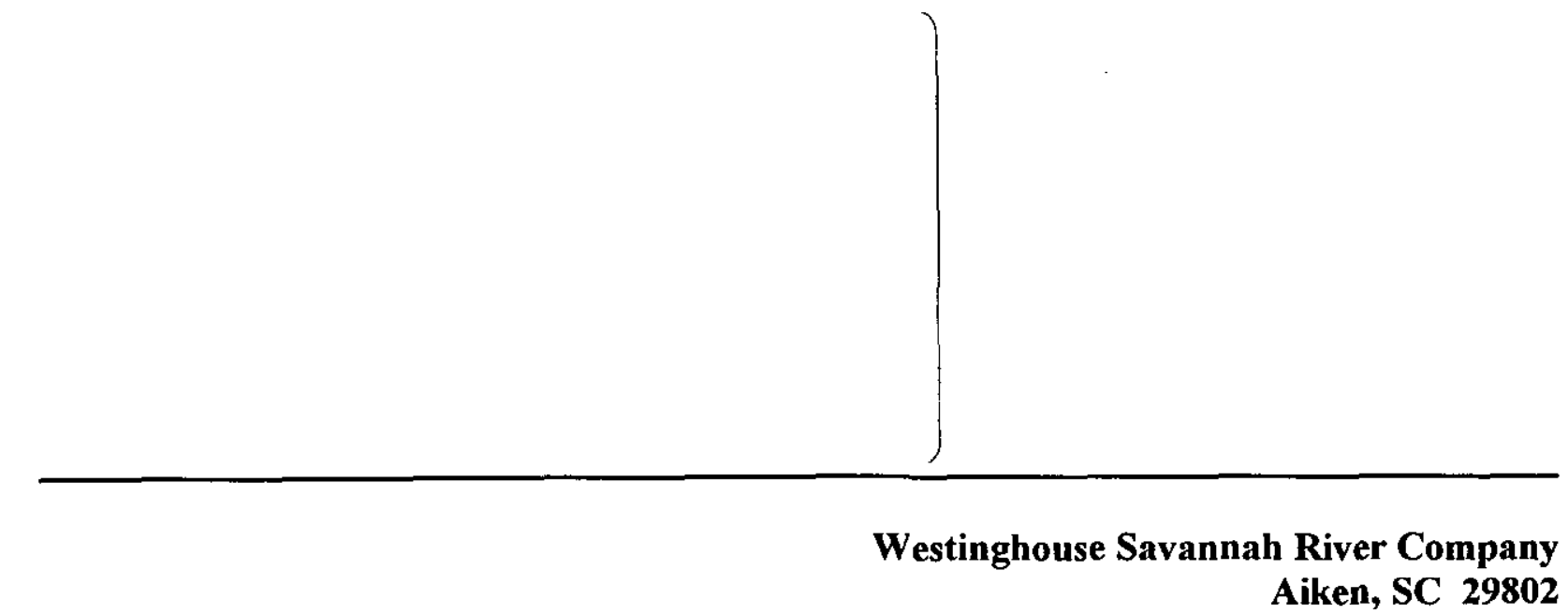

Prepared by the U. S. Department of Encrgy under Contract DE-AC09-96SR18500 
WSRC-TR-99-00027

Revision 0

\section{DISCLAIMER}

This report was prepared as an account of work sponsored by an agency of the United States Government. Neither the United States Government nor any agency thereof, nor any of their employees, makes any warranty, express or implied, or assumes any legal liability or responsibility for the accuracy, completeness, or usefulness of any information, apparatus, product, or process disclosed, or represents that its use would not infringe privately owned rights. Reference herein to any specific commercial product, process, or service by trade name, trademark, manufacturer, or otherwise does not necessarily constitute or imply its endorsement, recommendation, or favoring by the United States Government or any agency thereof. The views and opinions of authors expressed herein do not necessarily state or reflect those of the United States Government or any agency thereof.

This report has been reproduced directly from the best available copy.

Available to DOE and DOE contractors from the Office of Scientific and Technical Information, P.O. Box 62, Oak Ridge, TN 37831; prices available from (615) 576-8401.

Available to the public from the National Technical Information Service, U.S. Department of Commerce, 5285 Port Royal Road, Springfield, VA 22161. 
Thermal Analysis of LANL Ion Exchange Column (U)

By J. E. Laurinat and M. E. Pansoy-Hjelvik, LANL

Issued: May 20, 1999

Approvals 
Section Page

1.0 Introduction $1-2$

2.0 Summary of Results 2

3.0 Input Conditions for Heat Transfer Analysis 2

4.0 Models for Ion Exchange Chemistry ....................................................... 3-4

5.0 Models for Adsorption and Elution ....................................................... 4-5

6.0 Models for Bulk Heat and Mass Transfer ................................................... 6-10

7.0 Physical Property Correlations .................................................................... 10-11

8.0 Initial and Boundary Conditions ……................................................... 11-12

9.0 Heat Transfer Correlations ..................................................................... 12-13

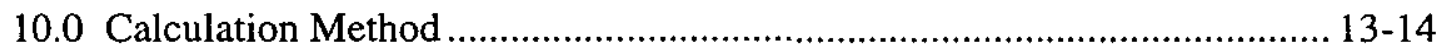

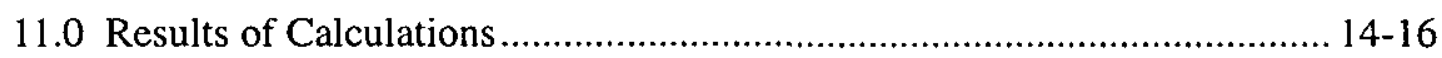

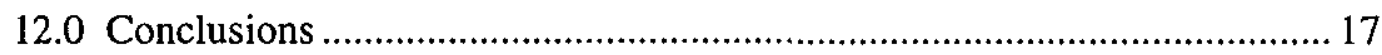

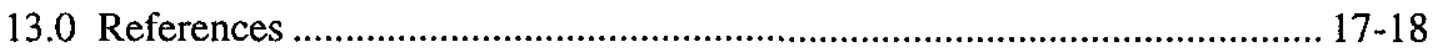

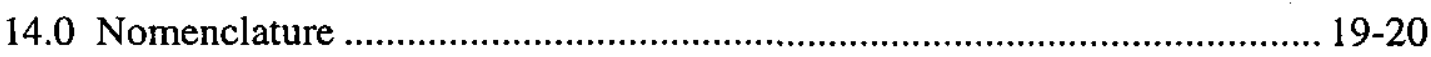

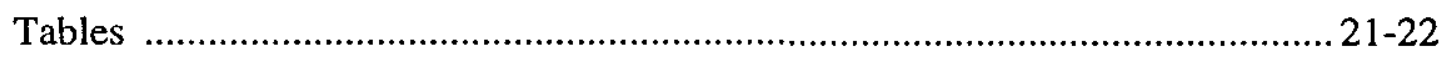

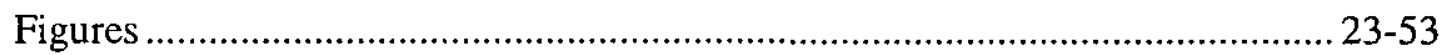

Appendix: Source Code, Sample Input, and Sample Output Listings ................ A1-A51 


\subsection{Introduction}

This document reports results from an ion exchange column heat transfer analysis requested by Los Alamos National Laboratory (LANL). LANL plans to operate a laboratory-scale anion exchange column to extract $\mathrm{Pu}-238$ from nitric acid solutions. The analysis is needed for a process hazards analysis.

The object of the analysis is to demonstrate that the decay heat from the Pu-238 will not . cause resin bed temperatures to increase to a level where the resin significantly degrades. At low temperatures, resin bed temperatures increase primarily due to decay heat. At higher temperatures, an exothermic reaction between nitric acid and the resin predominates. This reaction degrades the resin and can lead to a potentially violent thermal excursion.

The analysis is based on a previous study of the SRS Frames Waste Recovery (FWR) column, performed in support of the Pu-238 production campaign for NASA's Cassini mission. In that study, temperature transients following an interruption of flow to the column were calculated. The transient calculations were terminated after the maximum resin bed temperature reached the Technical Standard of $60^{\circ} \mathrm{C}$, which was set to prevent significant resin degradation.

LANL has requested calculations of temperature transients both during normal operation, including loading, washing, and elution, and following an interruption of flow. The LANL column differs from the FWR column in that it has a significantly smaller radius, $3.81 \mathrm{~cm}$ nominal versus approximately $28 \mathrm{~cm}$. It follows that natural convection removes heat much more effectively from the LANL column, so that the column may reach thermal equilibrium before the maximum resin bed temperature reaches $60^{\circ} \mathrm{C}$. Consequently, the calculations for a flow interruption were extended until an approach to thermal equilibrium was observed.

The LANL ion exchange process also uses a different resin than was used in the FWR column. The LANL column uses Reillex HPQ ${ }^{\mathrm{TM}}$ resin, which is more resistant to attack by nitric acid than the Ionac $641^{\mathrm{TM}}$ resin used in the FWR column. Therefore, heat generation and resin consumption by the nitric acid reaction, which was included in the previous study, is neglected in the LANL analysis.

Four parameters are varied in the LANL study: the plutonium feed concentration, the flow rate for loading, washing, and elution, the heat transfer conditions (either cooling by ambient air at $25^{\circ} \mathrm{C}$ or by a water jacket at $15^{\circ} \mathrm{C}$ ), and the amount of plutonium loaded (either one or two times bed capacity). Temperature transients are calculated for a twolevel matrix of sixteen different conditions. Calculations were performed using a finite difference computer code, which incorporates models for absorption and elution of plutonium and for forced and natural convection within the resin bed.

Calculations were performed to determine the maximum bed temperaturc during loading, washing, or elution for normal column operation and to determine the equilibrium 
temperature for no flow to the column. Calculations for normal column operation were performed using an initial temperature and a feed temperature equal to either the ambient air temperature or the cooling jacket temperature. The model for the normal flow calculations did not include natural convection. The no flow calculations were started with the temperature and concentration profiles at the end of the loading stage, when there would be a maximum amount of plutonium either adsorbed on the resin or in the feed solution in the column. The amount of plutonium that was loaded was varied by changing the time for loading (e.g., twice the normal loading time for two times the bed capacity).

\subsection{Summary of Results}

Calculated maximum bed temperatures range from close to the ambient air or cooling water temperature for normal operation at the high feed flow rate of $20 \mathrm{~mL} / \mathrm{sec}$ to $58.1^{\circ} \mathrm{C}$ for operation at the low feed flow rate of $0.5 \mathrm{~mL} / \mathrm{sec}$ with air cooling, a feed amount equal to twice the bed plutonium capacity, and a high feed concentration of 0.1304 $\mathrm{gm} / \mathrm{mL}$ Pu-238. Use of a $15^{\circ} \mathrm{C}$ cooling water jacket would lower this maximum temperature to $44.8^{\circ} \mathrm{C}$ for the same conditions. For the same feed conditions, the maximum temperatures for natural convection during a flow stoppage are $84.3^{\circ} \mathrm{C}$ for air cooling and $60.6^{\circ} \mathrm{C}$ for the water jacket. The maximum temperatures during normal operation occurred during washing. Following stoppages of flow, the maximum bed temperatures either peaked and then dropped slightly to an equilibrium temperature or reached their highest values at thermal equilibrium. Thermal equilibrium was achieved about 2 hours after flow was stopped.

The maximum calculated bed temperature exceeds $60^{\circ} \mathrm{C}$, where significant resin degradation commences, ${ }^{2}$ but is below $110^{\circ} \mathrm{C}$, the approximate temperature at which resin-nitric acid reactions become thermally excursive. ${ }^{3}$ Thus, the column can be operated safely at the specified conditions with either air or water-jacket cooling. Use of a water jacket will minimize resin degradation but might also slow rates of adsorption and elution, particularly at high feed concentrations and flow rates.

\subsection{Input Conditions for Heat Transfer Analysis}

Table 1 lists the input conditions for the LANL ion exchange column. As this table indicates, fixed conditions include the column dimensions and the resin bed physical characteristics. Variable conditions include the feed flow rate, the feed concentration, the amount of plutonium fed to the column, and the provisions for cooling the column, either a water cooling jacket or exposure to ambient air. The low and high feed concentrations apply to the solution that is fed to the column with and without pretreatment, respectively. Other variables have been selected to bound anticipated operating conditions. 


\section{Revision 0}

\subsection{Models for Ion Exchange Chemistry}

In the ion exchange process, plutonium is selectively adsorbed onto the resin from concentrated nitric acid solution during loading and washing and is eluted from the resin with dilute nitric acid. In the model, the adsorption and elution processes occur irreversibly during normal operation. During a flow interruption, however, the model assumes that plutonium adsorbs onto the resin when the acid solution between the resin beads is saturated with plutonium and is eluted when the acid solution is not saturated. Saturation conditions are calculated using measured equilibrium relationships for nitrated resins.

The following reaction occurs on the resin surfaces, ${ }^{2}$ which are assumed to be evenly distributed throughout the resin beads.

$$
\mathrm{R}_{2} \mathrm{Pu}\left(\mathrm{NO}_{3}\right)_{6} \text { (solid) } \Leftrightarrow \mathrm{PuNO}_{3}^{3+}+3 \mathrm{NO}_{3}^{-}+2 \mathrm{RNO}_{3} \text { (solid) }
$$

where $\mathrm{R}$ represents a chemically active site on the resin substrate.

Equilibrium for this reversible reaction is governed by the solubility product ${ }^{2}$

$$
\mathrm{K}_{1}=\left[\mathrm{PuNO}_{3}^{3+} \mathrm{NO}_{3}^{-}\right]^{3}
$$

where $\mathrm{K}_{1}$ is an equilibrium constant that depends on the resin type and the plutonium loading on the resin. The model uses a value of 0.26 , which has been measured for fully loaded Dowex-1 X-4 resin. ${ }^{2}$

In solution, the plutonium ions complex with nitrate ions according to ${ }^{2}$ :

$$
\mathrm{Pu}^{4+}+\mathrm{NO}_{3}^{-} \Leftrightarrow \mathrm{PuNO}_{3}^{3+}
$$

The equilibrium constant for this reaction is given $b y^{2}$

$$
\mathrm{K}_{2}=\frac{\left[\mathrm{PuNO}_{3}^{3+}\right]}{\left[\mathrm{Pu}^{4+}\left[\mathrm{NO}_{3}^{-}\right]\right.}=2.9 \pm 0.6
$$

These equilibrium relations can be combined with the following stoichiometric equations to calculate the plutonium and nitrate concentrations in a saturated solution.

$$
\left[\mathrm{NO}_{3}\right]_{\text {iotal }}=\left[\mathrm{NO}_{3}^{-}\right]+\left[\mathrm{PuNO}_{3}^{3+}\right]
$$

and

$$
[\mathrm{Pu}]_{\mathrm{rotal}}=\left[\mathrm{Pu}^{4+}\right]+\left[\mathrm{PuNO}_{3}^{3+}\right]
$$


For natural convection during a flow stoppage, the model solves these equations iteratively at each calculation node to calculate the saturation plutonium concentration based on the actual nitrate concentration and the saturation nitrate concentration based on the actual plutonium concentration. The calculated saturation values are then used to compute a rate of adsorption if the solution is supersaturated or desorption if the solution is unsaturated.

\subsection{Models for Adsorption and Elution}

The model assumes that the rates of adsorption and elution are controlled by diffusion of plutonium to and from the resin bead surfaces. Because the plutonium ionic species react rapidly at the resin surface, adsorption takes place at the outer surfaces of the resin beads before the plutonium can penetrate to the interior of the beads. Consequently, solidphase, or particle, diffusion controls the rate of adsorption. ${ }^{2}$ The particle diffusion model is analogous to a molecular diffusion model, with a particle diffusivity and the bulk adsorbed concentration replacing the ordinary diffusivity and the solution concentration.

A shrinking core diffusion approximation describes desorption of plutonium from the resin beads. ${ }^{2}$ For elution during normal operation, the rate of desorption is modified by a factor that accounts for mixing of the dilute elution acid with the concentrated acid used to load the resin. ${ }^{1}$ In addition, a pore diffusion model is used to calculate the rate of interchange of plutonium and nitrate between the interparticle and intraparticle, or pore, solutions. This takes the same form as the particle diffusion model for plutonium adsorption, with a pore diffusivity replacing the particle diffusivity. This interchange rate is calculated for normal operation but not for flow stoppages. To simplify the calculations during a flow stoppage, the model assumes that the acid is well mixed both in the spaces between resin beads and in the resin bead pores. The concentrations of plutonium between the beads and in the bead pores are combined on a volume average basis at the start of the flow stoppage. Thereafter, both solutions are treated as if they are located outside the resin beads.

Reference 1 describes details of the adsorption and elution models, so the adsorption and elution rate equations are not listed in this report. It must be noted, however, that there is an error in the equations for the rate of plutonium desorption, $G_{a}$ (Equations 33, A-34, A-36, and A-37 in Reference 1). Equation A-34 should read

$$
1-\frac{\bar{y}}{x_{\max }}=\frac{\sqrt{c-\frac{x}{x_{\max }}}}{\sqrt{\frac{x}{x_{\max }}}+\sqrt{c-\frac{x}{x_{\max }}}}
$$

With this change, Equations 33 and A-36 become 
$\mathrm{G}_{\mathrm{in}}\left(=-\frac{\mathrm{df}}{\mathrm{dt}}\right)=\frac{-\mathrm{cf}_{0}\left(\frac{\sqrt{c-\frac{\mathrm{x}}{\mathrm{x}_{\max }}}}{\sqrt{\frac{\mathrm{x}}{\mathrm{x}_{\max }}}+\sqrt{\mathrm{c}-\frac{\mathrm{x}}{\mathrm{x}_{\max }}}}\right)}{\tau_{\text {pore }}\left\{1-\frac{4}{5} \sqrt[3]{\frac{\mathrm{f}_{0}}{\mathrm{f}}}-\frac{1}{5}\left(\frac{\mathrm{f}_{0}}{\mathrm{f}}\right)^{2}\right\}}$

Equation A-37 no longer is valid. Instead, as expected, the concentration gradient factor, $1-\frac{\bar{y}}{x_{\max }}$, goes to zero as the saturation level of the acid, $c$, approaches that of the plutonium in solution, $\frac{\mathrm{x}}{\mathrm{x}_{\max }}$.

Particle and pore diffusion coefficients control the rates of particle diffusion during loading and pore diffusion during elution, respectively. In the calculations for the FWR column, diffusivity values were selected to fit loading profiles and discharge transients for test elutions. ${ }^{1}$ The particle diffusivity was set to $2 \times 10^{-9} \mathrm{~cm}^{2} / \mathrm{sec}$, and the pore diffusivity was set to $1 \times 10^{-6} \mathrm{~cm}^{2} / \mathrm{sec}$.

LANL has stated that their Reillex resin loads much more rapidly than the typical resins used at SRS. This implies that both the particle and pore diffusivities are much greater than these values. A bounding value for both diffusivities is the effective pore diffusivity for plutonium (IV) nitrate in aqueous solutions. This assumes that the controlling resistance for both adsorption and elution is pore diffusion and that the resin bead pores are sufficiently large so that steric hindrance is not a factor. The formula for the pore diffusivity is

$D_{\text {pore }}=\frac{\varepsilon_{i}}{1-\varepsilon_{0}} \frac{D_{m o l}}{\tau}$

where the term $\frac{\varepsilon_{\mathrm{i}}}{1-\varepsilon_{\mathrm{o}}}$ represents a volumetric correction factor relating the pore volume to the total volume of the resin beads and $\tau$ is the tortuosity. In Reference 1, the pore volume fraction $\varepsilon_{\mathrm{i}}$ was estimated to be 0.132 and the interparticle volume fraction $\varepsilon_{0}$ was estimated to be 0.326 . A tortuosity factor of 2 is used; this is typical for diffusion through either pores or unconsolidated solids. ${ }^{4}$ The molecular diffusivity for plutonium ions is approximately $1.25 \times 10^{-5} \mathrm{~cm}^{2} / \mathrm{sec}$ (see Equation 28, Section 7.0). These values give an effective diffusivity of $1.2 \times 10^{-6} \mathrm{~cm}^{2} / \mathrm{sec}$, which agrees with the pore diffusivity of $1 \times 10^{-6} \mathrm{~cm}^{2} / \mathrm{sec}$ for the FWR column analysis. Preliminary calculations demonstrated that the use of this diffusivity for both the particle and pore diffusion coefficients resulted in most of the plutonium being loaded onto the resin at the concentrations and flow rates specified by LANL. 


\subsection{Models for Bulk Mass and Heat Transfer}

The previous section describes the model for mass transfer within the resin beads. Mass and heat transfer in the bulk solution between the resin beads are modeled using standard equations for convection and dispersion. Because flow is restricted to the interparticle solution, the convective mass transfer equations for plutonium and nitrate apply to the interparticle concentrations. The total concentrations are calculated by summing the concentrations in the interparticle solution, in the intraparticle, or pore, solution, and adsorbed on the particles:

$$
\begin{aligned}
& \mathrm{C}_{\mathrm{Pu}_{\mathrm{u}}}=\mathrm{x}_{\mathrm{Pu}}+\mathrm{y}_{\mathrm{Pu}}+\mathrm{f} \\
& \mathrm{C}_{\mathrm{NO}_{3}}=\mathrm{x}_{\mathrm{NO}_{3}}+\mathrm{y}_{\mathrm{NO}_{3}}
\end{aligned}
$$

The convective mass transfer equations take the form

$$
\frac{\partial x_{P_{u}}}{\partial t}+v_{z s} \frac{\partial x_{P_{u}}}{\partial z}+v_{r s} \frac{\partial x_{P_{u}}}{\partial r}=\left(D_{\text {mol }}+\alpha_{z}+D_{\text {mix }}\right) \frac{\partial^{2} x_{P_{u}}}{\partial z^{2}}+\frac{\alpha_{r}}{r} \frac{\partial}{\partial r}\left(r \frac{\partial x_{P_{u}}}{\partial r}\right)-\frac{d y_{P_{u}}}{d t}-\frac{d f}{d t}
$$

and

$\frac{\partial \mathrm{x}_{\mathrm{NO}_{3}}}{\partial \mathrm{t}}+\mathrm{v}_{\mathrm{zs}} \frac{\partial \mathrm{x}_{\mathrm{NO}_{3}}}{\partial \mathrm{z}}+\mathrm{v}_{\mathrm{rs}} \frac{\partial \mathrm{x}_{\mathrm{NO}_{3}}}{\partial \mathrm{r}}=\left(\mathrm{D}_{\mathrm{mol}}+\alpha_{\mathrm{z}}+\mathrm{D}_{\mathrm{mix}}\right) \frac{\partial^{2} \mathrm{x}_{\mathrm{NO}_{3}}}{\partial \mathrm{z}^{2}}+\frac{\alpha_{\mathrm{r}}}{\mathrm{r}} \frac{\partial}{\partial \mathrm{r}}\left(\mathrm{r} \frac{\partial \mathrm{x}_{\mathrm{NO}_{3}}}{\partial \mathrm{r}}\right)-\frac{\mathrm{dy}_{\mathrm{NO}_{3}}}{\mathrm{dt}}$

The rates of change of the pore concentrations, $\frac{\mathrm{dy}_{\mathrm{Pu}_{\mathrm{u}}}}{\mathrm{dt}}$ and $\frac{\mathrm{dy}_{\mathrm{NO}_{3}}}{\mathrm{dt}}$, are modeled using a pore diffusion model, and the rate of change of the adsorbed plutonium, $\frac{\mathrm{df}}{\mathrm{dt}}$, is modeled using a particle diffusion model. The pore and particle diffusion models are described in the previous section and in more detail in Reference 1.

The convective heat transfer equation includes a term for the decay heat, $Q_{\text {decay }}$. This equation is

$$
\begin{aligned}
& \rho_{\text {bed }} c_{p, b e d} \frac{\partial T}{\partial t}+\rho_{f} c_{p, f} v_{z s} \frac{\partial T}{\partial z}+\rho_{f} c_{p, f} v_{r s} \frac{\partial T}{\partial r} \\
& =\left(k_{\text {bed }}+\rho_{f} c_{p, f} \alpha_{z}+\rho_{f} c_{p, f} D_{\text {mix }}\right) \frac{\partial^{2} T}{\partial z^{2}}+\left(k_{\text {bed }}+\rho_{f} c_{p, f} \alpha_{r}\right) \frac{1}{r} \frac{\partial}{\partial r}\left(r \frac{\partial T}{\partial r}\right)+Q_{\text {decay }} C_{P u}
\end{aligned}
$$

The axial dispersion coefficients in the mass and heat transfer equations is given by ${ }^{5}$ 
$\alpha_{\mathrm{z}}=2 \mathrm{~d}_{\mathrm{p}} \mathrm{v}_{\mathrm{zs}}$

The radial dispersion coefficient is about one-fifth as large. ${ }^{6}$ Thus,

$\alpha_{\mathrm{r}}=0.4 \mathrm{~d}_{\mathrm{p}} \mathrm{v}_{z s}$

For normal operating conditions (loading, washing, and elution), the superficial axial velocity, $v_{z s}$, is specified, and the superficial radial velocity, $v_{r s}$, is assumed to be zero. For flow stoppages, these velocities result from natural convection. Natural convection velocities are ignored during loading washing, and elution. At high feed flow rates, the omission of natural convection does not have a significant effect. At lower feed flow rates, this omission is conservative in that it results in higher resin bed temperatures than would be predicted if natural convection were included.

Velocity components for natural convection flow are calculated by combining the Ergun equation with axial and radial component momentum equations, as suggested by Stewart and Dona. The axial velocity for natural convection is modeled using a form of the Ergun equation for laminar flow, which is ${ }^{8,9}$

$\mathrm{v}_{\mathrm{zs}}=\frac{\mathrm{d}_{\mathrm{p}}^{2} \varepsilon_{\mathrm{o}}^{4}}{200\left(1-\varepsilon_{\mathrm{o}}\right)^{2} \mu_{\mathrm{L}}}\left[-\frac{\Delta \mathrm{P}}{\Delta \mathrm{z}}\right]$

It may be noted that in Equation 15, $\mathrm{v}_{\mathrm{zs}} \propto \frac{\varepsilon_{\mathrm{o}}^{4}}{\left(1-\varepsilon_{\mathrm{o}}\right)^{2}}$, while in the Ergun equation, $v \propto \frac{\varepsilon_{0}^{3}}{\left(1-\varepsilon_{0}\right)^{2}}$. The extra void fraction multiplier is added because the buoyant force applies only to the fraction of the total volume occupied by the bulk solution and not to the resin beads.

The Ergun equation was originally derived for unidirectional flow. To model the twodimensional flow in the resin bed, separate equations are used for the axial and radial velocity components. These equations take the form

$$
\mathrm{v}_{\mathrm{zs}}=\frac{\mathrm{d}_{\mathrm{p}}^{2} \varepsilon_{\mathrm{o}}^{4}}{200\left(1-\varepsilon_{\mathrm{o}}\right)^{2} \mu}\left[-\frac{\partial \mathrm{P}}{\partial \mathrm{z}}+(\rho-\bar{\rho}) \mathrm{g}\right]
$$

and

$$
\mathrm{v}_{\mathrm{rs}}=\frac{\mathrm{d}_{\mathrm{p}}^{2} \varepsilon_{\mathrm{o}}^{4}}{200\left(1-\varepsilon_{\mathrm{o}}\right)^{2} \mu}\left[-\frac{\partial \mathrm{P}}{\partial \mathrm{r}}\right]
$$


The buoyancy term in the axial velocity equation contains a reference density, $\bar{\rho}$. At equilibrium, the reference density must be set so that there is no net flow upward or downward at any bed level. This implies that the reference density must equal the average fluid density at a given bed level. In other words,

$\bar{\rho}=\frac{2}{\mathrm{R}^{2}} \int_{r=0}^{\mathrm{R}} \mathrm{r} \rho \mathrm{dr}$

The pressure gradient terms must be eliminated from Equations 17 and 18 to solve for the velocity components. This is accomplished by taking cross derivatives. The resulting equation is

$\frac{\partial v_{\mathrm{rs}}}{\partial \mathrm{z}}-\frac{\partial \mathrm{v}_{\mathrm{zs}}}{\partial \mathrm{r}}+\frac{\mathrm{d}_{\mathrm{p}}^{2} \varepsilon_{\mathrm{o}}^{4} \mathrm{~g}}{200\left(1-\varepsilon_{\mathrm{o}}\right)^{2} \mu} \frac{\partial \rho}{\partial \mathrm{r}}=0$

The radial velocity is calculated by combining the continuity relation,

$\frac{1}{\mathrm{r}} \frac{\partial \mathrm{rv}}{\partial \mathrm{r}}+\frac{\partial \mathrm{v}_{\mathrm{zs}}}{\partial \mathrm{z}}=0$

with Equation 19.

The vorticity equation is derived by eliminating the pressure gradient terms from the axial and radial component equations of motion.

To simplify the solution of these equations, the axial and radial velocities are expressed in terms of a stream function, defined by

$\mathrm{v}_{\mathrm{zs}}=-\frac{1}{\mathrm{r}} \frac{\partial \mathrm{r} \psi}{\partial \mathrm{r}}$

and

$\mathrm{v}_{\mathrm{rs}}=\frac{\partial \psi}{\partial \mathrm{z}}$

In terms of this stream function, the vorticity equation becomes:

$\frac{\partial^{2} \psi}{\partial \mathrm{z}^{2}}+\frac{\partial}{\partial \mathrm{r}}\left(\frac{1}{\mathrm{r}} \frac{\partial \mathrm{r} \psi}{\partial \mathrm{r}}\right)+\frac{\mathrm{d}_{\mathrm{p}}^{2} \varepsilon_{\mathrm{o}}^{4} \mathrm{~g}}{200\left(1-\varepsilon_{\mathrm{o}}\right)^{2} \mu} \frac{\partial \rho}{\partial \mathrm{r}}=0$

This equation is solved with the boundary conditions 
$\psi=0$ at $\mathrm{r}=0$ and $\mathrm{r}=\frac{\mathrm{d}}{2}$

and

$\frac{\partial^{2} \psi}{\partial z^{2}}=0$ at $z=0$ and $z=L$

The first set of conditions specifies that there is no flow across the column wall or the column centerline. The second set of conditions states that the radial velocity gradient is zero at the top and bottom of the resin bed.

The natural convection velocities defined by Equations 16, 17, and 18 do not account for convection due to cross-sectional average axial density gradients. At the start of a flow stoppage, the solution in the resin bed is unstably stratified, with the higher plutonium concentrations and therefore the higher densities at the top of the resin bed. Preliminary calculations with these velocities showed that the solution remained unstably stratified even as equilibrium approached. Actually, significant unstable axial density variations would cause heavier fluid from above to mix with lighter fluid from below in regularly spaced regions called Bénard cells. A detailed model of Bénard cell convection was not attempted. Instead, mixing due to axial density gradients is calculated using an analogy to bubble columns. A dispersion model is used to describe mixing in bubble columns. The dispersion coefficient for bubble columns is defined in terms of the circulation velocity induced by the bubble motion, $v_{c}$, and the column diameter: ${ }^{10}$

$\mathrm{D}_{\text {mix }}=0.24 \mathrm{dv}_{\mathrm{c}}$

The same correlation is used to calculate the dispersion due to buoyancy-induced mixing in the resin bed. The circulation velocity is set equal to half that given by the Ergun equation and the pressure gradient based on the difference between the average densities for different levels:

$\mathrm{v}_{\mathrm{c}}=\frac{\mathrm{d}_{\mathrm{p}}^{2} \varepsilon_{\mathrm{o}}^{4}\left(\left.\bar{\rho}\right|_{z}-\left.\bar{\rho}\right|_{z+\Delta z}\right) g}{400\left(1-\varepsilon_{\mathrm{o}}\right)^{2} \mu}$

The one-half factor appears because mixing occurs in both directions and can therefore occupy only haif of the cross-sectional flow area in either direction. The use of crosssectional average densities accounts for the axial pressure gradients neglected by Equation 16. That equation already incorporates local density variations in the radial direction, so local density gradients are not included.

In the model, the dispersion coefficient is calculated using a weighted distribution of circulation velocities for density differences at different levels. The distribution is based on the mixing height for the dispersion coefficient, which is 0.8 times the column 
diameter. ${ }^{10}$ If it is assumed that the mixing intensity decreases exponentially with axial distance, these values for the mixing height and velocity give the following expression for the local mixing velocity:

$\mathrm{v}_{\mathrm{eff}}=\mathrm{v}_{\mathrm{c}} \exp \left(-2 \frac{\left|\mathrm{z}-\mathrm{z}_{0}\right|}{0.8 \mathrm{~d}}\right)$

where $z_{0}$ is the axial location at which the dispersion coefficient is evaluated. It may be confirmed that an integration of this equation with respect to axial displacement gives the mixing height.

\subsection{Physical Property Correlations}

Correlations for physical properties, including densities, heat capacities, thermal conductivities, and viscosities, are listed in Reference 1 . An additional correlation for molecular diffusivity has been added for this analysis.

The only change from the correlations in Reference 1 is to the density correlation. The terms that account for density changes due to the presence of plutonium and nitrate in solution have been changed. No density data for plutonium nitrate solutions could be found, so the new density correlation uses a correlation based on apparent molar densities. This correlation takes the form ${ }^{\prime \prime}$

$\rho=\rho_{\mathrm{H}_{2} \mathrm{O}}+\frac{\left(\mathrm{M}_{\mathrm{Pu}\left(\mathrm{NO}_{3}\right)_{4}}-\phi_{\left.\mathrm{Pu}_{\left(\mathrm{NO}_{3}\right)_{4}} \rho_{\mathrm{H}_{2} \mathrm{O}}\right)}\right.}{1000}\left[\mathrm{Pu}\left(\mathrm{NO}_{3}\right)_{4}\right]+\frac{\left(\mathrm{M}_{\mathrm{HNO}_{3}}-\phi_{\mathrm{HNO}_{3} \rho_{\mathrm{H}_{2} \mathrm{O}}}\right)}{1000}\left[\mathrm{HNO}_{3}\right]$

The terms $\phi_{\mathrm{Pu}_{\left(\mathrm{NO}_{3}\right)_{4}}}$ and $\phi_{\mathrm{HNO}_{3}}$ represent partial molar volume for deviations from ideal solution densities. The partial molar volume for $\mathrm{HNO}_{3}$ is not calculated because the effect of nitric acid concentration on the density has been measured. The partial molar volume for $\mathrm{Pu}\left(\mathrm{NO}_{3}\right)_{4}$ is given by the sum of the ionic partial molar densities: ${ }^{11}$

$\phi_{\mathrm{Pu}_{\left(\mathrm{NO}_{3}\right)_{4}}}=\phi_{\mathrm{Pu}^{4+}}+\phi_{\mathrm{NO}_{3}^{-}}$

The partial molar density for $\mathrm{NO}_{3}{ }^{-}$, in turn, has been determined to be ${ }^{12}$

$\phi_{\mathrm{NO}_{3}^{-}}=29.5$

The partial molar density for $\mathrm{Pu}^{4+}$ is given by the formula ${ }^{11}$

$\phi_{\mathrm{Pu}^{4+}}=16+4.9 \mathrm{r}_{\mathrm{x}}^{3}-20 \mathrm{n}_{+}$

where $r_{x}$, the ionic crystal radius for $\mathrm{Pu}^{4+}$, is 0.96 Angstroms. ${ }^{13}$ 
Substitution of terms for the partial molar volume of $\mathrm{Pu}\left(\mathrm{NO}_{3}\right)_{4}$ and of a measured density coefficient for $\mathrm{HNO}_{3}{ }^{14}$ results in the following approximate equation for the overall density.

$$
\rho=\rho_{\mathrm{H}_{2} \mathrm{O}}+0.4277\left[\mathrm{Pu}\left(\mathrm{NO}_{3}\right)_{4}\right]+0.031\left[\mathrm{HNO}_{3}\right]
$$

The $\mathrm{HNO}_{3}$ concentration in this equation refers to the excess nitrate that is not ionically coupled with plutonium.

The molecular diffusivity is computed using the Nernst-Haskell equation, which takes the form $^{15}$

$\mathrm{D}_{\mathrm{mol}}=\frac{\mathrm{R}_{\mathrm{g}} \mathrm{T}}{\mathrm{F}^{2}} \frac{\frac{1}{\mathrm{n}_{+}}+\frac{1}{\mathrm{n}_{-}}}{\frac{1}{\lambda_{+}^{0}}+\frac{1}{\lambda_{-}^{0}}}$

The cation and anion valences, $n_{+}$and $n_{-}$, are 3 and 1 , respectively. The value for $\lambda_{-}^{0}$ for nitrate is $71.4 \mathrm{~A} / \mathrm{cm}^{2}(\mathrm{~V} / \mathrm{cm})\left(\mathrm{g}\right.$-equiv $\left./ \mathrm{cm}^{3}\right)$. For plutonium the value of $\lambda_{+}^{0}$ for lanthanum, which is also a trivalent ion, $69.5 \mathrm{~A} / \mathrm{cm}^{2}(\mathrm{~V} / \mathrm{cm})\left(\right.$ g-equiv $\left./ \mathrm{cm}^{3}\right)$, was used.

\subsection{Initial and Boundary Conditions}

Solution of the mass and heat transfer equations requires initial conditions for concentrations, temperatures, and velocities and boundary conditions for velocity and mass and heat transfer rates at the column walls and at the top and bottom of the column. At the start of loading, the plutonium concentrations in the resin bed are set at zero, and the temperature is set equal to either the ambient air temperature of $25^{\circ} \mathrm{C}$ or the cooling water temperature of $15^{\circ} \mathrm{C}$. The starting concentrations and temperatures for flow stoppage analyses are taken from the end of the loading cycle. This is deemed to be conservative in that it results in the maximum amount of plutonium in the resin bed.

Boundary conditions at the ends of the column are fulfilled by having the flow mix with a head of feed solution at the top of the resin bed and discharge into a heel of solution at the bottom of the bed. The rates of heat and mass transfer in the liquid volumes above and below the resin bed are assumed to be much greater than the transfer rates within the bed. In the calculation, this assumption is implemented by setting temperatures and concentrations at the top and bottom bed surfaces equal to those in the head and heel volumes. The rates of heat and mass transfer into the head and the heel are then computed using one-sided gradients that include the temperatures and concentrations at the top two calculation nodes within the resin bed. 
The calculation includes a continuity check to ensure that the area-averaged superficial head and heel velocities are equal to the feed velocity. At the side walls of the column, the radial superficial velocity is set equal to zero. There is no restriction on the axial velocity. In cases for which it is assumed that the column is cooled by ambient air, heat losses out the sides, top, and bottom of the column are calculated using relations for thermal radiation and natural and forced convection. When a water cooling jacket is specified, the surface temperature of the resin bed is set equal to the cooling water temperature, and it is assumed that the top and bottom are cooled by ambient air. The following section describes the heat transfer correlations for convection and radiation.

\subsection{Heat Transfer Correlations}

Heat transfer from the surface of the column is calculated by adding the thermal radiation heat flux to the maximum of the heat fluxes for natural convection and forced convection:

$$
\mathrm{q}_{\text {tot }}=\mathrm{q}_{\mathrm{rad}}+\max \left(\mathrm{q}_{\mathrm{nc}}, \mathrm{q}_{\mathrm{fc}}\right)
$$

The thermal radiation heat flux is calculated using the equation:

$$
\mathrm{q}_{\mathrm{rad}}=\sigma \varepsilon\left(\mathrm{T}_{\text {surf }}^{4}-\mathrm{T}_{\text {amb }}^{4}\right)
$$

A value of 0.6 is used for the surface emissivity $\varepsilon$. This emissivity is characteristic for steel surfaces and is a conservatively low estimate for glass surfaces. ${ }^{16}$

The natural convection heat flux is calculated from correlations for vertical surfaces and for horizontal surfaces facing upward. These correlations take the form

$$
\mathrm{q}_{\mathrm{nc}}=\mathrm{h}_{\mathrm{nc}}\left(\mathrm{T}_{\text {surf }}-\mathrm{T}_{\mathrm{amb}}\right)
$$

The heat transfer coefficient is defined in terms of a Nusselt number, $\mathrm{Nu}$ :

$$
h_{n c}=N u \frac{k}{L}
$$

For the side walls of the column, the Nusselt number is given by the correlation ${ }^{17}$

$$
\mathrm{Nu}=0.59 \mathrm{Ra}_{\mathrm{L}}^{0.25}
$$

where $\mathrm{Ra}_{\mathrm{L}}$ is the Rayleigh number based on the length of the column, defined by

$$
\operatorname{Ra}_{\mathrm{L}}=\frac{\mathrm{g} \rho_{\text {amb }}\left(\rho_{\text {amb }}-\rho_{\text {surf }}\right) \mathrm{L}^{3}}{\mu^{2}} \frac{\mathrm{c}_{\mathrm{p}} \mu}{\mathrm{k}}
$$


For the top and bottom column surfaces, the Nusselt numbers are given by correlations for heat transfer from a warm surface facing upward and a warm surface facing downward, respectively: ${ }^{17}$

$\mathrm{Nu}=0.54 \mathrm{Ra}_{\mathrm{D}}^{0.25}$

and

$\mathrm{Nu}=0.27 \mathrm{Ra}_{\mathrm{D}}^{0.25}$

where $R a_{D}$ is the Rayleigh number based on the column diameter, defined by

$\mathrm{Ra}_{\mathrm{D}}=\frac{g \rho_{\mathrm{amb}}\left(\rho_{\mathrm{amb}}-\rho_{\text {surf }}\right) \mathrm{d}^{3}}{\mu^{2}} \frac{c_{\mathrm{p}} \mu}{k}$

The natural convection heat transfer coefficient is compared to the heat transfer coefficient for forced convection, with an assumed air velocity of $30 \mathrm{~cm} / \mathrm{sec}$, or $1 \mathrm{ft} / \mathrm{sec}$. If the natural convection coefficient is smaller than the forced convection coefficient, the overall convective coefficient is set equal to that for forced convection. The correlation for forced convection takes the form:

$h_{\mathrm{fc}}=\mathrm{Nu}_{\mathrm{fc}} \frac{\mathrm{k}}{\mathrm{d}}$

The Nusselt number for forced convection, $\mathrm{Nu}_{\mathrm{fc}}$, is defined in terms of a Reynolds number, $\operatorname{Re}_{\mathrm{fc}}::^{18}$

$\mathrm{Nu}_{\mathrm{fc}}=0.683 \mathrm{Re}_{\mathrm{fc}}^{0.466}$

where

$\operatorname{Re}_{\mathrm{fc}}=\frac{\mathrm{dv}_{\mathrm{fc}} \rho_{\mathrm{amb}}}{\mu}$

\subsection{Calculation Method}

The finite difference heat and mass transfer calculations were performed on a VAX computer using Fortran codes. Separate codes were written to calculate transients during normal operation of the column (loading, washing, and elution) and following a stoppage of flow. Each code generates an output of maximum resin bed temperatures as a function of time as well as temperature, concentration, velocity, and modified stream function profiles at specified times. The output files containing temperature and concentration 
profiles from the transient calculation for normal column operation are used to initialize the conditions for the flow stoppage calculations. The modified stream function profiles were used to make contour plots that show the natural convection flow streamlines. These plots were used to check the validity of the natural convection velocity calculations. The modified stream function, $\mathrm{r} \psi$, is calculated from Equations 23 through 25 .

The calculations for normal conditions were performed using a donor cell algorithm that was semi-implicit in the dispersion terms and explicit in all other terms. An explicit donor cell algorithm was used to perform the calculations following a flow stoppage.

Code listings and sample input and output files appear in the Appendix.

\subsection{Results of Calculations}

Prior to calculating maximum temperature transients for the matrix of test conditions specified by LANL, preliminary analyses were performed to determine an optimum time step size and cell size for the finite difference method. Results were found to be insensitive to the time step size, provided it was small enough to guarantee numerical stability. Time step sizes of $0.02 \mathrm{sec}$ for the high feed flow rate of $20 \mathrm{~mL} / \mathrm{sec}, 1.0 \mathrm{sec}$ for the low feed flow rate of $0.5 \mathrm{~mL} / \mathrm{sec}$, and $0.5 \mathrm{sec}$ for natural convection during flow stoppages were used.

Cell sizes were decreased until approximate convergence of temperature profiles and flow streamlines was obtained. The test case with the low feed flow rate of $0.5 \mathrm{~mL} / \mathrm{sec}$, the high feed concentration of $0.1304 \mathrm{gm} / \mathrm{cm}^{3} \mathrm{Pu}-238$, cooling by ambient air, and twice the bed adsorption capacity fed was selected because it should result in the highest maximum bed temperature, at least during normal operation. It was determined that a grid of 48 axial cells by 24 radial cells gave an adequate approximation. Figures 1 through 9 show temperature profiles and flow streamlines for this grid, as well grids of 96 axial cells by 24 radial cells and 48 axial cells by 48 radial cells.

Figures 1 through 3 depict temperature profiles at the end of loading. These figures give a cross-sectional view of the column, split lengthwise along its axis; negative values of the radius are plotted to show both halves of the cross-section. It may be noted that at this low feed flow rate, the maximum bed temperature is located only slightly below the column center, toward the discharge end. A comparison of these figures shows that the radial cell length has little effect on the temperature profile. Decreasing the axial cell length results in a maximum temperature which is about $1^{\circ} \mathrm{C}$ higher. The increase in the maximum temperature can be attributed to better resolution of the plutonium peak at finer axial discretization.

Figures 4 through 6 show temperature profiles as thermal equilibrium approaches 10 hours after flow is interrupted. Again, a comparison of results for difference cell sizes demonstrates that there are only slight differences in the temperature profiles. The peak 
temperature varies between $84.3^{\circ} \mathrm{C}$ and $84.6^{\circ} \mathrm{C}$. For all three calculations, the peak temperature is located near the column center, slightly more than halfway down from the top of the resin bed.

Figures 7 through 9 depict flow streamlines for the same conditions. The numbers in these figures are values of the stream function multiplied by 10,000. Two toroidal recirculation cells appear, one in the top half of the resin bed and another in the bottom half. These cells are driven by mixing with the liquid layers above and below the bed, respectively. At these equilibrium conditions, the solution within the resin bed is wellmixed. Consequently, the recirculation is primarily due to thermal density gradients. Warmer solution flows upward in the center of the resin bed, and cooler solution flow downward along the column walls. Similar recirculation patterns have been calculated for two-dimensional rectangular fluid containers with uniform volumetric heat sources. ${ }^{19}$ Both the shape and intensity of the recirculation, as indicated by the values of the stream function, remain about the same for the different cell sizes.

Because the column's length is much greater than its diameter, the calculated recirculation cells have a high axial/radial aspect ratio. This suggests that there might be more than one series of cells stacked one above another. The model does not test for the hydrodynamic stability of the recirculation pattern, so it does not account for this possibility. Nevertheless, the model should give a reasonably accurate estimate of heat transfer. The reasoning is that the magnitude of both the solution density gradients and the recirculation velocities, which are proportional to those gradients, would remain about the same. In fact, measured heat transfer rates for natural convection in volumes filled with porous glass exceed theoretical heat transfer rates at high aspect ratios. ${ }^{20}$ These differences diminish as the convection velocities and hence the heat transfer rates increase. This seems to indicate that the assumption of a single vertical layer of recirculation cells is conservative in that it underestimates the actual rate of heat transfer.

Figures 10 and 11 show the effect of cell size on maximum temperature transients during normal operation and after a flow stoppage. As Figure 10 shows, a change from 24 to 48 radial cells does not make any appreciable difference in the calculated maximum temperatures, and an increase from 48 to 96 axial cells raises the maximum bed temperature by less than $1^{\circ} \mathrm{C}$. Figure 11 shows that, as thermal equilibrium approaches following a flow stoppage, there is no significant change in the maximum temperature going from 24 to 48 radial cells or from 48 to 96 axial cells.

The preceding comparisons demonstrate that the 48 by 24 cell discretization adequately models natural convection and heat transfer within the column, so this grid was used to analyze the sixteen operating conditions specified by LANL and listed in Table 1.

Table 2 lists maximum temperatures from those calculations, and Figures 12 through 27 portray maximum temperature transients. For normal operation, the maximum calculated temperatures range from just over either the ambient air or cooling water temperature at high feed flow rates to $58.1^{\circ} \mathrm{C}$ for the high feed concentration of 0.1304 $\mathrm{gm} / \mathrm{mL}$, the low feed flow rate of $0.5 \mathrm{~mL} / \mathrm{sec}$, cooling by ambient air at $25^{\circ} \mathrm{C}$, and 
feeding of an amount of plutonium equal to twice the bed capacity. When flow is stopped at the end of the load cycle, the maximum temperatures vary from $42.6^{\circ} \mathrm{C}$ to $84.3^{\circ} \mathrm{C}$.

As Figures 12 through 19 show, during normal operation, temperatures remain low at the high feed flow rate because of the short duration of the load and wash cycles. As may be seen in Figures 20 through 27, at the low feed flow rate, bed temperatures increase during loading and the first stages of washing. Subsequently, after excess plutonium in solution is washed out of the column, the maximum temperature either decreases or remains stable. Maximum temperatures following a flow stoppage increase at a slightly more rapid rate than during the initial phases of washing. Eventually, these temperatures reach equilibrium levels which exceed the maximum temperatures during washing.

A comparison of results in Table 2 shows that the water jacket is effective in lowering temperatures within the resin bed. The maximum temperature is between $10^{\circ} \mathrm{C}$ and $14^{\circ} \mathrm{C}$ cooler with the water jacket at the low feed flow rate, and ranges from $16^{\circ} \mathrm{C}$ to $24^{\circ} \mathrm{C}$ cooler for natural convection during a flow stoppage. These temperature differences slightly exceed the temperature difference of $10^{\circ} \mathrm{C}$ between the ambient air and the cooling water due to improved heat transfer to the cooling jacket. (Natural convection correlations were used for cooling by ambient air, and no heat transfer resistance was assumed for cooling by the water jacket.)

Finally, increasing the amount of plutonium fed to the column raised the maximum bed temperatures only in certain cases. Significant temperature increases occurred for normal operation at the low feed flow rate and the high feed concentration and for a flow stoppage at the high feed concentration. The amount of plutonium fed to the column does not produce significantly higher temperatures at low feed concentrations because the plutonium concentration in solution is small and the amount of plutonium adsorbed on the column is limited by the resin capacity. Instead, at low concentrations, most of the excess plutonium that has been fed to the column at any particular time has passed through the column. According to the model, doubling the amount of plutonium fed to the column has a smaller effect on equilibrium temperatures during natural convection than at the low feed flow rate. The reason is that natural convection more effectively mixes the solution and transfers heat than the feed flow itself. This apparent anomaly is due to the lack of natural convection in the normal flow model.

To ensure that the maximum temperatures calculated for flow stoppages are truly bounding cases, additional calculations were performed. These calculations were restricted to the cases with the low feed flow rate and high feed concentration, where the maximum temperatures increased significantly during washing. In the additional cases, it was assumed that the flow stoppages occur when the maximum bed temperature peaks during washing. Figures 28 through 31 illustrate the results of these calculations, and Table 3 compares equilibrium temperatures for flow stoppages at peak resin bed temperatures with those for flow stoppages at maximum loadings. In each case, the equilibrium temperature for flow stoppages at the peak bed temperatures are lower. This confirms that flow stoppages at the end of the load cycle represent bounding conditions. 


\subsection{Conclusions}

Calculated maximum bed temperatures range from close to the ambient air or cooling water temperature for normal operation at the high feed flow rate of $20 \mathrm{~mL} / \mathrm{sec}$ to $58.1^{\circ} \mathrm{C}$ for operation at the low feed flow rate of $0.5 \mathrm{~mL} / \mathrm{sec}$ with air cooling, a feed amount equal to twice the bed plutonium capacity, and a high feed concentration of 0.1304 $\mathrm{gm} / \mathrm{mL}$ Pu-238. Use of a $15^{\circ} \mathrm{C}$ cooling water jacket would lower this maximum temperature to $44.8^{\circ} \mathrm{C}$ for the same conditions. For the same feed conditions, the maximum temperatures for natural convection during a flow stoppage are $84.3^{\circ} \mathrm{C}$ for air cooling and $60.6^{\circ} \mathrm{C}$ for the water jacket. The maximum temperatures during normal operation occurred during washing. Following stoppages of flow, the maximum bed temperatures either peaked and then dropped slightly to an equilibrium temperature or reached their highest values at thermal equilibrium. Thermal equilibrium was achieved about 2 hours after flow was stopped.

The maximum calculated bed temperature exceeds $60^{\circ} \mathrm{C}$, where significant resin degradation commences, ${ }^{2}$ but is below $110^{\circ} \mathrm{C}$, the approximate temperature at which resin-nitric acid reactions become thermally excursive. ${ }^{3}$ Thus, the column can be operated safely at the specified conditions with either air or water-jacket cooling. Use of a water jacket will minimize resin degradation but might also slow rates of adsorption and elution, particularly at high feed concentrations and flow rates.

\subsection{References}

1. J. E. Laurinat, "Self-Heating of Pu-238 Anion Exchange Column (U)," WSRC-TR-94-0166, Rev. 0, March 23, 1994.

2. J. L. Ryan and E. J. Wheelwright, "The Recovery, Purification, and Concentration of Plutonium by Anion Exchange in Nitric Acid (Declassified)," General ElectricHanford Atomic Products Operation Report HW-55893, January 2, 1959.

3. W. J. Van Slyke, G. Jansen, Jr., and W. H. Swift, "Thermal Effects in Anion Exchange Resin - Nitric Acid Systems", Pacific Northwest Laboratory Report BNWL-114, August, 1965.

4. C. N. Satterfield, Mass Transfer in Heterogeneous Catalysis, Colonial Press (1975), 35-36.

5. R. H. Perry and D. W. Green, eds., Perry's Chemical Engineers' Handbook, $6^{\text {th }}$ ed., McGraw Hill, New York (1984), 16-27.

6. E. A. Ebach and R. R. White, "Mixing of Fluids Flowing through Beds of Packed Solids," A.I.Ch.E. J., 4(2), 161-169. 
7. W. E. Stewart, Jr., and C. L. G. Dona, "Free Convection in a Heat Generating Porous Medium in a Finite Vertical Cylinder," J. Heat Transfer, 110(5), 1988, 517-520.

8. R. H. Perry and D. W. Green, eds., Perry's Chemical Engineers' Handbook, $6^{\text {th }}$ ed., McGraw Hill, New York (1984), 5-54.

9. M. Leva, Fluidization, McGraw-Hill, New York (1959), 47.

10. J. B. Joshi, "Axial Mixing in Multiphase Contactors - A Unified Correlation,". Trans. I. Chem. E., 58, 1980, 155-165.

11. A. M. Couture and K. J. Laidler, "The Partial Molar Volumes of Ions in Aqueous Solution: 1. Dependence on Charge and Radius," Can. J. Chem., 34, 1956, 1209-1216.

12. A. L. Horvath, Handbook of Aqueous Electrolyte Solutions: Physical Properties, Estimation, and Corelation Methods, Ellis Horwood Ltd., Chichester, England (1985), 131-133.

13. J. J. Katz, G. T. Seaborg, and L. R. Morss, The Chemistry of the Actinide Elements, $2^{\text {nd }}$ ed., Volume 2, Chapman and Hall, London (1986), 1448.

14. C. M. Slansky, "Appendix I: Physical Properties of the Uranyl Nitrate, Aluminum Nitrate, Nitric Acid and Water System," in F. R. Bruce, J. M. Fletcher, and H. H. Hyman, Progress in Nuclear Energy, Series III: Process Chemistry, Vol. 2, Pergamon Press (New York (1958).

15. R. C. Reid, J. M. Prausnitz, and T. K. Sherwood, The Properties of Gases and Liquids, McGraw-Hill, New York (1977), 591.

16. R. H. Perry and D. W. Green, eds., Perry's Chemical Engineers' Handbook, $6^{\text {th }}$ ed., McGraw Hill, New York (1984), 10-51.

17. R. H. Perry and D. W. Green, eds., Perry's Chemical Engineers' Handbook, $6^{\text {th }}$ ed., McGraw Hill, New York (1984), 10-13.

18. F. Kreith and W. Z. Black, Basic Heat Transfer, Harper and Row, New York (1980), 251.

19. A. A. Emara and F. A. Kulacki, "A Numerical Investigation of Thermal Convection in a Heat-Generating Fluid Layer," J. Heat Transfer, 102(8), 1980, 531-537.

20. N. Seki, S. Fukusako, and H.Inaba, "Heat Transfer in a Cavity Packed with Fibrous Glass," J. Heat Transfer, 100(11), 1978, 748-750. 


\subsection{Nomenclature}

$\mathrm{c}=$ relative saturation of nitric acid in the solution between the resin beads, dimensionless

$c_{p}=$ heat capacity of air, cal/gm/K

$\mathrm{c}_{\mathrm{p}, \mathrm{bed}}=$ heat capacity of the resin bed, $\mathrm{cal} / \mathrm{gm} / \mathrm{K}$

$\mathrm{c}_{\mathrm{p}, \mathrm{f}}=$ heat capacity of the feed solution, $\mathrm{cal} / \mathrm{gm} / \mathrm{K}$

$\mathrm{C}_{\mathrm{NO}_{3}}=$ total bulk nitrate concentration, $\mathrm{gm} / \mathrm{cm}^{3}$

$\mathrm{C}_{\mathrm{Pu}}=$ total bulk plutonium concentration, $\mathrm{gm} / \mathrm{cm}^{3}$

$\mathrm{d}=$ column diameter, $\mathrm{cm}$

$\mathrm{d}_{\mathrm{p}}=$ resin bead diameter, $\mathrm{cm}$

$\mathrm{D}_{\text {mix }}=$ axial dispersion coefficient for buoyancy-induced or bubble-induced mixing, $\mathrm{cm}^{2} / \mathrm{sec}$

$\mathrm{D}_{\mathrm{mol}}=$ molecular diffusivity of plutonium nitrate in aqueous solution, $\mathrm{cm}^{2} / \mathrm{sec}$

$\mathrm{D}_{\text {pore }}=$ pore diffusivity for diffusion of plutonium nitrate in resin beads, $\mathrm{cm}^{2} / \mathrm{sec}$

$\mathrm{f}=$ amount of plutonium adsorbed on resin, $\mathrm{gm} / \mathrm{cm}^{3}$

$\mathrm{f}_{0}=$ amount of plutonium adsorbed at beginning of elution, $\mathrm{gm} / \mathrm{cm}^{3}$

$\mathrm{F}=$ Faraday's constant, $96,500 \mathrm{~K} /$ gmole

$\mathrm{g}=$ gravitational acceleration, $980 \mathrm{~cm} / \mathrm{sec}^{2}$

$\mathrm{G}_{\mathrm{a}}=$ mass transfer rate for adsorption of plutonium, $\mathrm{gm} / \mathrm{cm}^{3} / \mathrm{sec}$

$\mathrm{h}_{\mathrm{nc}}=$ natural convection heat transfer coefficient, $\mathrm{cal} / \mathrm{cm}^{2} / \mathrm{sec} / \mathrm{K}$

$\mathrm{k}=$ thermal conductivity of air, $\mathrm{cal} / \mathrm{cm} / \mathrm{sec} / \mathrm{K}$

$\mathrm{k}_{\text {bed }}=$ thermal conductivity of the resin bed, cal $/ \mathrm{cm} / \mathrm{sec} / \mathrm{K}$

$\mathrm{L}=$ column length, $\mathrm{cm}$

$M_{i}=$ molecular weight of $i$ th compound, gm/gmole

$\mathrm{n}_{+}=$cation valence for Nernst-Haskell diffusivity equation

$\mathrm{n}_{-}=$anion valence for Nernst-Haskell diffusivity equation

$\mathrm{Nu}=$ Nusselt number

$\mathrm{P}=$ pressure, $10^{-1}$ Pascal

$\mathrm{q}_{\mathrm{nc}}=$ natural convection heat flux, $\mathrm{cal} / \mathrm{cm}^{2} / \mathrm{sec}$

$\mathrm{q}_{\mathrm{rad}}=$ radiation heat flux, $\mathrm{cal} / \mathrm{cm}^{2} / \mathrm{sec}$

$\mathrm{q}_{\text {tot }}=$ total heat flux, $\mathrm{cal} / \mathrm{cm}^{2} / \mathrm{sec}$

$\mathrm{Q}_{\text {decay }}=$ volumetric rate of heat generation due to alpha decay, $\mathrm{cal} / \mathrm{cm}^{3} / \mathrm{sec}$

$\mathrm{r}=$ radial distance from center of resin bed, $\mathrm{cm}$

$r_{x}=$ ionic radius, Angstroms

$\mathrm{R}=$ column radius, $\mathrm{cm}$

$\mathrm{R}_{\mathrm{g}}=$ gas law constant, $8.314 \mathrm{~J} / \mathrm{gmole} / \mathrm{K}$

$R a_{D}=$ the Rayleigh number based on the column diameter

$R a_{L}=$ the Rayleigh number based on the length of the column

$\mathrm{T}=$ temperature, $\mathrm{K}$

$\mathrm{T}_{\mathrm{amb}}=$ ambient temperature, $\mathrm{K}$ 
$\mathrm{T}_{\text {surf }}=$ surface temperature, $\mathrm{K}$

$\mathrm{v}_{\mathrm{c}}=$ mixing velocity for interchange between adjacent solution layers, also, circulation velocity for bubble mixing, $\mathrm{cm} / \mathrm{sec}$

$v_{\text {eff }}=$ effective velocity for mixing between solution layers at different levels within the resin bed, $\mathrm{cm} / \mathrm{sec}$

$\mathrm{v}_{\mathrm{fc}}=$ circulation velocity of ambient air, $\mathrm{cm} / \mathrm{sec}$

$\mathrm{V}_{\mathrm{rs}}=$ radial component of the superficial velocity of solution in the resin bed, $\mathrm{cm} / \mathrm{sec}$

$v_{z s}=$ axial component of the superficial velocity of solution in the resin bed, $\mathrm{cm} / \mathrm{sec}$

$\mathrm{x}=$ plutonium concentration in bulk solution between resin beads, $\mathrm{gm} / \mathrm{cm}^{3}$

$\mathrm{x}_{\max }=$ maximum plutonium concentration in bulk solution between resin beads, $\mathrm{gm} / \mathrm{cm}^{3}$

$\mathrm{x}_{\mathrm{NO}_{3}}=$ nitrate concentration in the bulk solution between resin beads, $\mathrm{gm} / \mathrm{cm}^{3}$

$\mathrm{X}_{\mathrm{Pu}_{\mathrm{u}}}=$ plutonium concentration in the bulk solution between resin beads, $\mathrm{gm} / \mathrm{cm}^{3}$

$\bar{y}=$ time-averaged plutonium concentration in the resin bead pores at the bead surface, used in the calculation of elution rates through the bead, $\mathrm{gm} / \mathrm{cm}^{3}$

$\mathrm{y}_{\mathrm{NO}_{3}}=$ nitrate concentration in the solution in the resin bead pores, $\mathrm{gm} / \mathrm{cm}^{3}$

$\mathrm{y}_{\mathrm{Pu}}=$ plutonium concentration in the solution in the resin bead pores, $\mathrm{gm} / \mathrm{cm}^{3}$

$\mathrm{z}=$ axial distance from bed entrance, $\mathrm{cm}$

$\alpha_{\mathrm{r}}=$ radial dispersion coefficient for mixing by the feed flow, $\mathrm{cm}^{2} / \mathrm{sec}$

$\alpha_{z}=$ axial dispersion coefficient for mixing by the feed flow, $\mathrm{cm}^{2} / \mathrm{sec}$

$\varepsilon=$ surface emissivity, assumed to be 0.6 (for machined steel) ${ }^{2}$

$\varepsilon_{\mathrm{i}}=$ fraction of bulk volume occupied by liquid inside resin beads

$\varepsilon_{0}=$ fraction of bulk volume occupied by liquid in spaces between resin beads

$\lambda_{+}^{0}=$ limiting cationic conductance for Nernst-Haskell diffusivity equation,

$\mathrm{A} / \mathrm{cm}^{2}(\mathrm{~V} / \mathrm{cm})\left(\mathrm{g}\right.$-equiv $\left./ \mathrm{cm}^{3}\right)$

$\lambda_{-}^{0}=$ limiting anionic conductance for Nernst-Haskell diffusivity equation,

$\mathrm{A} / \mathrm{cm}^{2}(\mathrm{~V} / \mathrm{cm})\left(\mathrm{g}\right.$-equiv $\left./ \mathrm{cm}^{3}\right)$

$\mu=$ viscosity of air, $\mathrm{gm} / \mathrm{cm} / \mathrm{sec}$

$\mu_{\mathrm{L}}=$ viscosity of resin bed solution, $\mathrm{gm} / \mathrm{cm} / \mathrm{sec}$

$\rho=$ solution mixture density, $\mathrm{gm} / \mathrm{cm}^{3}$

$\bar{\rho}=$ average solution density at a given axial level, $\mathrm{gm} / \mathrm{cm}^{3}$

$\rho_{\text {amb }}=$ ambient air density, $\mathrm{gm} / \mathrm{cm}^{3}$

$\rho_{\mathrm{H}_{2} \mathrm{O}}=$ water density, $\mathrm{gm} / \mathrm{cm}^{3}$

$\rho_{\text {surf }}=$ air density at column surface, $\mathrm{gm} / \mathrm{cm}^{3}$

$\sigma=$ Boltzmann's constant, $1.356 \times 10^{-12} \mathrm{cal} / \mathrm{cm}^{2} / \mathrm{sec} / \mathrm{K}^{4}$

$\tau=$ tortuosity factor for pore diffusion

$\tau_{\text {pore }}=$ charcteristic time for pore diffusion, sec

$\phi_{\mathrm{i}}=$ excess partial molar volume for ith anion, cation, or salt, $\mathrm{cm}^{3} / \mathrm{gmole}$

$\psi=$ stream function, $\mathrm{cm}^{2} / \mathrm{sec}$ 
Table 1. Conditions for LANL Anion Exchange Column

\section{Constant Condition}

Column Radius

Length of Resin Bed

Height of Feed Solution above Bed

Depth of Discharge Solution below Bed

Resin Bead Diameter
Value

$3.81 \mathrm{~cm}$ nominal

$3.73 \mathrm{~cm}$ measured by displacement

$34.1 \mathrm{~cm}$

$2.54 \mathrm{~cm}$

$2.54 \mathrm{~cm}$

$0.04 \mathrm{~cm}$
Variable Condition

Feed Flow Rate

Feed Concentration

Amount of Pu Fed*

Heat Transfer Conditions

\section{High Value}

$20 \mathrm{~cm}^{3} / \mathrm{sec}$

$0.1304 \mathrm{gm} / \mathrm{cm}^{3} \mathrm{Pu}-238$

$0.163 \mathrm{gm} / \mathrm{cm}^{3}$ total $\mathrm{Pu}$

2 times bed capacity

for $\mathrm{Pu}$ adsorption

Exposure to $25^{\circ} \mathrm{C}$

ambient air
Low Value

$0.5 \mathrm{~cm}^{3} / \mathrm{sec}$

$0.0122 \mathrm{gm} / \mathrm{cm}^{3} \mathrm{Pu}-238$

$0.01525 \mathrm{gm} / \mathrm{cm}^{3}$ total $\mathrm{Pu}$ equal to bed capacity for $\mathrm{Pu}$ adsorption Cooling by $15^{\circ} \mathrm{C}$ water jacket

*The amount of Pu fed was controlled by varying the times for loading the bed with plutonium nitrate solution. A summary of loading, washing, and elution times follows.

$\begin{array}{lllrrr}\text { Flow Rate } & \text { Concentration } & \text { Amount Fed } & \text { Load Time } & \text { Wash Time } & \text { Elution T } \\ \text { High } & \text { High } & 1 \times \text { capacity } & 29 \mathrm{sec} & 149 \mathrm{sec} & 187 \mathrm{sec} \\ \text { High } & \text { High } & 2 \times \text { capacity } & 58 \mathrm{sec} & 149 \mathrm{sec} & 187 \mathrm{sec} \\ \text { High } & \text { Low } & 1 \times \text { capacity } & 307 \mathrm{sec} & 149 \mathrm{sec} & 187 \mathrm{sec} \\ \text { High } & \text { Low } & 2 \times \text { capacity } & 614 \mathrm{sec} & 149 \mathrm{sec} & 187 \mathrm{sec} \\ \text { Low } & \text { High } & 1 \times \text { capacity } & 1150 \mathrm{sec} & 5974 \mathrm{sec} & 7468 \mathrm{sec} \\ \text { Low } & \text { High } & 2 \times \text { capacity } & 2300 \mathrm{sec} & 5974 \mathrm{sec} & 7468 \mathrm{sec} \\ \text { Low } & \text { Low } & 1 \times \text { capacity } & 12264 \mathrm{sec} & 5974 \mathrm{sec} & 7468 \mathrm{sec} \\ \text { Low } & \text { Low } & 2 \times \text { capacity } & 24528 \mathrm{sec} & 5974 \mathrm{sec} & 7468 \mathrm{sec}\end{array}$


Table 2. Maximum Temperatures for Operation of LANL Anion Exchange Column

$\begin{array}{lllclc}\begin{array}{l}\text { Pu Feed } \\ \text { Conc. } \\ (\mathbf{g m} / \mathbf{m L})\end{array} & \begin{array}{l}\text { Flow } \\ \text { Rate } \\ (\mathbf{m L} / \mathbf{s e c})\end{array} & \begin{array}{l}\text { Cooling } \\ \text { Jacket } \\ (\text { Yes/No) }\end{array} & \begin{array}{l}\text { Feed Quantity } \\ (\# \text { times } \\ \text { bed capacity) }\end{array} & \begin{array}{l}\text { Max. T during } \\ \text { Operation } \\ \left({ }^{\circ} \mathbf{C}\right)\end{array} & \begin{array}{l}\text { Equil. T } \\ \text { for no flow } \\ \left({ }^{\circ} \mathbf{C}\right)\end{array} \\ 0.1304 & 20.0 & \text { No } & 1 & 25.5 & 58.7 \\ 0.1304 & 20.0 & \text { No } & 2 & 25.9 & 77.6 \\ 0.1304 & 20.0 & \text { Yes } & 1 & 15.6 & 42.6 \\ 0.1304 & 20.0 & \text { Yes } & 2 & 15.9 & 57.1 \\ & & & & & \\ 0.0122 & 20.0 & \text { No } & 1 & 25.7 & 62.3 \\ 0.0122 & 20.0 & \text { No } & 2 & 25.7 & 63.1 \\ 0.0122 & 20.0 & \text { Yes } & 1 & 15.7 & 45.2 \\ 0.0122 & 20.0 & \text { Yes } & 2 & 15.7 & 45.2 \\ & & & & & \\ 0.1304 & 0.5 & \text { No } & 1 & 46.7 & 66.3 \\ 0.1304 & 0.5 & \text { No } & 2 & 58.1 & 84.3 \\ 0.1304 & 0.5 & \text { Yes } & 1 & 34.6 & 47.0 \\ 0.1304 & 0.5 & \text { Yes } & 2 & 44.8 & 60.6 \\ & & & & & \\ 0.0122 & 0.5 & \text { No } & 1 & 47.3 & 62.5 \\ 0.0122 & 0.5 & \text { No } & 2 & 47.6 & 63.1 \\ 0.0122 & 0.5 & \text { Yes } & 1 & 34.9 & 45.2 \\ 0.0122 & 0.5 & \text { Yes } & 2 & 35.2 & 45.2\end{array}$

Table 3. Comparison of Maximum Equilibrium Temperatures for Flow Stoppages at the End of Loading and at the Maximum Transient Temperature during Washing

$\begin{array}{llllll}\begin{array}{l}\text { Pu Feed } \\ \text { Conc. } \\ (\mathbf{g m} / \mathbf{m L})\end{array} & \begin{array}{l}\text { Flow } \\ \text { Rate } \\ (\mathbf{m L} / \mathrm{sec})\end{array} & \begin{array}{l}\text { Cooling } \\ \text { Jacket } \\ (\text { Yes/No) }\end{array} & \begin{array}{l}\text { Feed Quantity } \\ \text { (\# times } \\ \text { bed capacity) }\end{array} & \begin{array}{l}\text { Equil. T for } \\ \text { Flow Stoppage } \\ \text { at End of } \\ \text { Loading } \\ \left({ }^{\circ} \mathbf{C}\right)\end{array} & \begin{array}{l}\text { Equil. T for } \\ \text { Flow Stoppage } \\ \text { at Max. T } \\ \text { during Wash } \\ \left({ }^{\circ} \mathbf{C}\right)\end{array} \\ & & & & & \\ 0.1304 & 0.5 & \text { No } & 1 & 66.3 & 60.3 \\ 0.1304 & 0.5 & \text { No } & 2 & 84.3 & 60.5 \\ 0.1304 & 0.5 & \text { Yes } & 1 & 47.0 & 42.9 \\ 0.1304 & 0.5 & \text { Yes } & 2 & 60.6 & 52.0\end{array}$




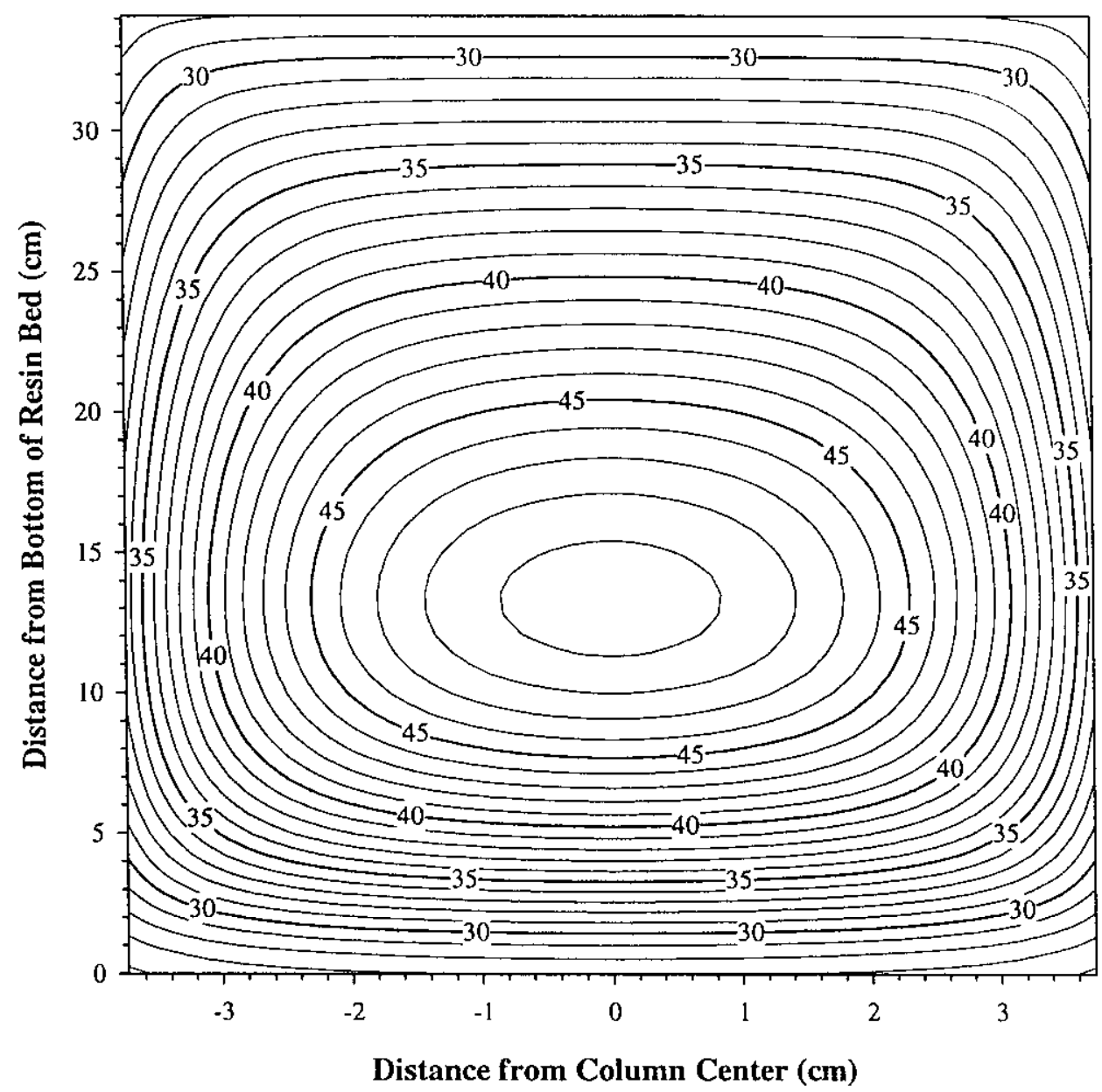

Figure 1. Temperature Distribution at the End of the Load Cycle for Low Feed Flow Rate, High Feed Concentration, Exposure to $25^{\circ} \mathrm{C}$ Air, and Twice the Resin Capacity Fed, for a Grid Resolution of 48 Axial and 24 Radial Cells. 


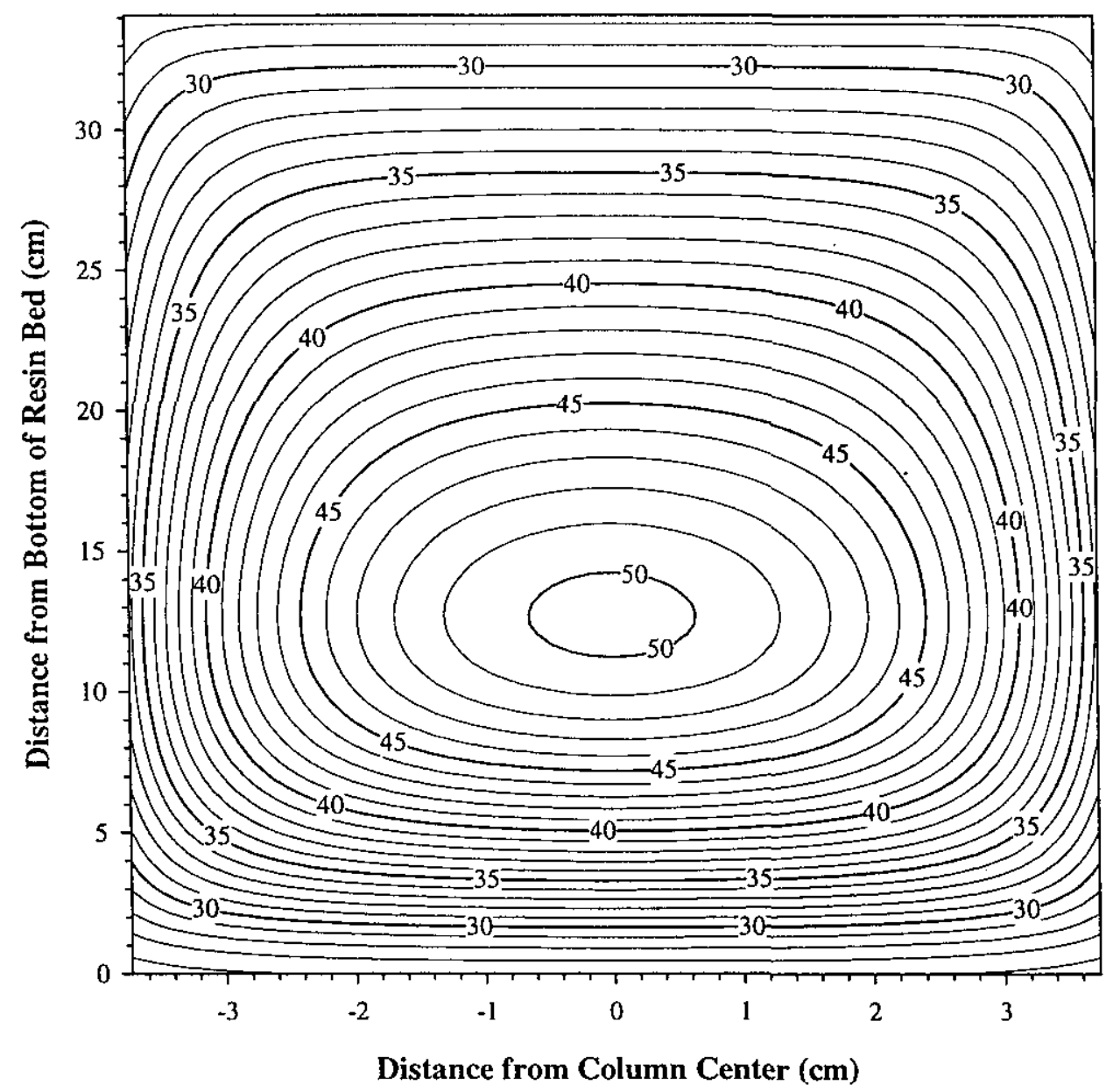

Figure 2. Temperature Distribution at the End of the Load Cycle for Low Feed Flow Rate, High Feed Concentration, Exposure to $25^{\circ} \mathrm{C}$ Air, and Twice the Resin Capacity Fed, for a Grid Resolution of 96 Axial and 24 Radial Cells. 


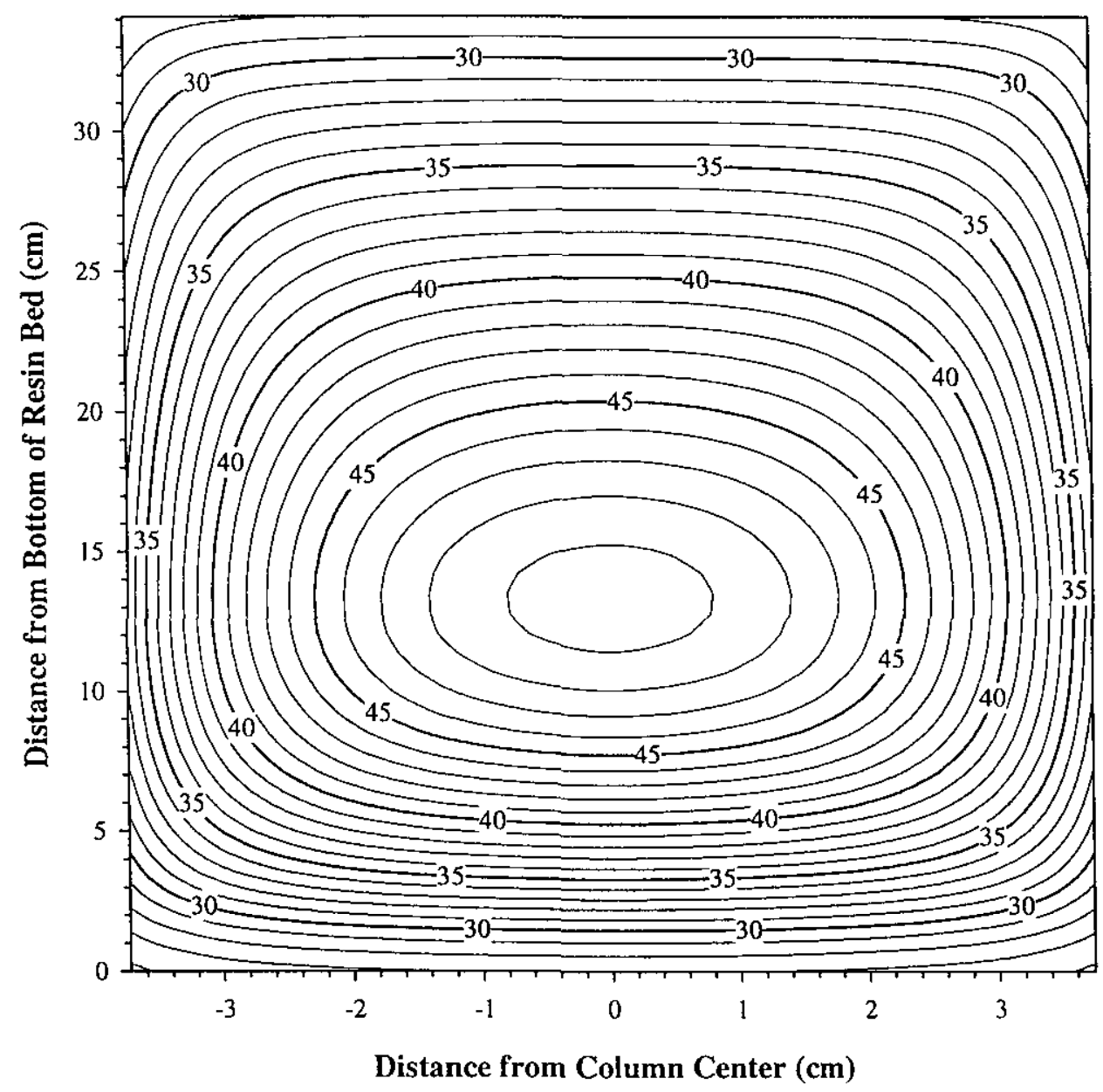

Figure 3. Temperature Distribution at the End of the Load Cycle for Low Feed Flow Rate, High Feed Concentration, Exposure to $25^{\circ} \mathrm{C}$ Air, and Twice the Resin Capacity Fed, for a Grid Resolution of 48 Axial and 48 Radial Cells. 


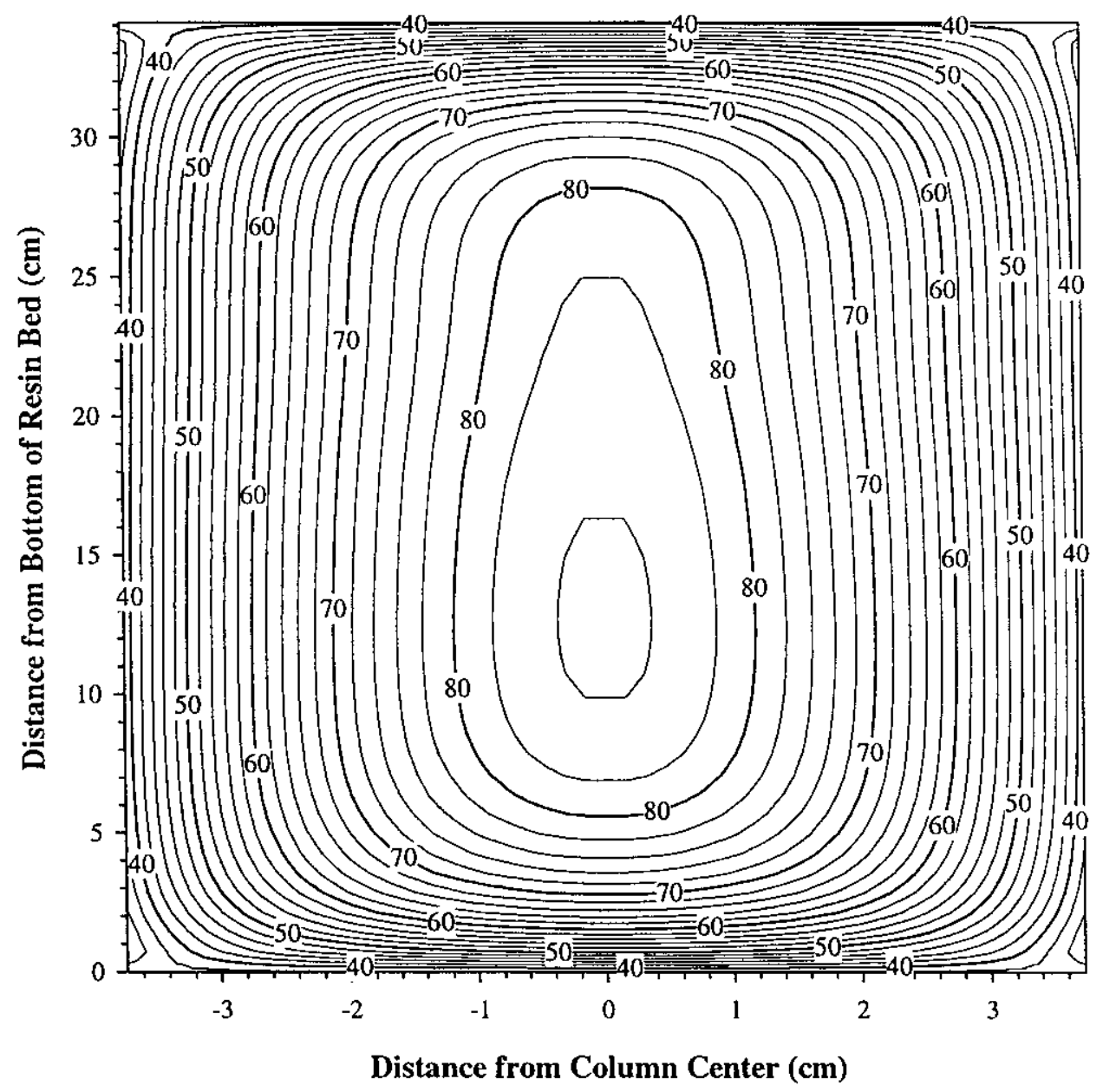

Figure 4. Temperature Distribution at Thermal Equilibrium after a Flow Stoppage for Low Feed Flow Rate, High Feed Concentration, Exposure to $25^{\circ} \mathrm{C}$ Air, and Twice the Resin Capacity Fed, for a Grid Resolution of 48 Axial and 24 Radial Cells. 
WSRC-TR-99-00027

Revision 0

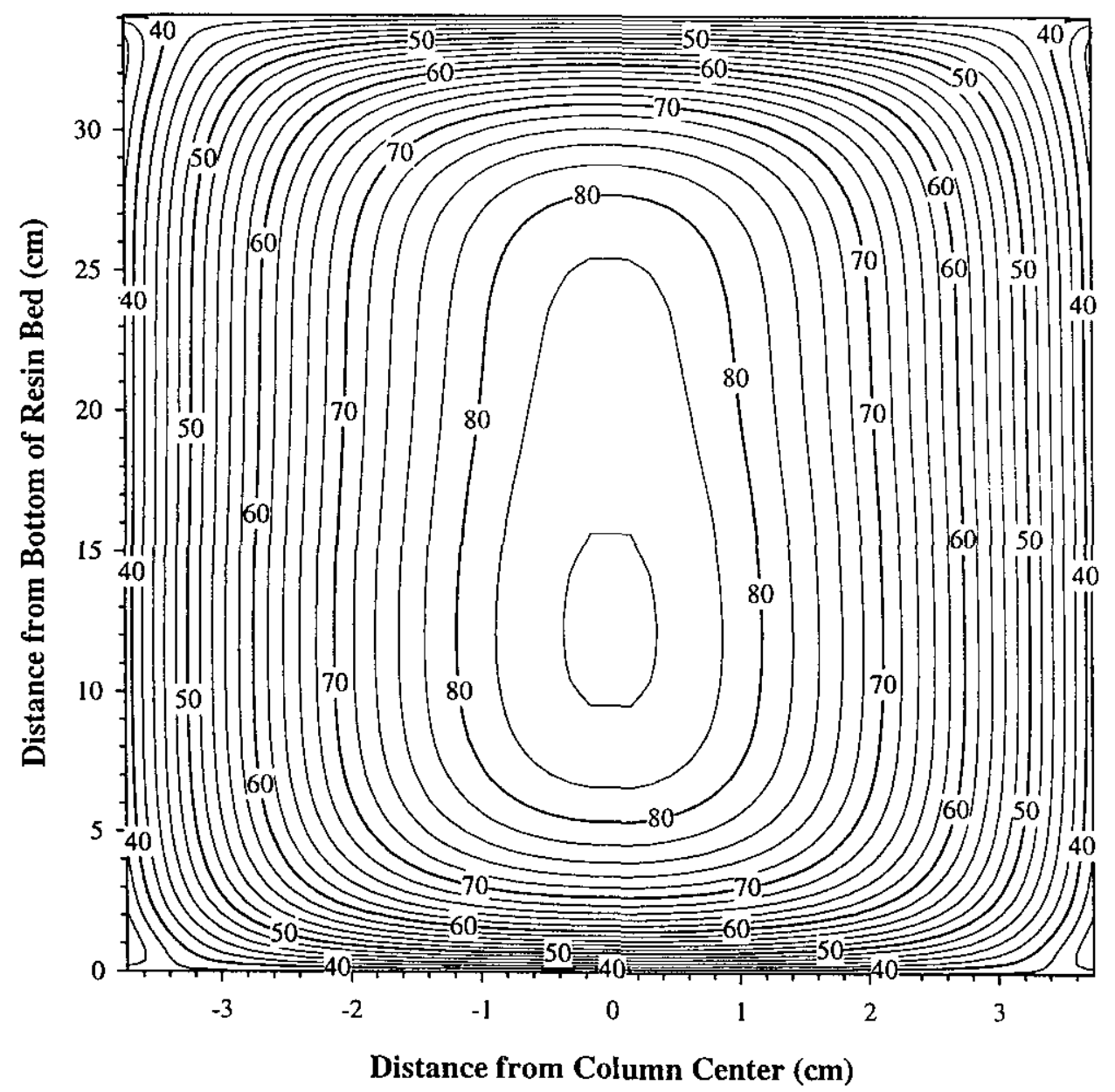

Figure 5. Temperature Distribution at Thermal Equilibrium after a Flow Stoppage for Low Feed Flow Rate, High Feed Concentration, Exposure to $25^{\circ} \mathrm{C}$ Air, and Twice the Resin Capacity Fed, for a Grid Resolution of 96 Axial and 24 Radial Cells. 


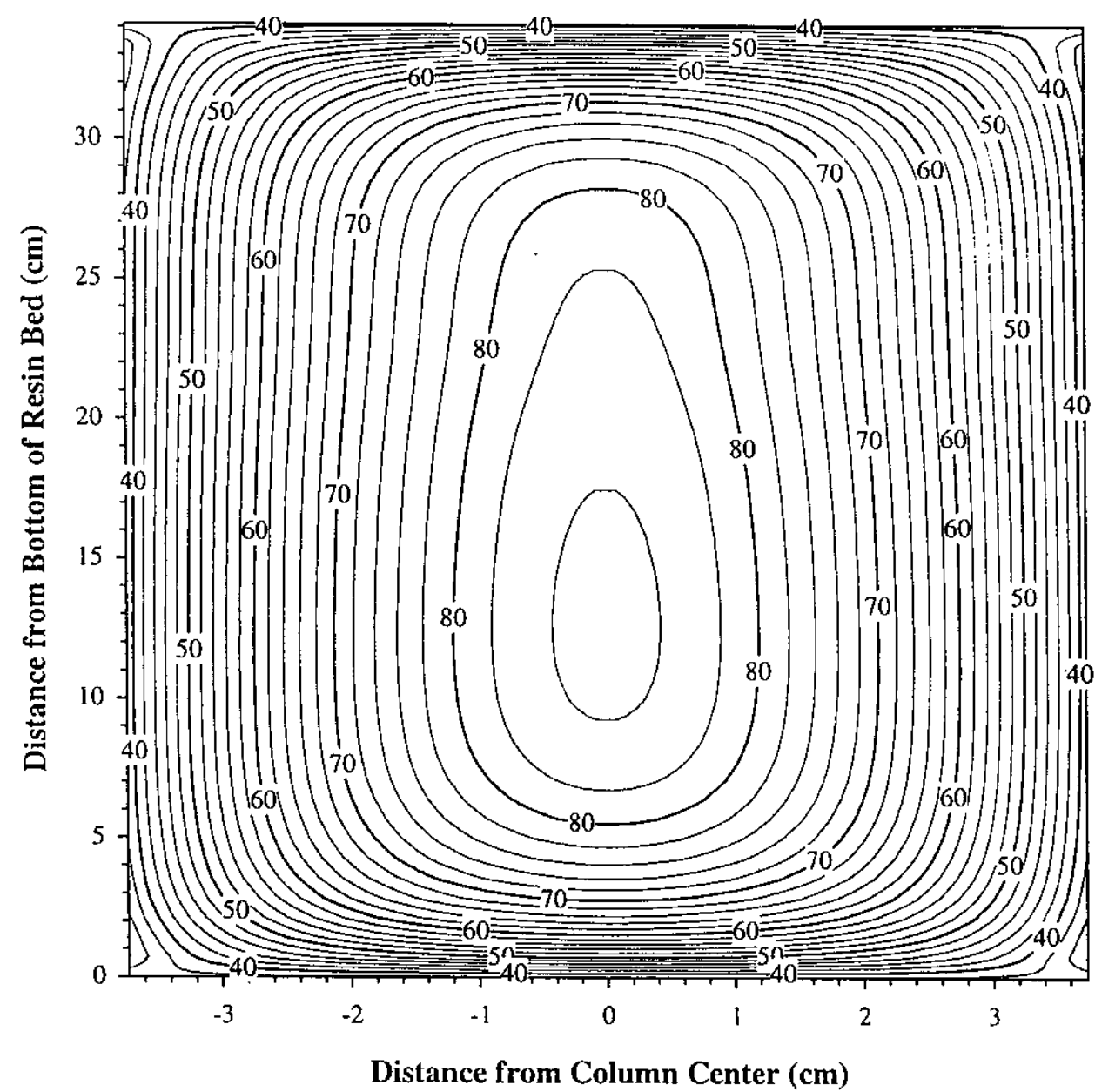

Figure 6. Temperature Distribution at Thermal Equilibrium after a Flow Stoppage for Low Feed Flow Rate, High Fèed Concentration, Exposure to $25^{\circ} \mathrm{C}$ Air, and Twice the Resin Capacity Fed, for a Grid Resolution of 48 Axial and 48 Radial Cells. 


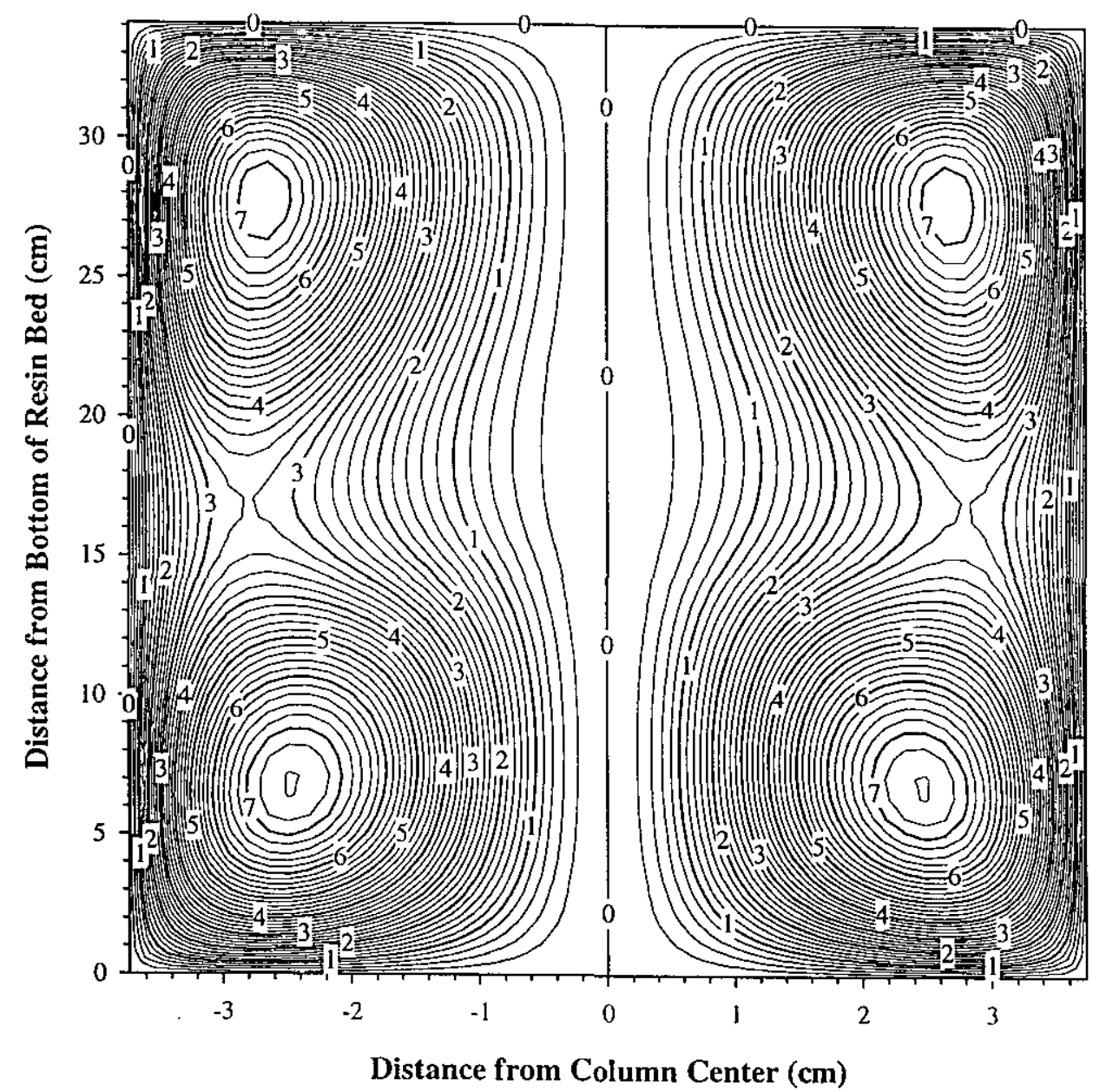

Figure 7. Flow Streamlines at Thermal Equilibrium after a Flow Stoppage for Low Feed Flow Rate, High Feed Concentration, Exposure to $25^{\circ} \mathrm{C}$ Air, and Twice the Resin Capacity Fed, for a Grid Resolution of 48 Axial and 24 Radial Cells. (Numbers on chart refer to values of stream function.) 
WSRC-TR-99-00027

Revision 0

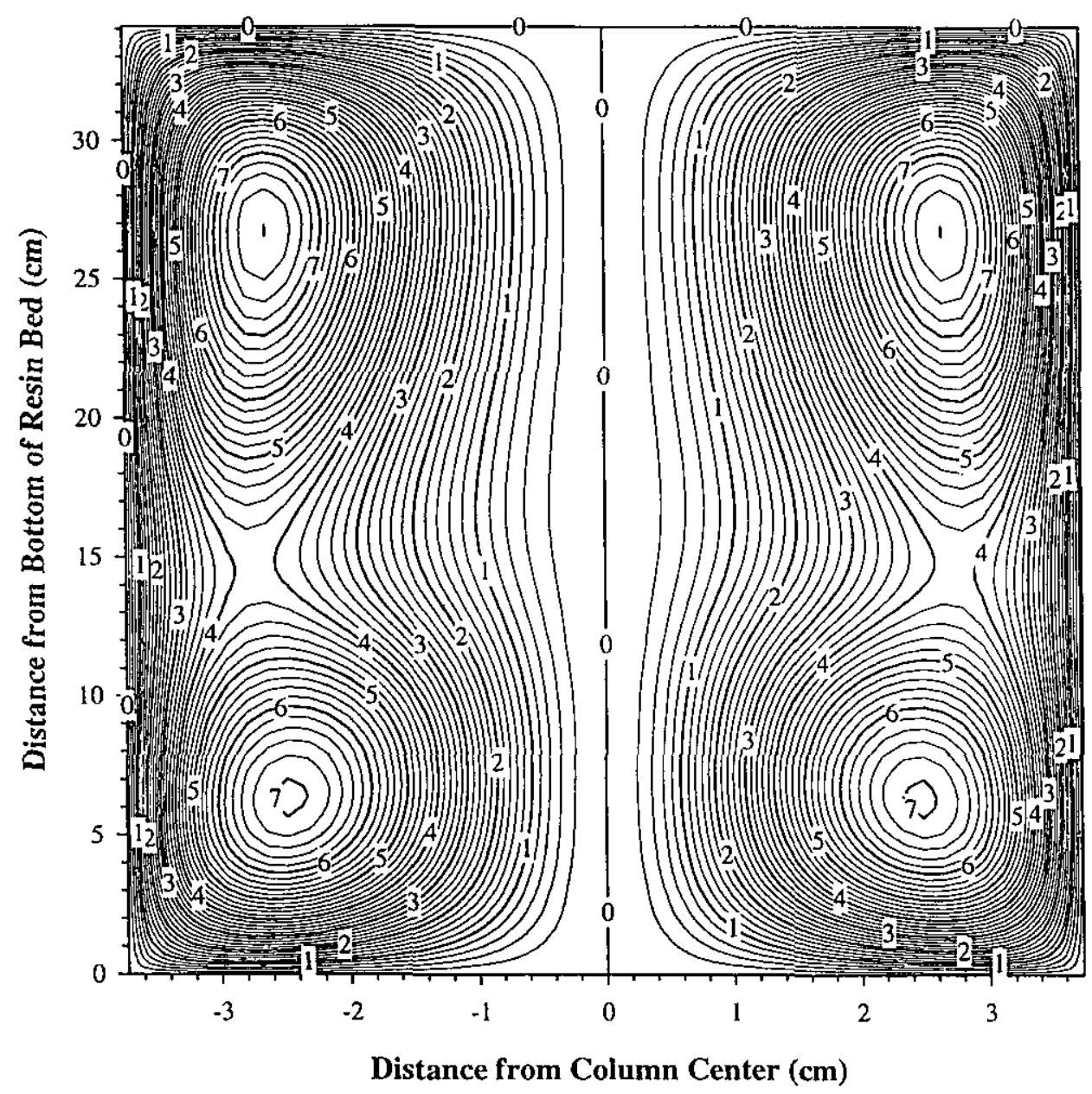

Figure 8. Flow Streamlines at Thermal Equilibrium after a Flow Stoppage for Low Feed Flow Rate, High Feed Concentration, Exposure to $25^{\circ} \mathrm{C}$ Air, and Twice the Resin Capacity Fed, for a Grid Resolution of 96 Axial and 24 Radial Cells. (Numbers on chart refer to values of stream function.) 


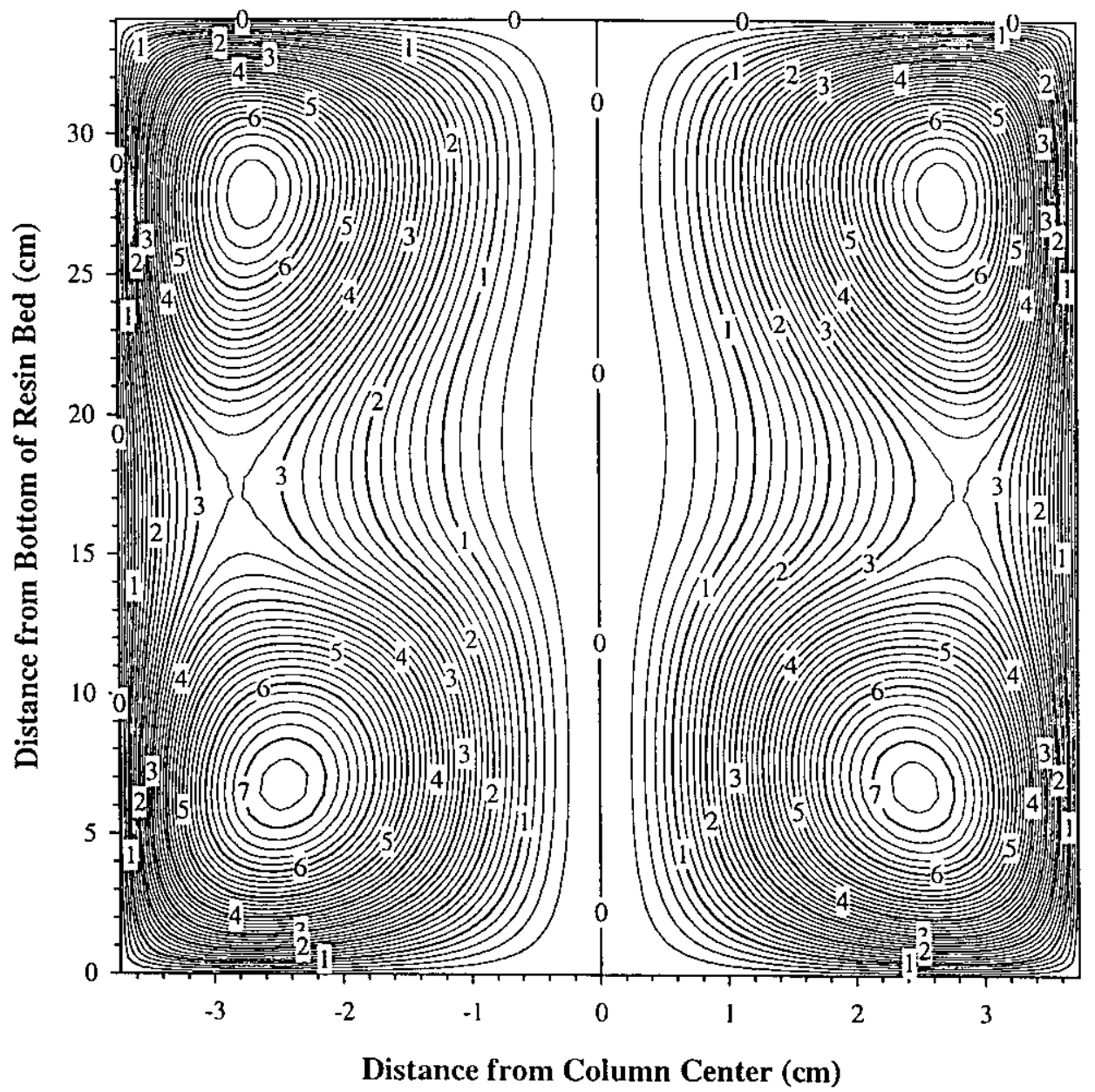

Figure 9. Flow Streamlines at Thermal Equilibrium after a Flow Stoppage for Low Feed Flow Rate, High Feed Concentration, Exposure to $25^{\circ} \mathrm{C}$ Air, and Twice the Resin Capacity Fed, for a Grid Resolution of 48 Axial and 48 Radial Cells. (Numbers on chart refer to values of stream function.) 


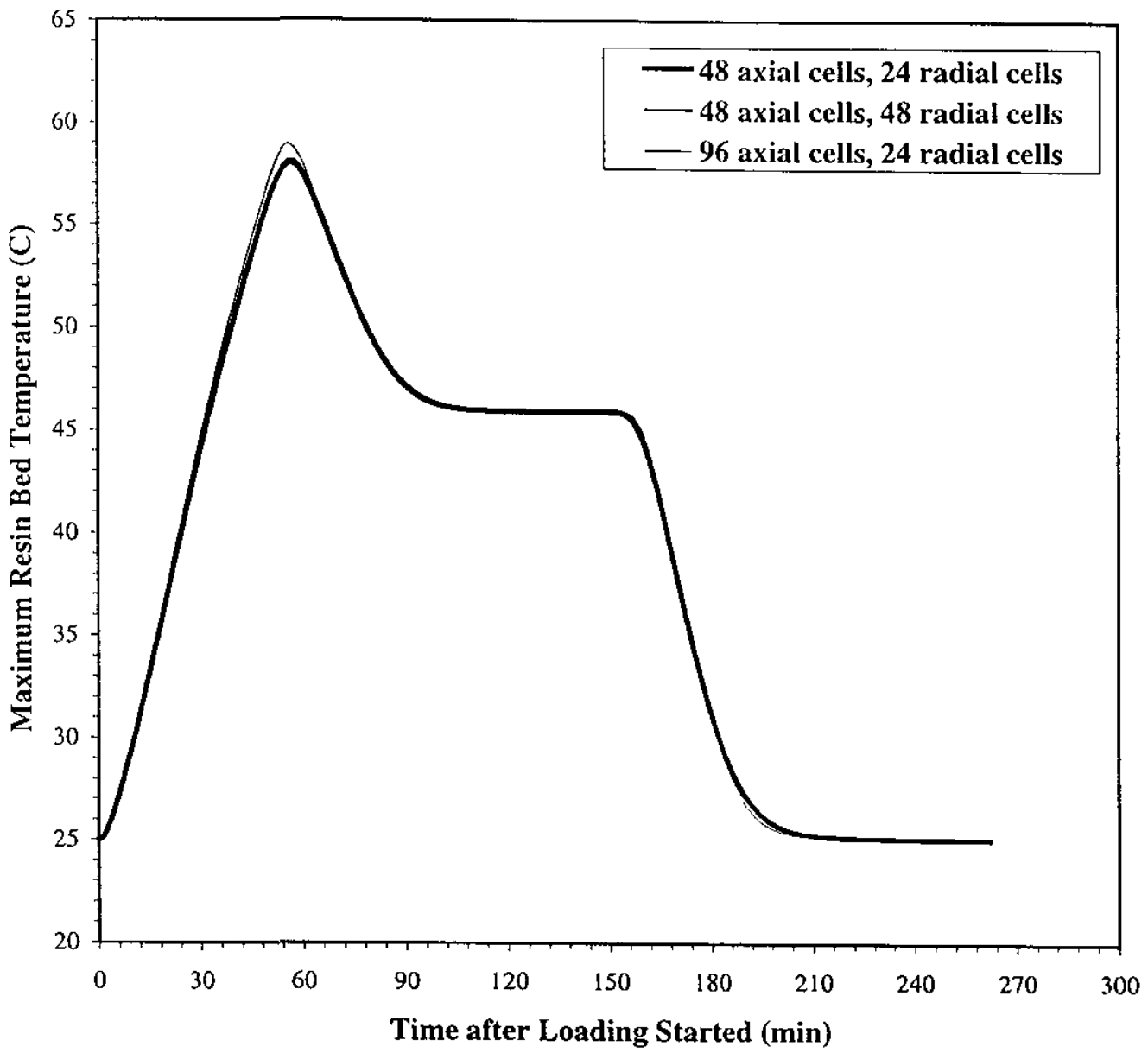

Figure 10. Effect of Finite Difference Cell Size on Maximum Resin Bed Temperatures during Normal Operation of the Column. (Conditions are low feed flow rate, high feed concentration, exposure to $25^{\circ} \mathrm{C}$ air, and twice the resin capacity fed.) 
WSRC-TR-99-00027

Revision 0

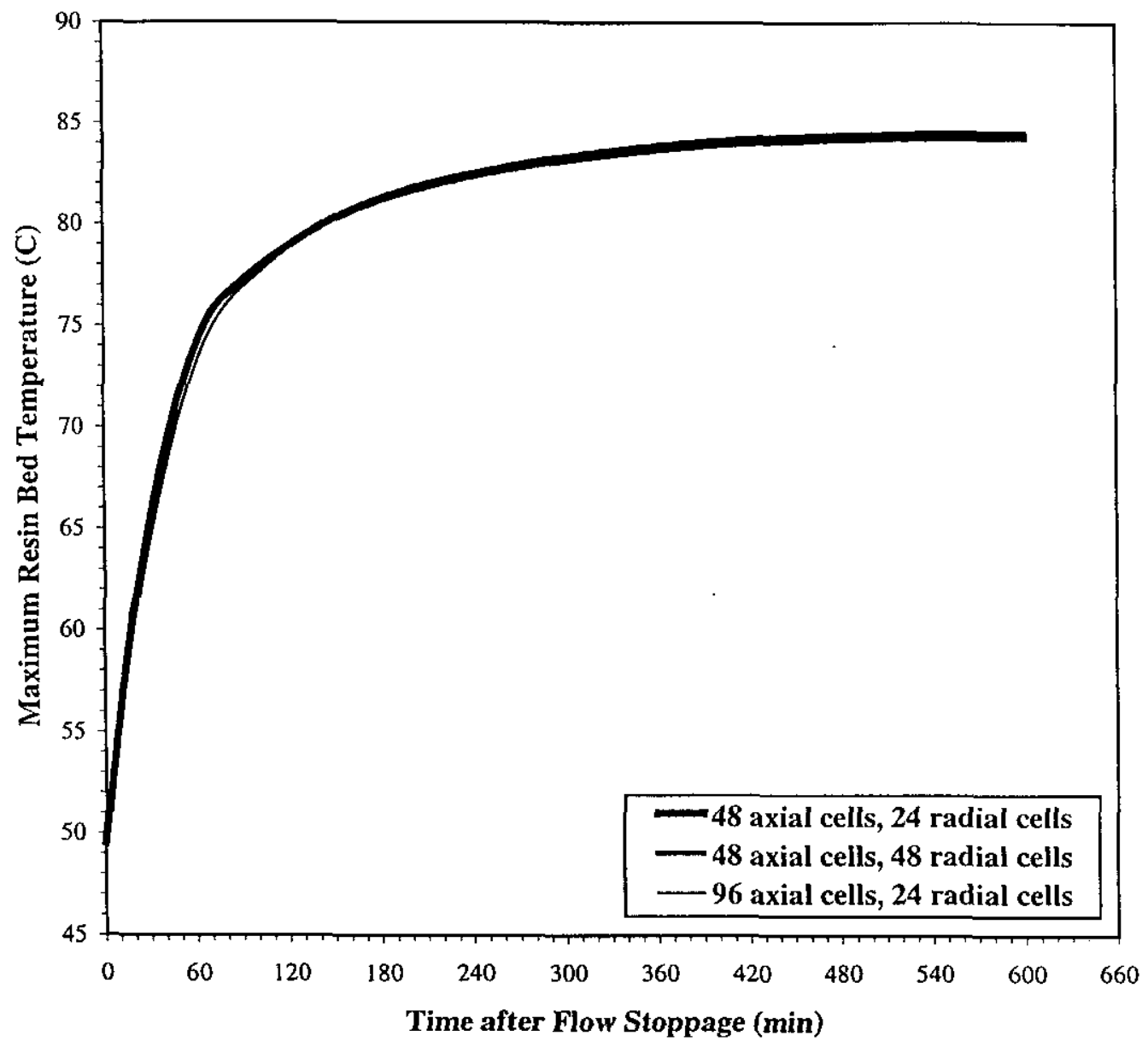

Figure 11. Effect of Finite Difference Cell Size on Maximum Resin Bed Temperatures during a Flow Stoppage. (Conditions are low feed flow rate, high feed concentration, exposure to $25^{\circ} \mathrm{C}$ air, and twice the resin capacity fed.) 


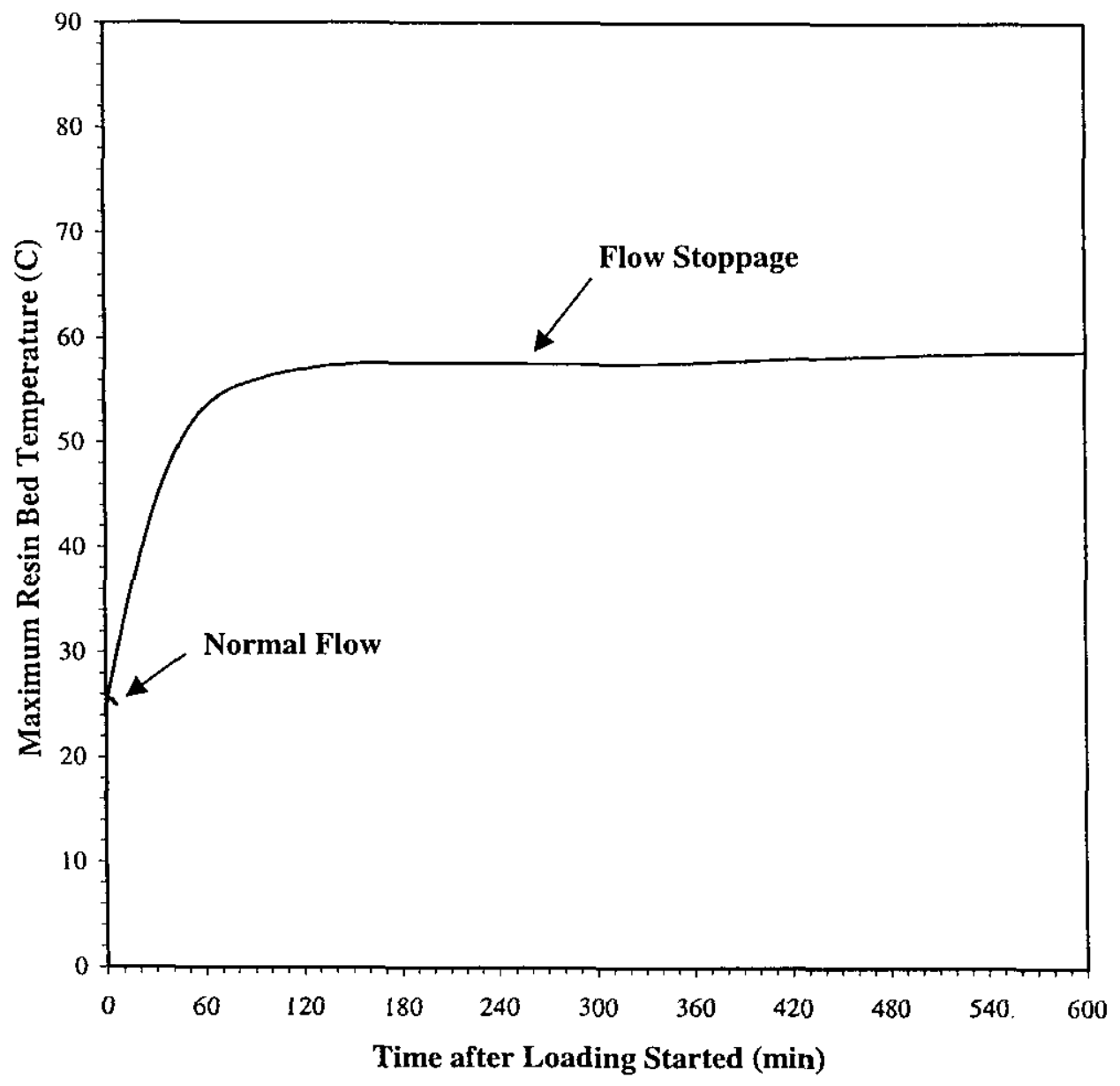

Figure 12. Maximum Resin Bed Temperatures for a High Feed Flow Rate, High Feed Concentration, Exposure to $25^{\circ} \mathrm{C}$ Air, and Stoichiometric Resin Capacity Fed. 
WSRC-TR-99-00027

Revision 0

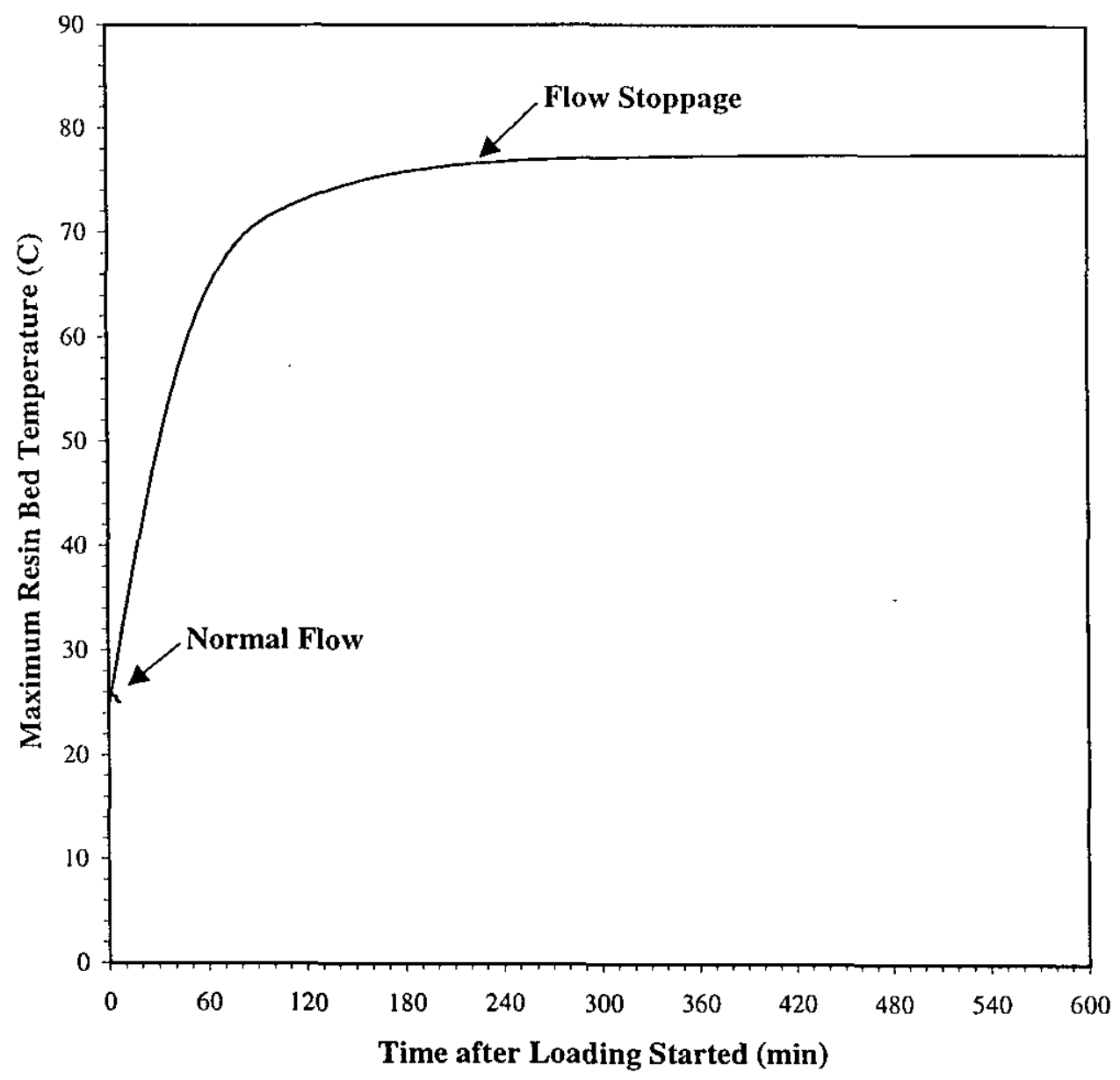

Figure 13. Maximum Resin Bed Temperatures for a High Feed Flow Rate, High Feed Concentration, Exposure to $25^{\circ} \mathrm{C}$ Air, and Twice the Resin Capacity Fed. 


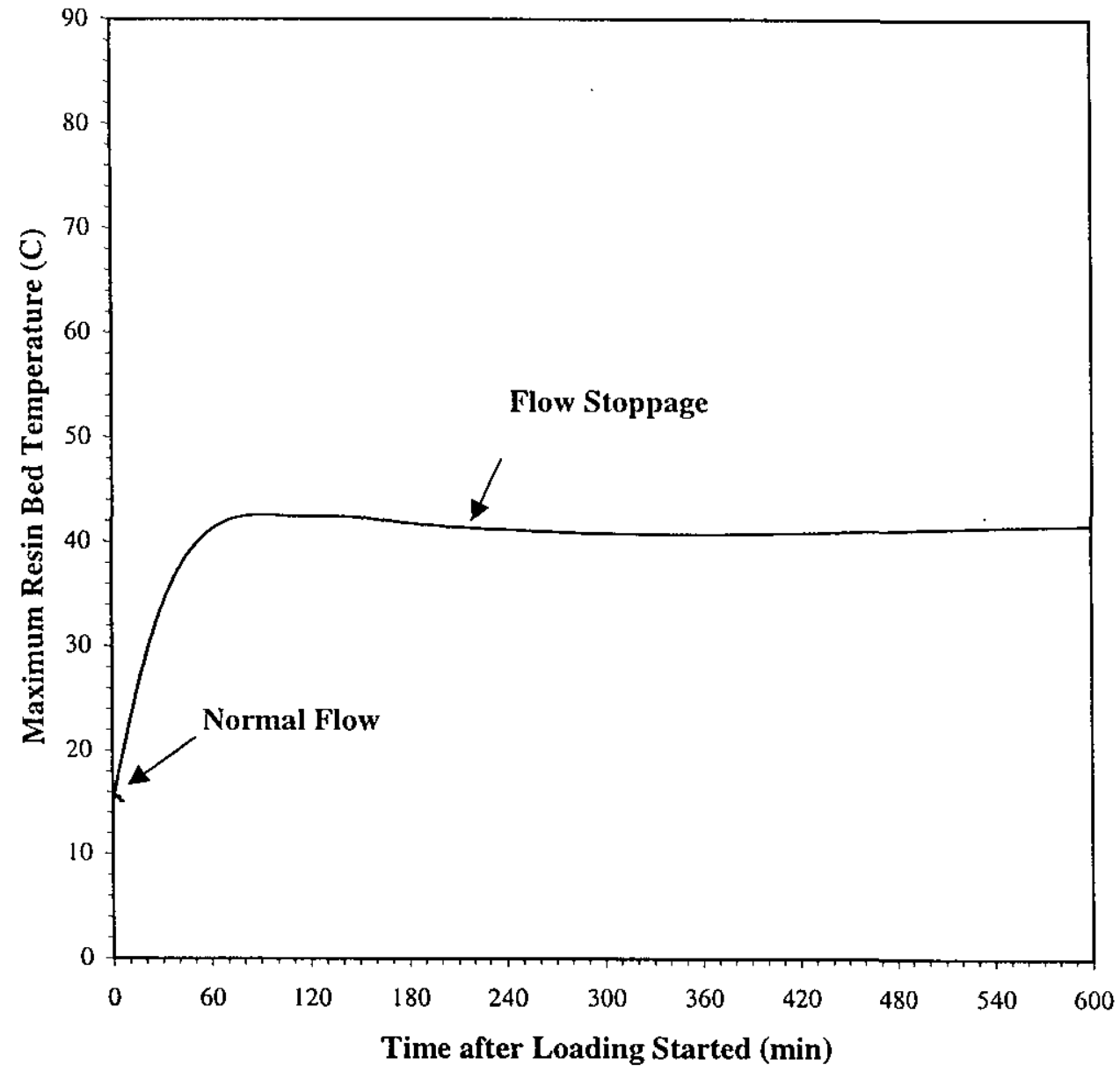

Figure 14. Maximum Resin Bed Temperatures for a High Feed Flow Rate, High Feed Concentration, Cooling by $15^{\circ} \mathrm{C}$ Water Jacket, and Stoichiometric Resin Capacity Fed. 
WSRC-TR-99-00027

Revision 0

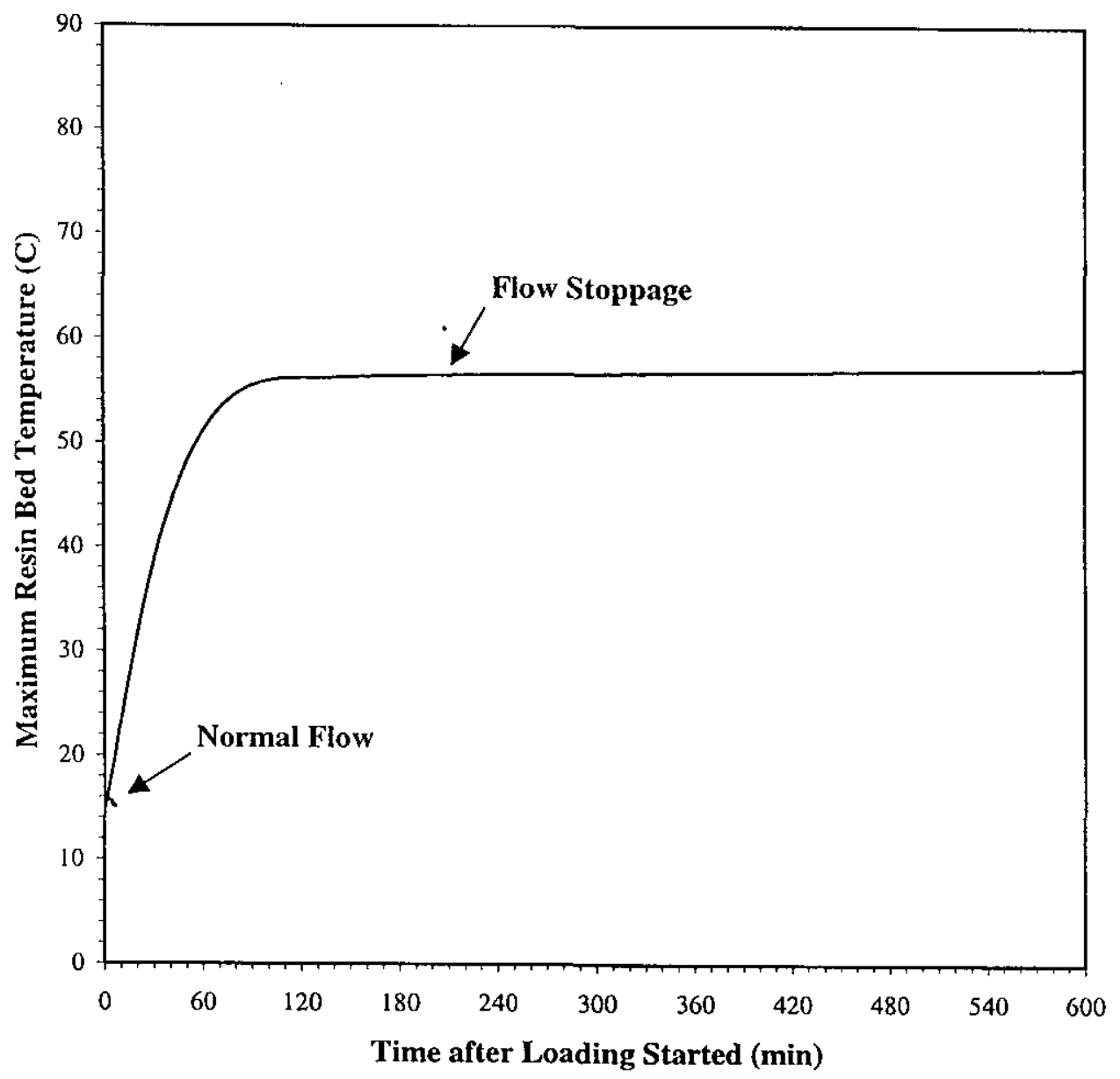

Figure 15. Maximum Resin Bed Temperatures for a High Feed Flow Rate, High Feed Concentration, Cooling by $15^{\circ} \mathrm{C}$ Water Jacket, and Twice the Resin Capacity Fed. 


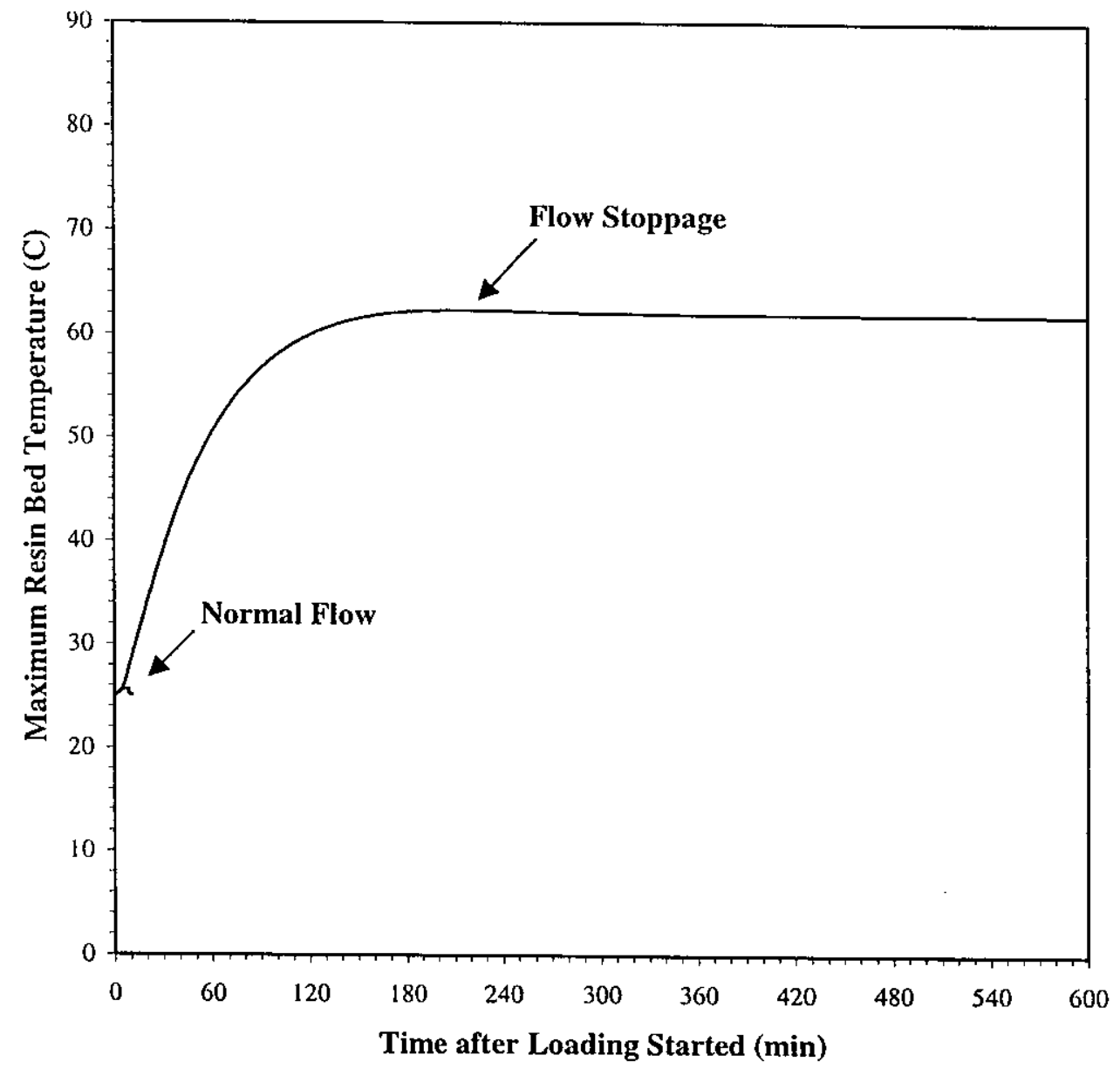

Figure 16. Maximum Resin Bed Temperatures for a High Feed Flow Rate, Low Feed Concentration, Exposure to $25^{\circ} \mathrm{C}$ Air, and Stoichiometric Resin Capacity Fed. 


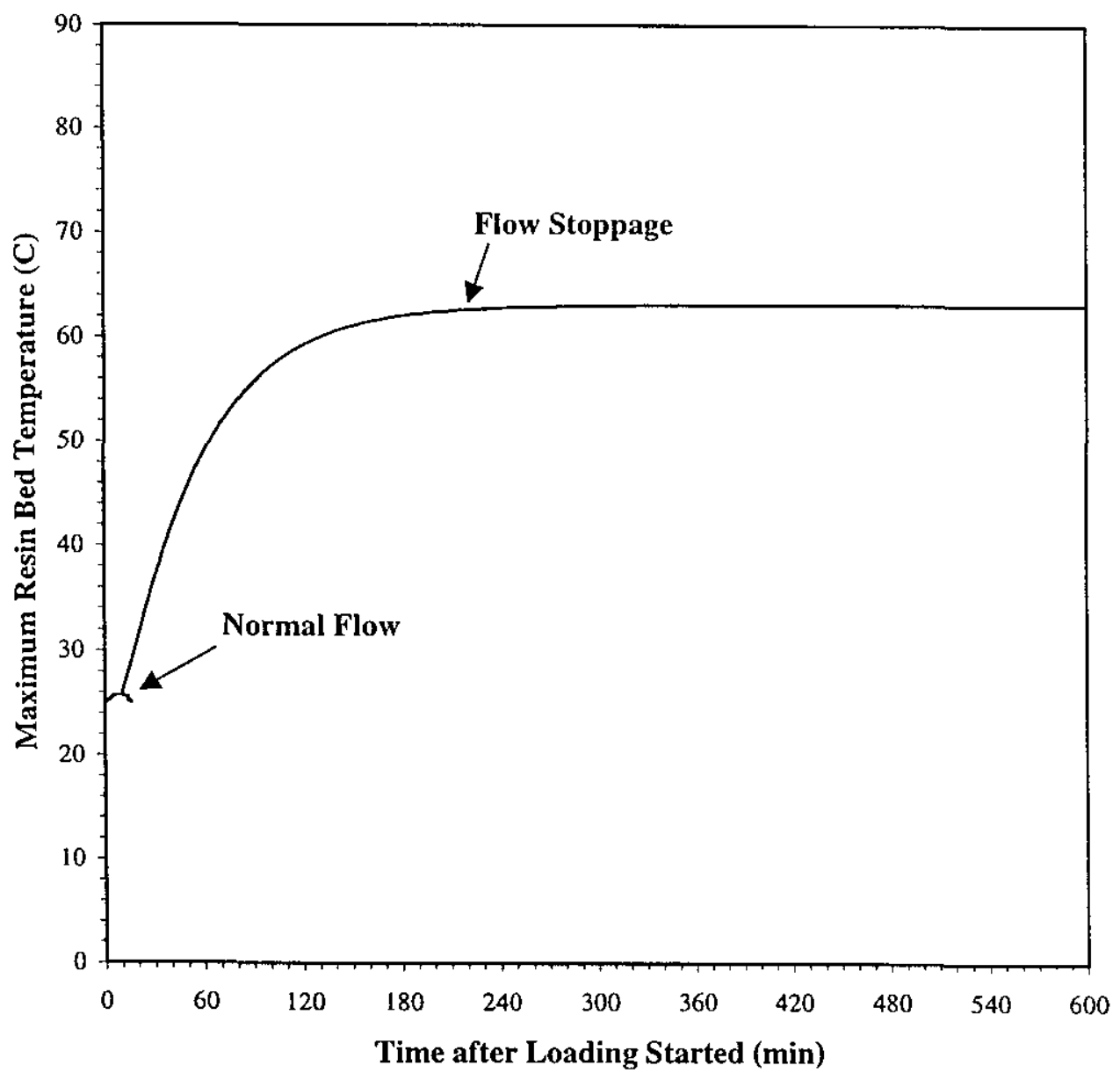

Figure 17. Maximum Resin Bed Temperatures for a High Feed Flow Rate, Low Feed Concentration, Exposure to $25^{\circ} \mathrm{C}$ Air, and Twice the Resin Capacity Fed. 


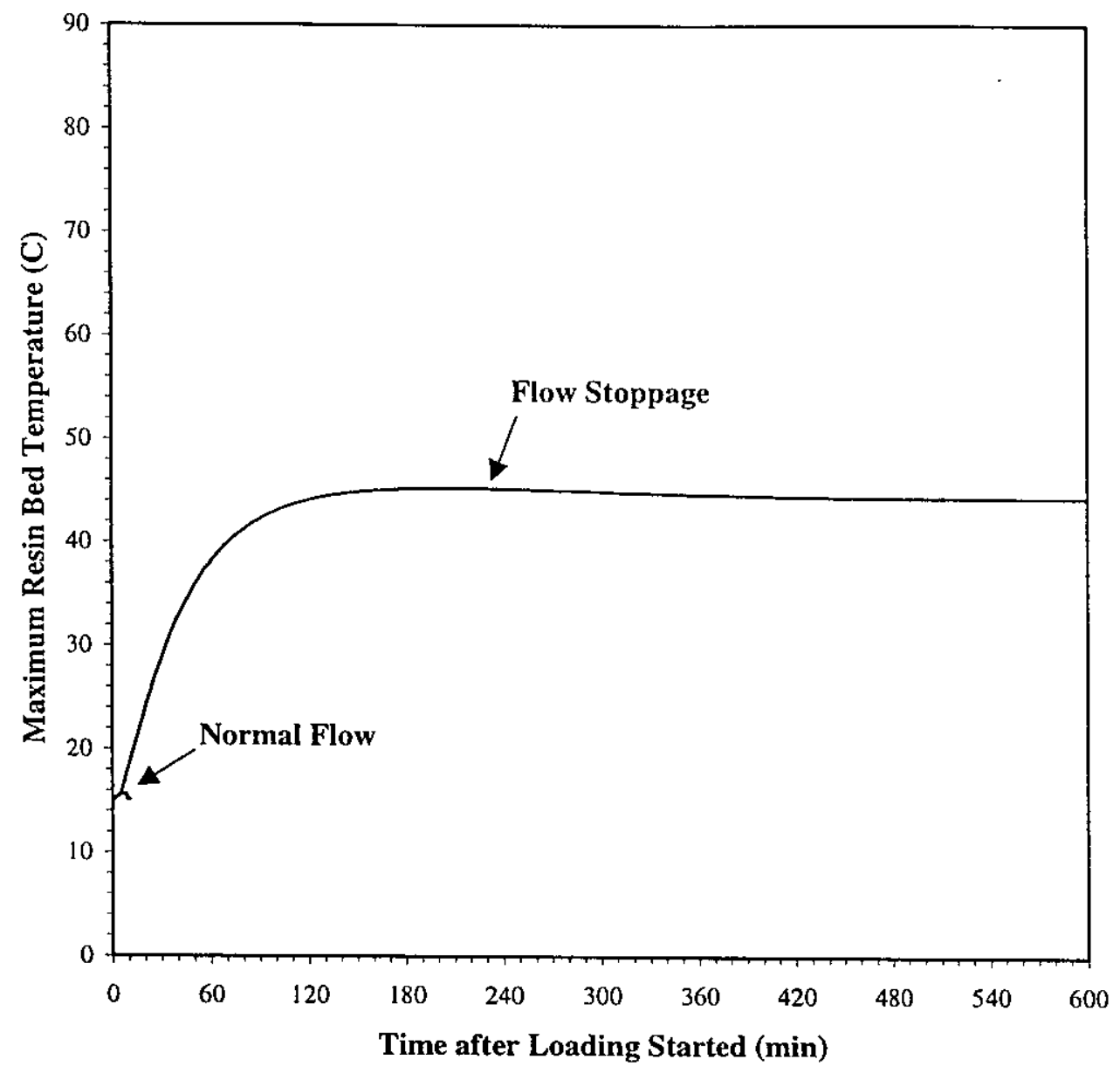

Figure 18. Maximum Resin Bed Temperatures for a High.Feed Flow Rate, Low Feed Concentration, Cooling by $15^{\circ} \mathrm{C}$ Water Jacket, and Stoichiometric Resin Capacity Fed. 
Revision 0

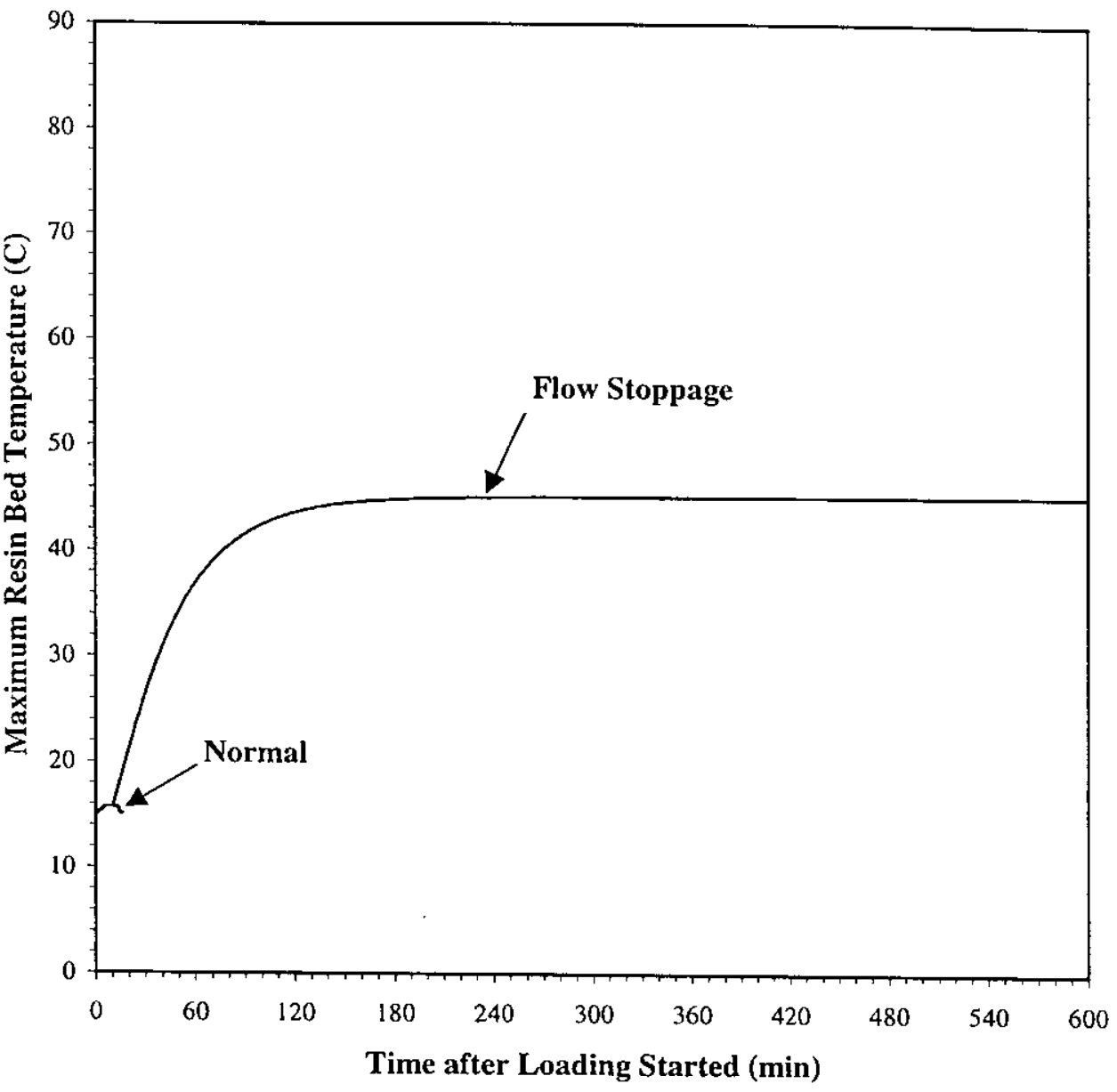

Figure 19. Maximum Resin Bed Temperatures for a High Feed Flow Rate, Low Feed Concentration, Cooling by $15^{\circ} \mathrm{C}$ Water Jacket, and Twice the Resin Capacity Fed. 
WSRC-TR-99-00027

Revision 0

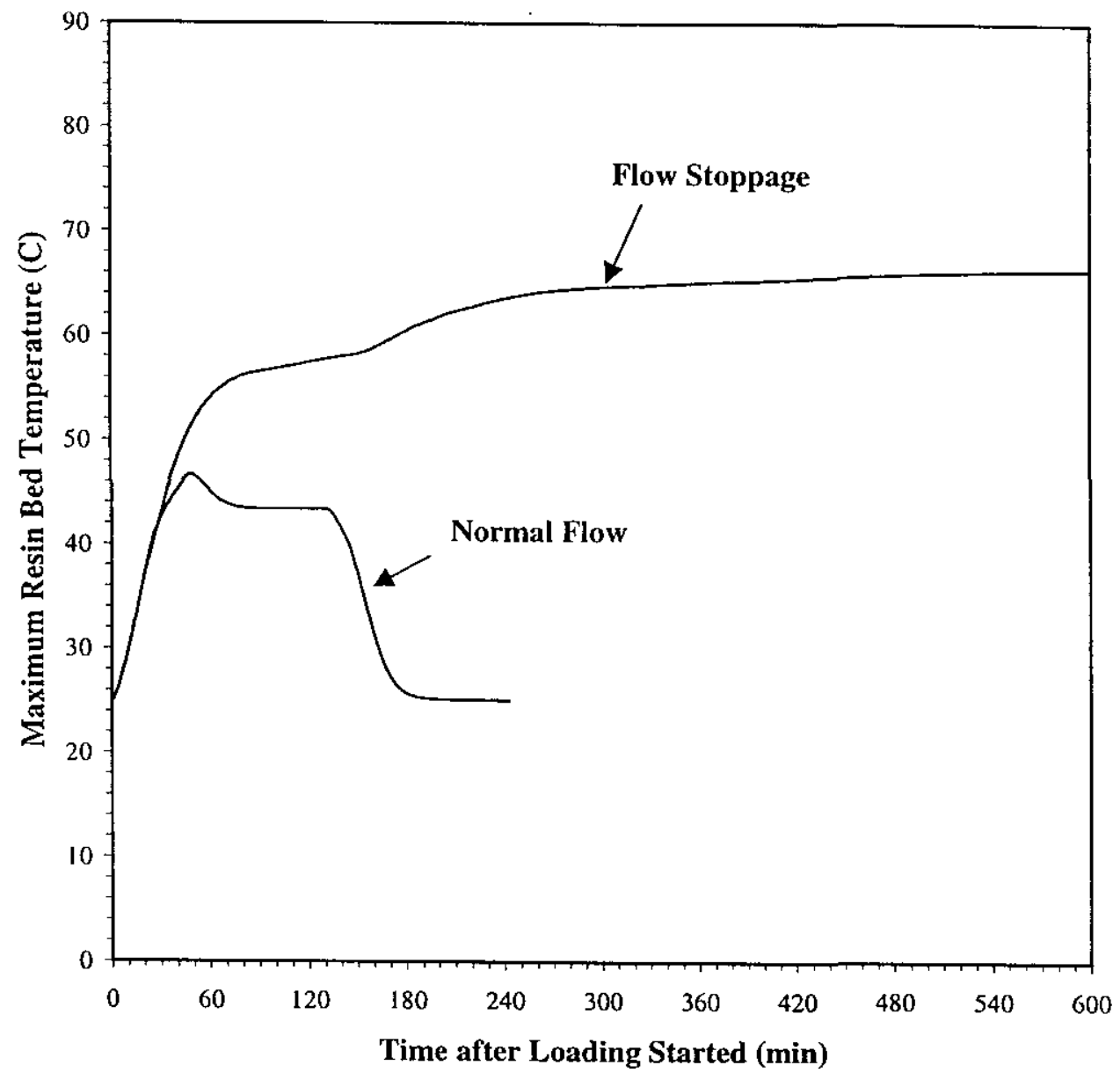

Figure 20. Maximum Resin Bed Temperatures for a Low Feed Flow Rate, High Feed Concentration, Exposure to $25^{\circ} \mathrm{C}$ Air, and Stoichiometric Resin Capacity Fed. 


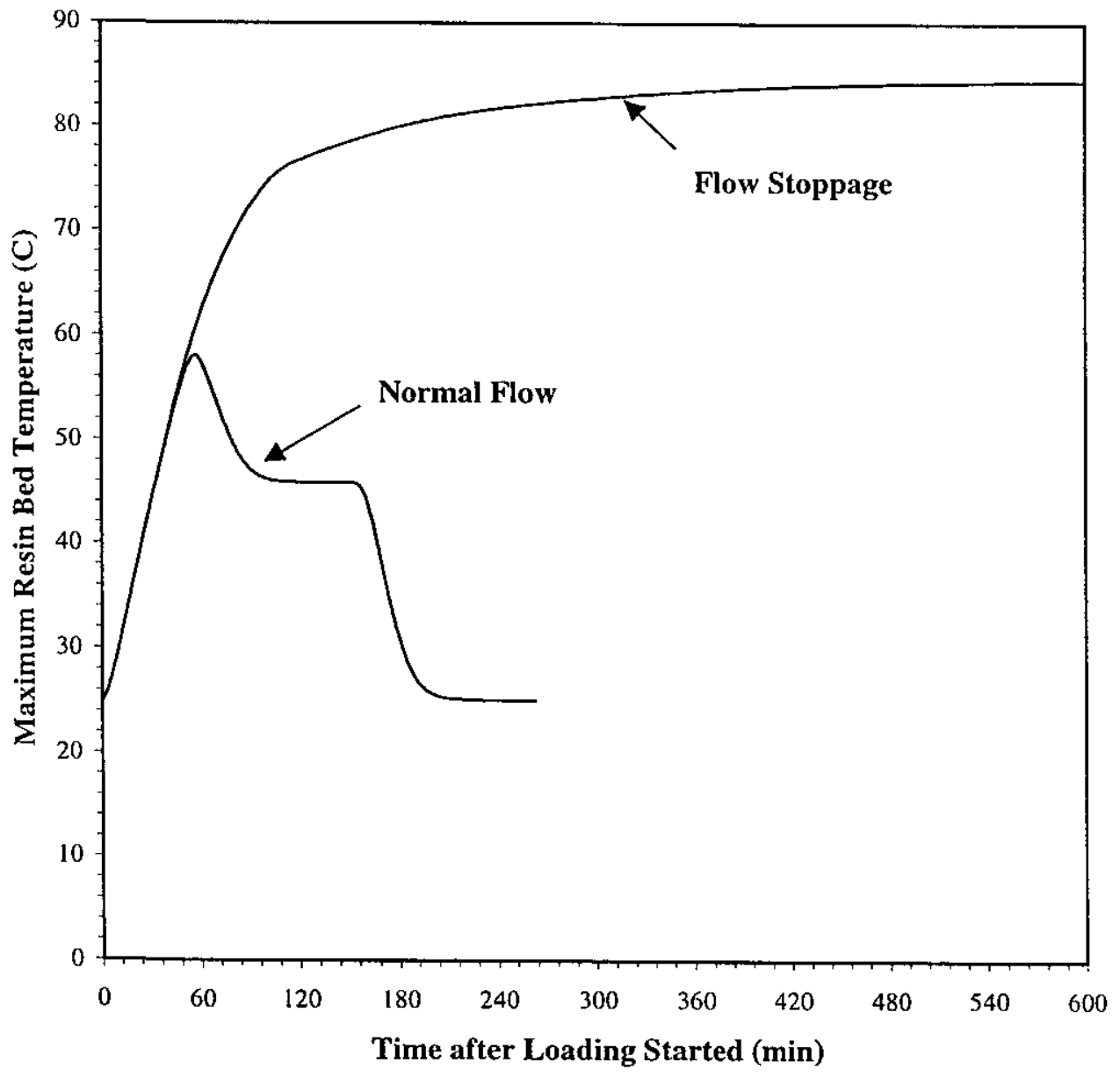

Figure 21. Maximum Resin Bed Temperatures for a Low Feed Flow Rate, High Feed Concentration, Exposure to $25^{\circ} \mathrm{C} \mathrm{Air,} \mathrm{and} \mathrm{Twice} \mathrm{the} \mathrm{Resin} \mathrm{Capacity} \mathrm{Fed.}$ 


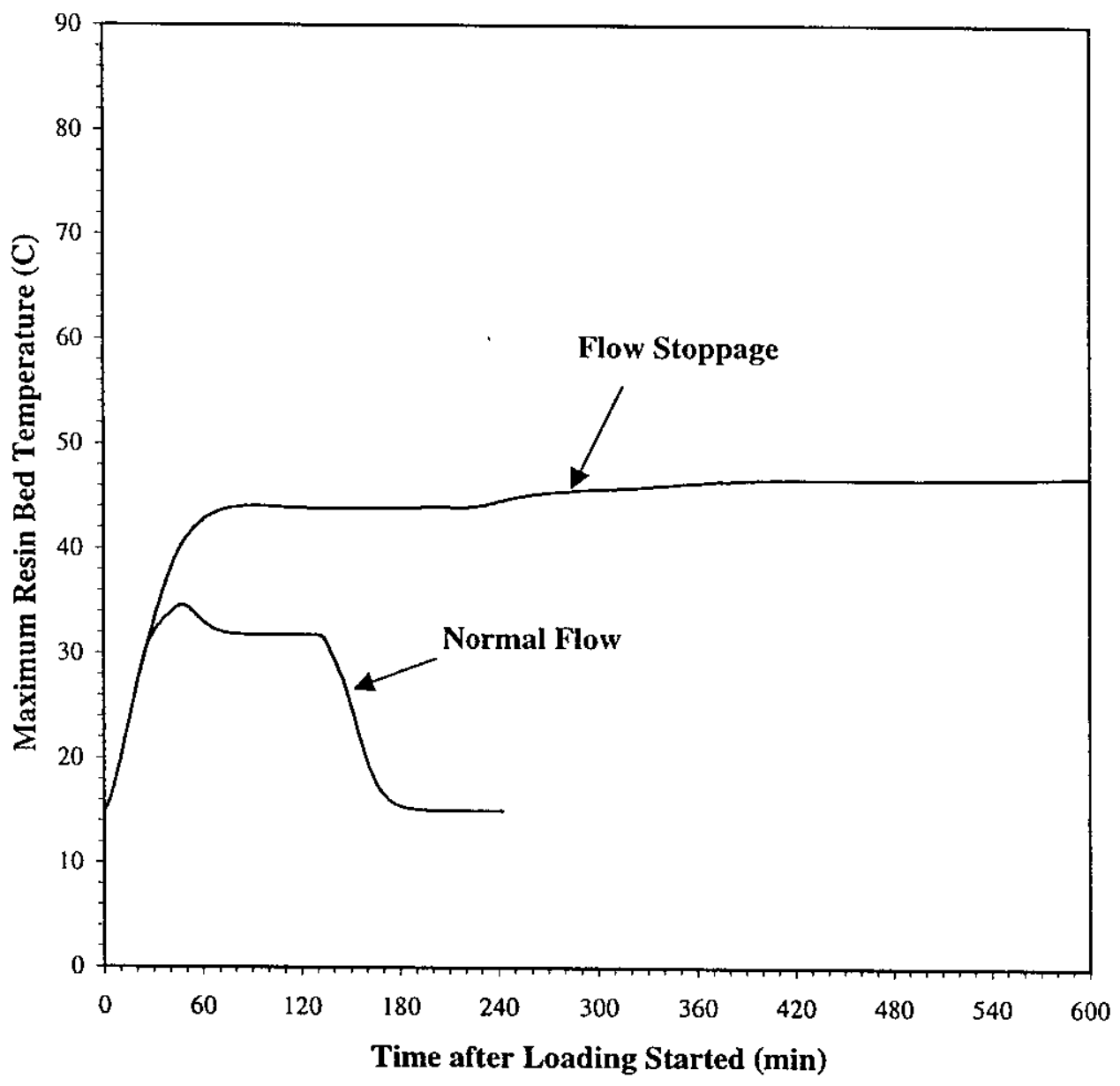

Figure 22. Maximum Resin Bed Temperatures for a Low Feed Flow Rate, High Feed Concentration, Cooling by $15^{\circ} \mathrm{C}$ Water Jacket, and Stoichiometric Resin Capacity Fed. 


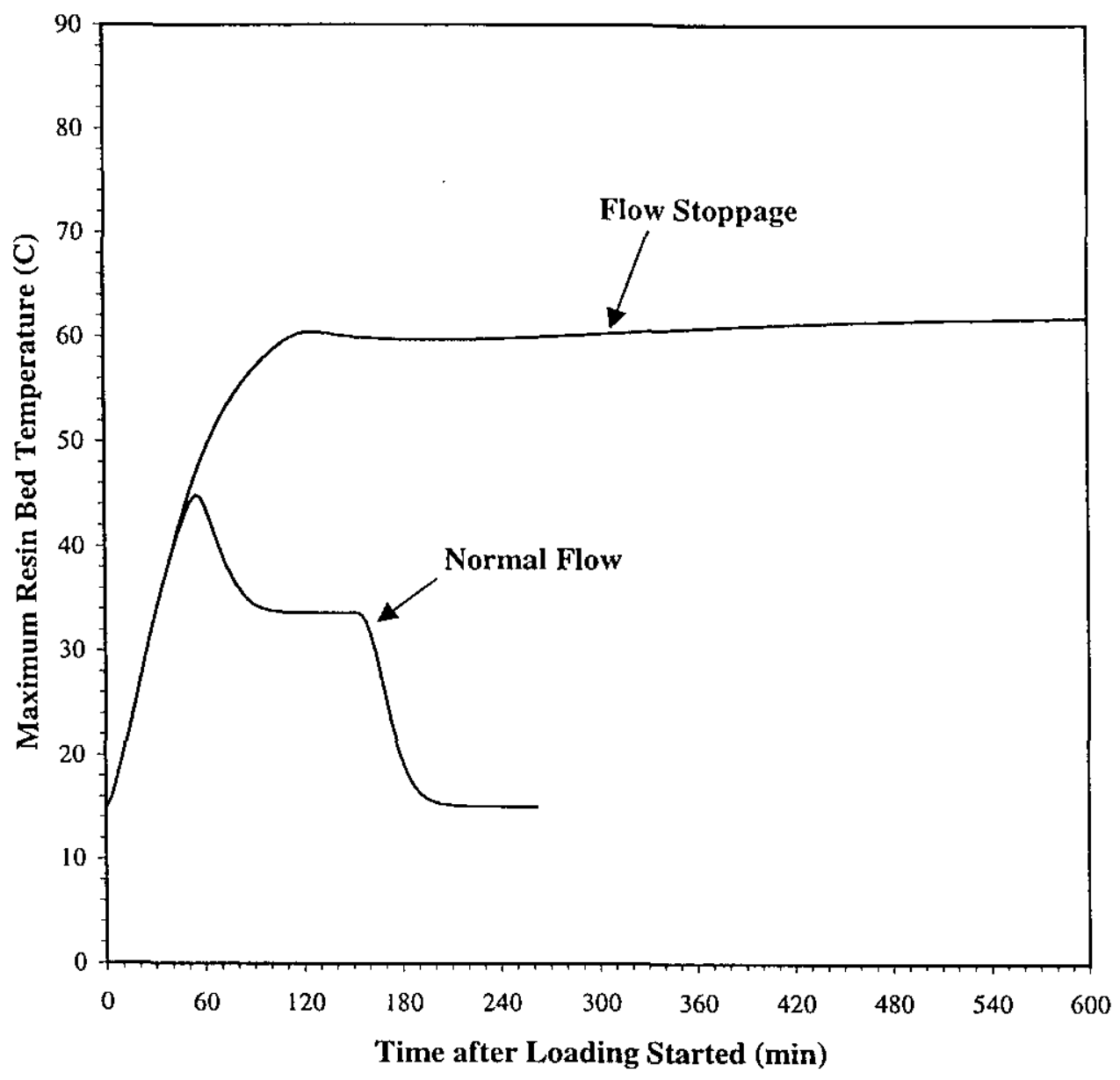

Figure 23. Maximum Resin Bed Temperatures for a Low Feed Flow Rate, High Feed Concentration, Cooling by $15^{\circ} \mathrm{C}$ Water Jacket, and Twice the Resin Capacity Fed. 
WSRC-TR-99-00027

Revision 0

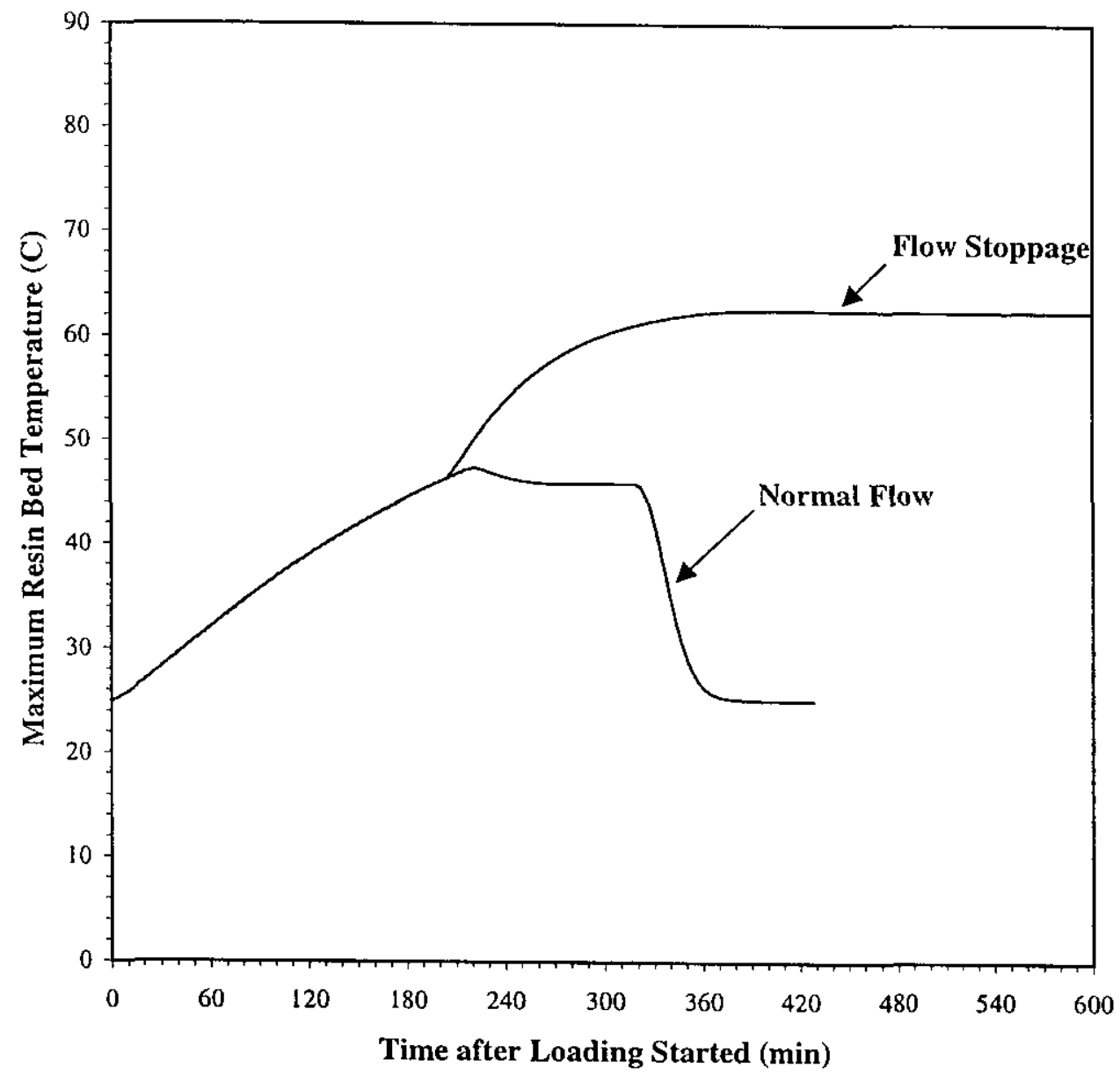

Figure 24. Maximum Resin Bed Temperatures for a Low Feed Flow Rate, Low Feed Concentration, Exposure to $25^{\circ} \mathrm{C}$ Air, and Stoichiometric Resin Capacity Fed. 


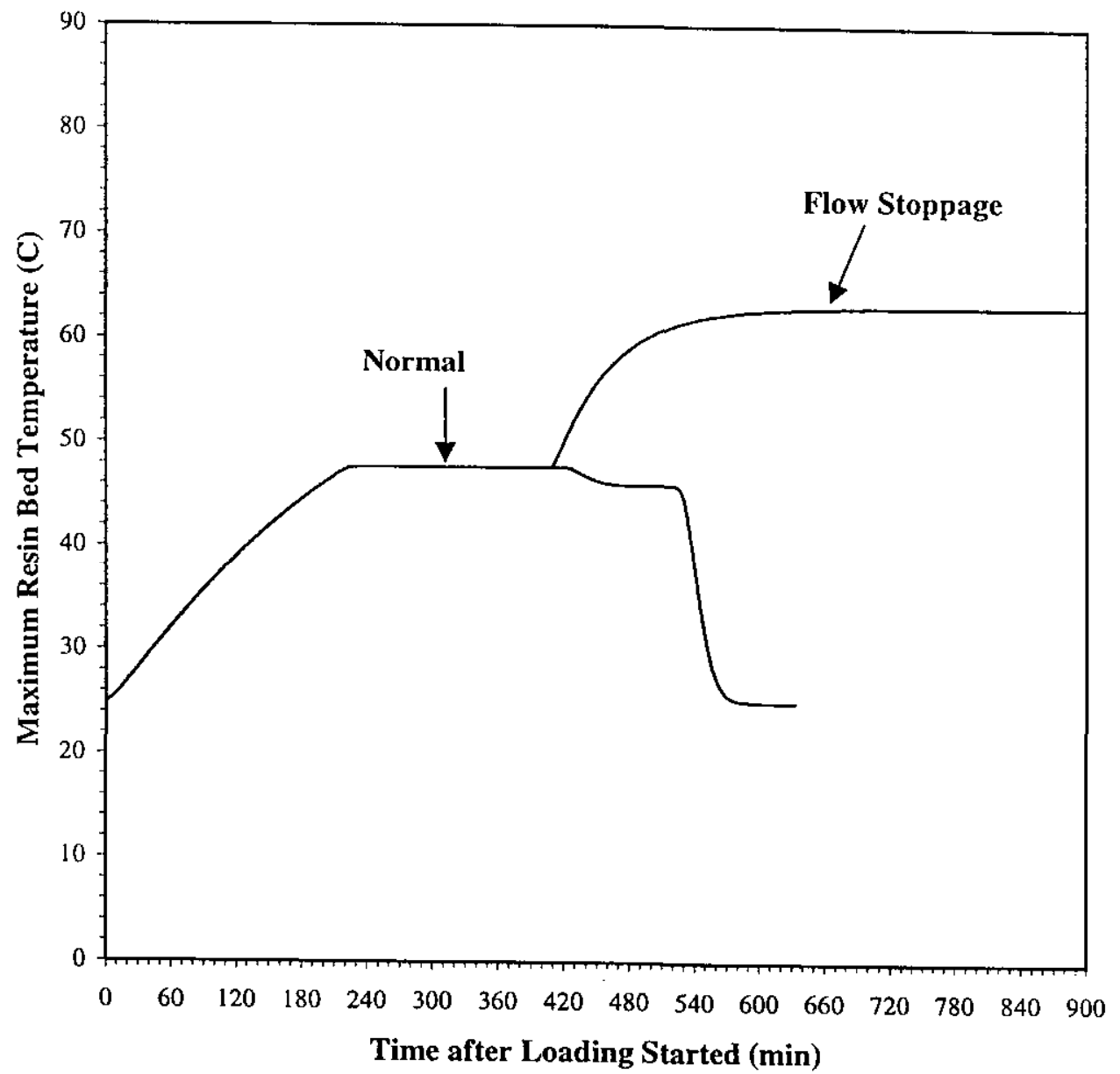

Figure 25. Maximum Resin Bed Temperatures for a Low Feed Flow Rate, Low Feed Concentration, Exposure to $25^{\circ} \mathrm{C}$ Air, and Twice the Resin Capacity Fed. 


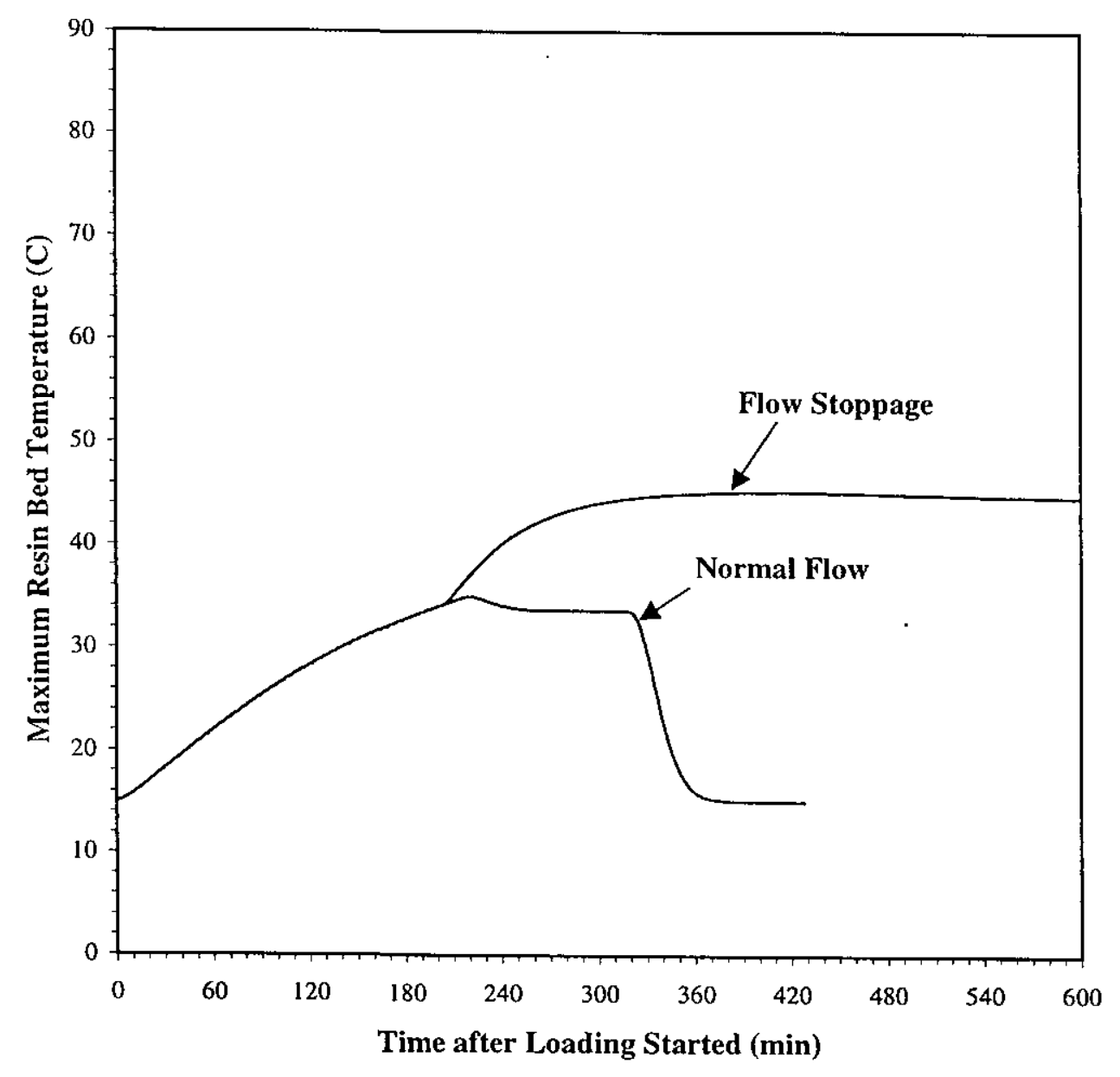

Figure 26. Maximum Resin Bed Temperatures for a Low Feed Flow Rate, Low Feed Concentration, Cooling by $15^{\circ} \mathrm{C}$ Water Jacket, and Stoichiometric Resin Capacity Fed. 


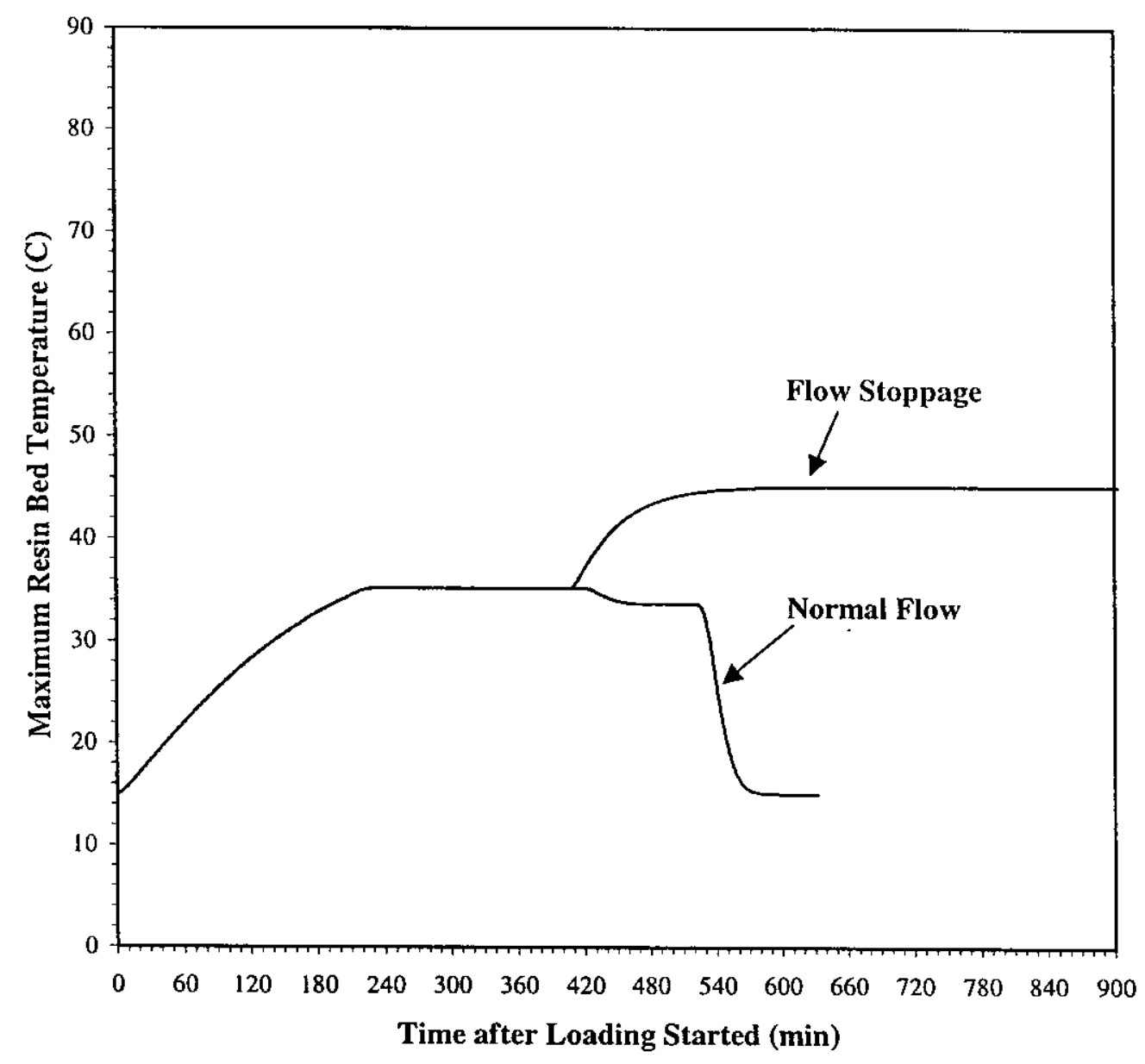

Figure 27. Maximum Resin Bed Temperatures for a Low Feed Flow Rate, Low Feed Concentration, Cooling by $15^{\circ} \mathrm{C}$ Water Jacket, and Twice the Resin Capacity Fed. 


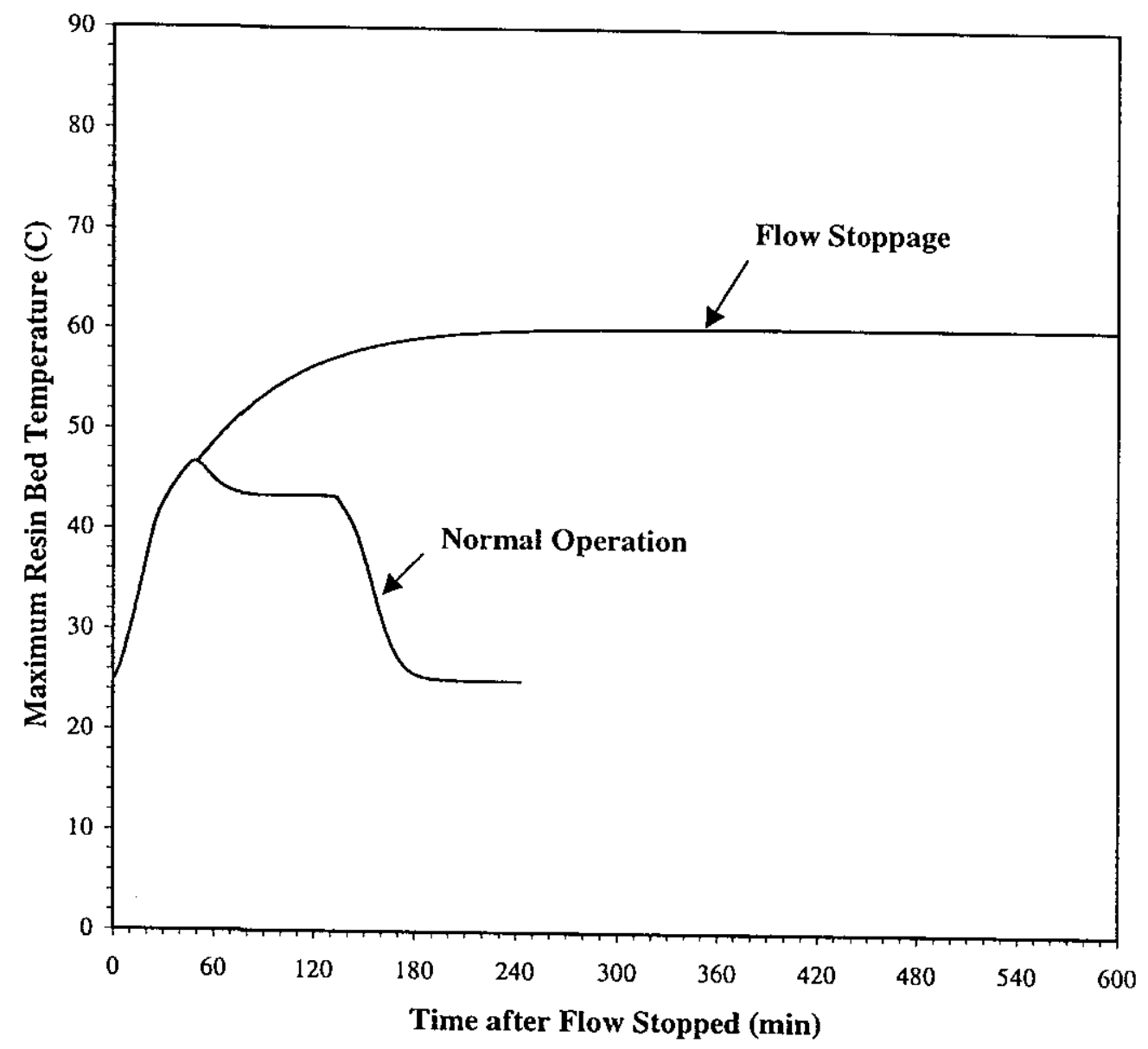

Figure 28. Maximum Resin Bed Temperatures for a Low Feed Flow Rate, High Feed Concentration, Exposure to $25^{\circ} \mathrm{C}$ Air, and Stoichiometric Resin Capacity Fed, with Stoppage of Flow at the Maximum Bed Temperature during Washing. 


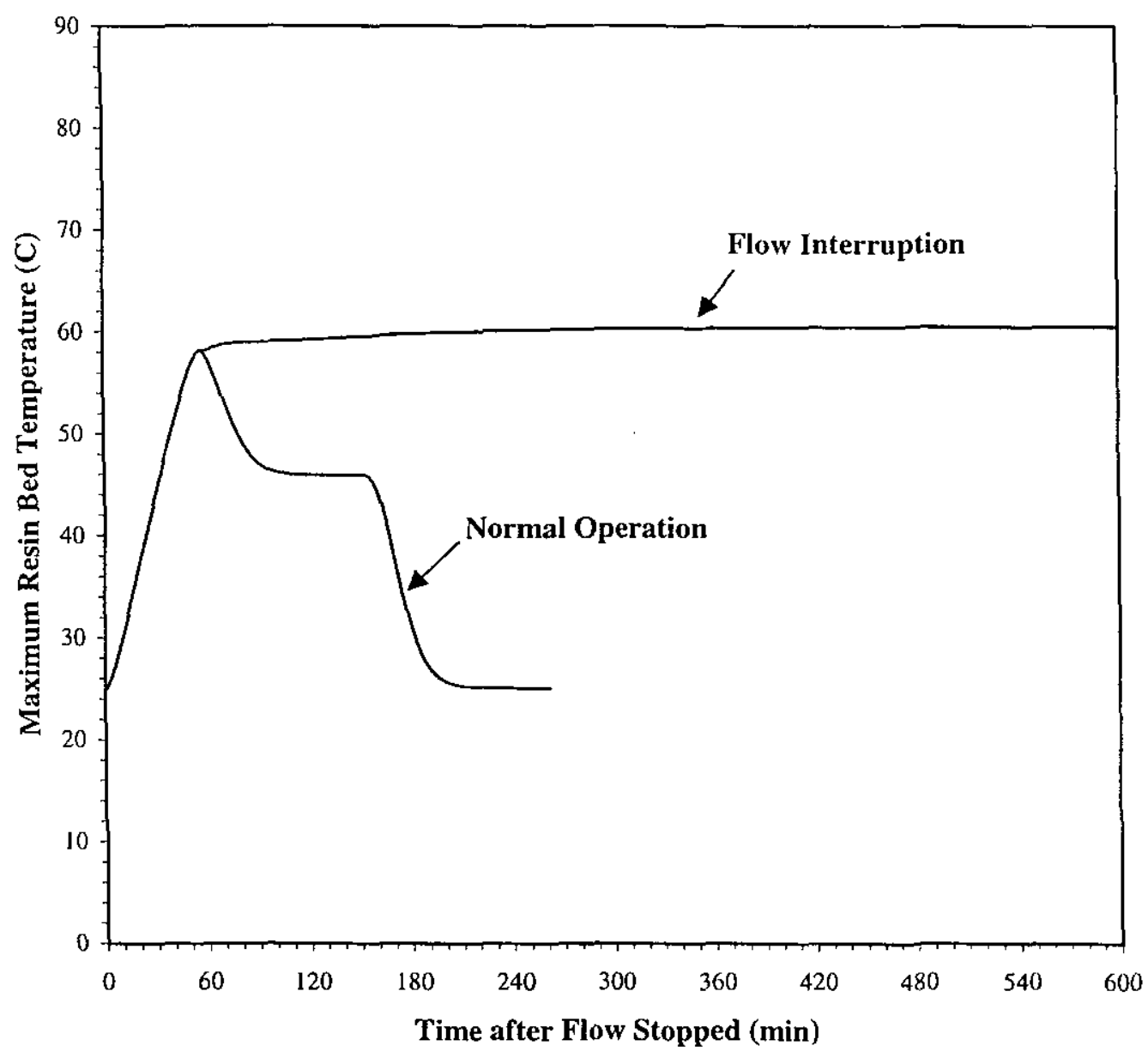

Figure 29. Maximum Resin Bed Temperatures for a Low Feed Flow Rate, High Feed Concentration, Exposure to $25^{\circ} \mathrm{C}$ Air, and Twice the Resin Capacity Fed, with Stoppage of Flow at the Maximum Bed Temperature during Washing. 


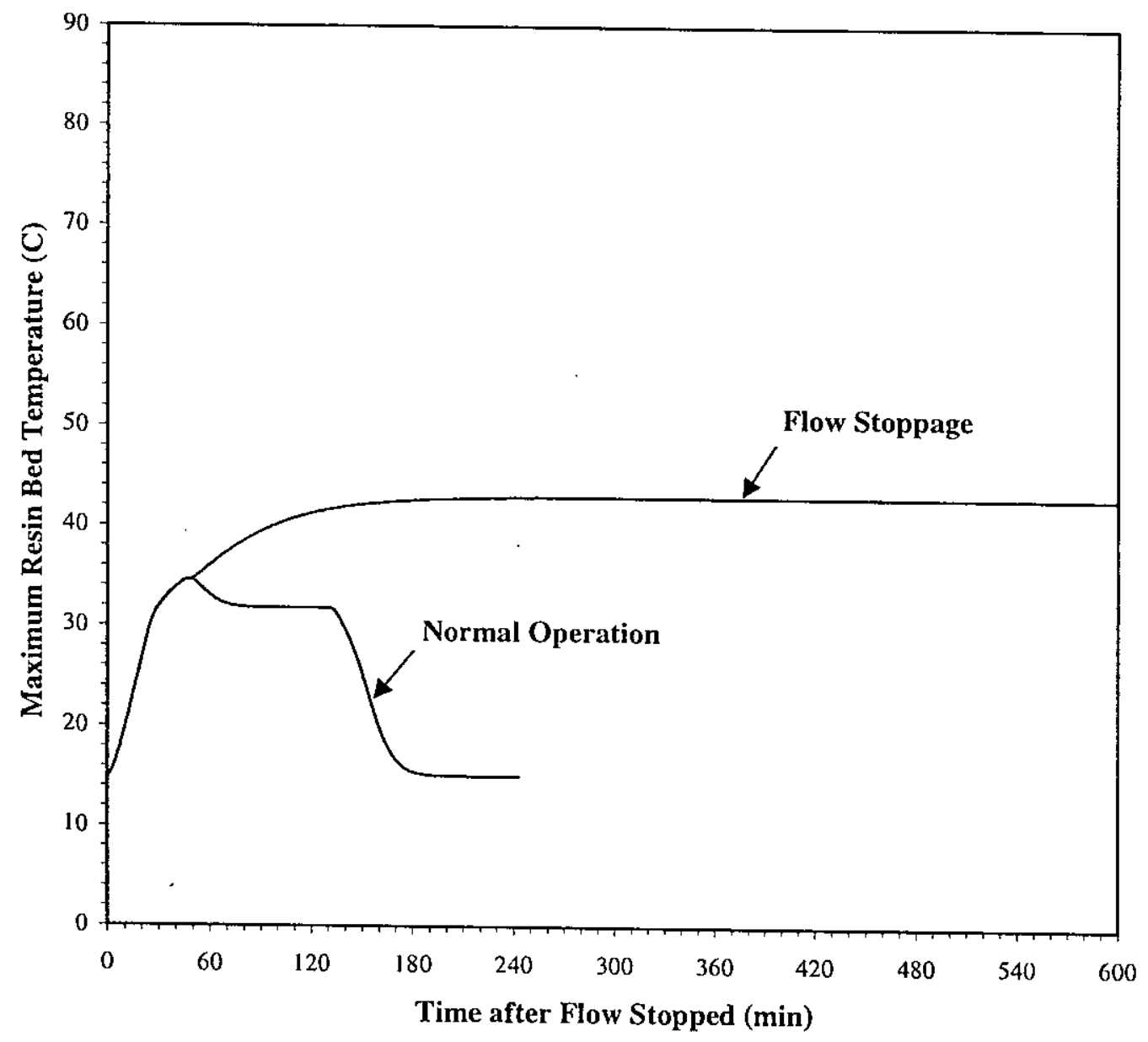

Figure 30. Maximum Resin Bed Temperatures for a Low Feed Flow Rate, High Feed Concentration, Cooling by $15^{\circ} \mathrm{C}$ Water Jacket, and Stoichiometric Resin Capacity Fed, with Stoppage of Flow at the Maximum Bed Temperature during Washing. 


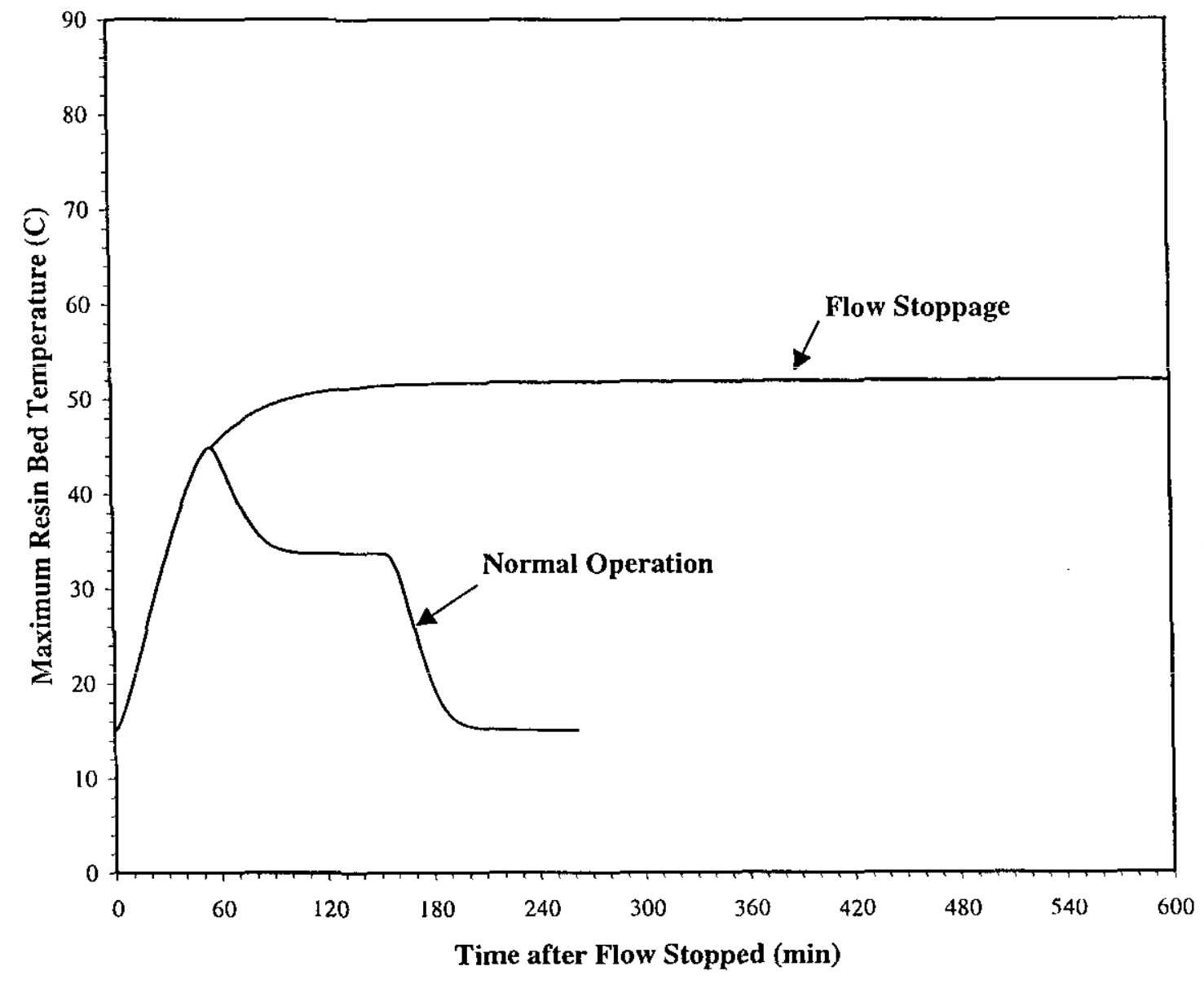

Figure 31. Maximum Resin Bed Temperatures for a Low Feed Flow Rate, High Feed Concentration, Cooling by $15^{\circ} \mathrm{C}$ Water Jacket, and Twice the Resin Capacity Fed, with Stoppage of Flow at the Maximum Bed Temperature during Washing. 


\section{Appendix: Source Code, Sample Input, and Sample Output Listings}

This appendix contains the source code, sample input, and sample output listings for the LANL ion exchange column heat transfer analysis. Two sets of listings appear, one for calculations during normal operation, which includes loading, washing, and elution, and another assuming that the feed flow to the column has stopped. The calculations performed by these codes are described in the text. In addition, both codes include comments that give definitions of variables and outline the code structure. The sample input and output listings are for the case with a high flow rate, a high plutonium feed concentration, exposure to ambient air at $25^{\circ} \mathrm{C}$, and addition of a stoichiometric amount of plutonium to the column. The output files that contain the maximum temperature transients appear; other output files are not shown.

The source code for normal operation is named FEDFLO.FOR, and the source code for a flow stoppage is called NATCON.FOR. Both are stored in Vax subdirectory [t6930.hcolumn].

\section{Source Code for Thermal Analysis during Normal Operation}

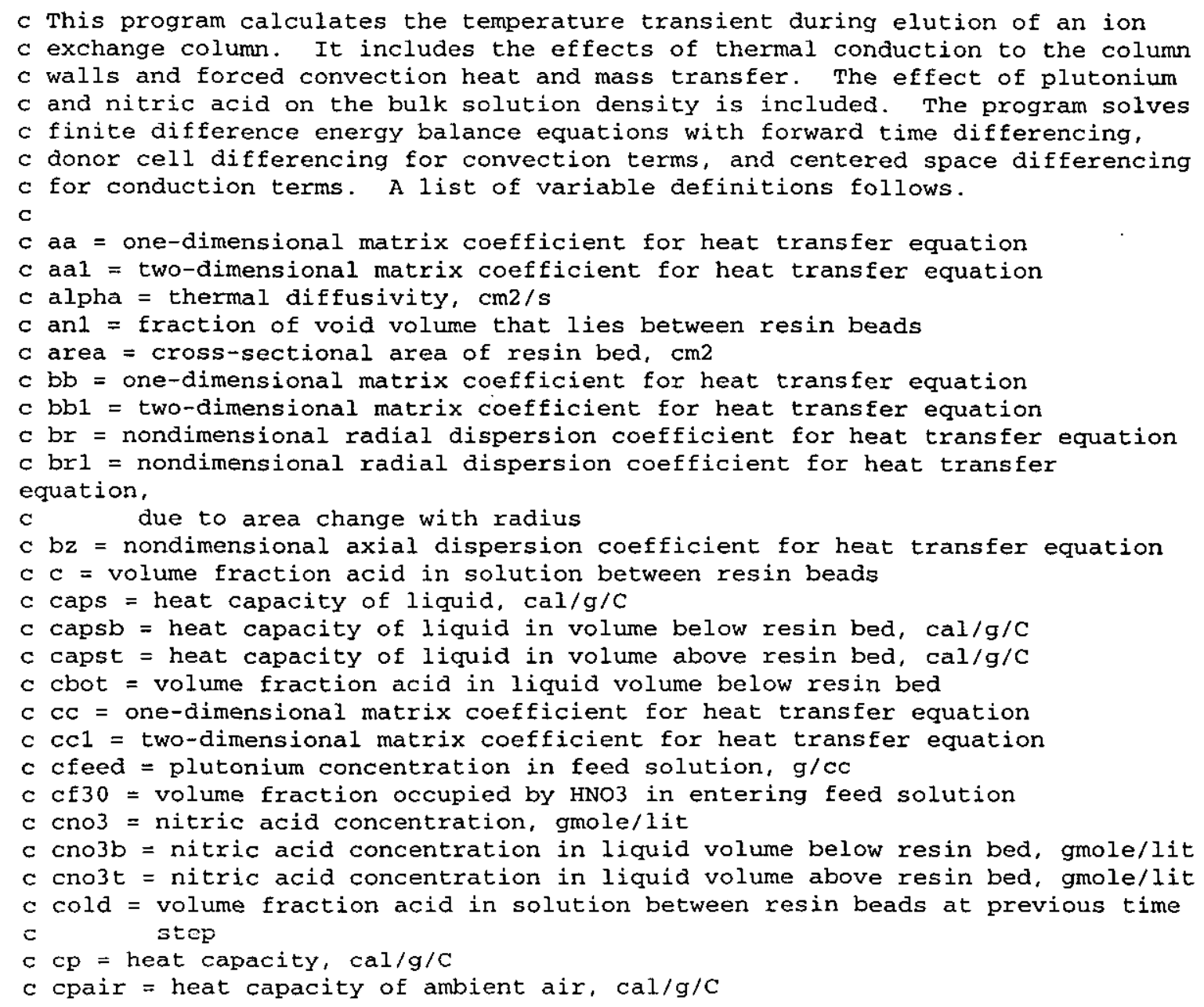


c cond = thermal conductivity

c $\mathrm{clfeed}=$ plutonium concentration in liquid volume above resin bed, $\mathrm{g} / \mathrm{cc}$

c den1 = density of pure HNO3, g/cc

$c$ denlb = density of pure HNO3 in liquid volume below resin bed, g/cc

$c$ denlt = density of pure $\mathrm{HNO}$ in liquid volume above resin bed, $\mathrm{g} / \mathrm{CC}$

$\mathrm{c}$ den 2 = density of pure $\mathrm{H} 2 \mathrm{O}, \mathrm{g} / \mathrm{cc}$

$c$ den2b = density of pure $\mathrm{H} 2 \mathrm{O}$ in liquid volume below resin bed, $\mathrm{g} / \mathrm{cc}$

$c$ den $2 t=$ density of pure $\mathrm{H} 2 \mathrm{O}$ in liquid volume above resin bed, $\mathrm{g} / \mathrm{cc}$

$\mathrm{c}$ dens = Iiquid density, g/cc

c densb = liquid density in volume below resin bed, $\mathrm{g} / \mathrm{cc}$

$c$ denst = liquid density in volume above resin bed, g/cc

c depor = pore diffusivity, $\mathrm{cm} 2 / \mathrm{s}$

c dfprt = particle diffusivity, $\mathrm{cm} 2 / \mathrm{s}$

$\mathrm{c} \mathrm{df}=$ change in adsorbed plutonium concentration during feeding and elution, c $g / c c$

$c \mathrm{dg}=$ change in plutonium concentration in pore solution due to elution, $g / c c$

$c$ dpart = resin bead diameter, $\mathrm{cm}$

$c \mathrm{dr}=$ radial discretization step size, $\mathrm{cm}$

$c d t=$ time step, $s$

$c \mathrm{dz}=$ axial discretization step size, $\mathrm{cm}$

$c$ dy 2 = change in plutonium concentration in solution between resin beads

c during feeding and elution, g/cc

c emiss = surface emissivity for column

$c \mathrm{E}=$ plutonium loading on resin, $\mathrm{g} / \mathrm{CC}$

c $f c x$ = weighting factor for elution of plutonium by acid dilution

c $f f c x=$ weighting factor for elution of plutonium by acid dilution

c ffeed = maximum plutonium resin bed concentration, g/cc

$c$ fold $=$ plutonium loading on resin at previous time step, g/cc

$\mathrm{c} f \mathrm{x}=$ total bulk plutonium concentration, $\mathrm{g} / \mathrm{cc}$

c grav = gravitational acceleration, $\mathrm{cm} / \mathrm{s} 2$

$c$ hconv = coefficient for natural convection heat transfer to sides of column, also overall convective heat transfer coefficient, cal/cm $2 / \mathrm{s} / \mathrm{C}$

$c$ hconv2 = coefficient for natural convection heat transfer to top and bottom of column, cal/cm2/s/C

c hconv3 = coefficient for forced convection heat transfer to column, assuming an ambient air velocity of $30 \mathrm{~cm} / \mathrm{s}(1 \mathrm{ft} / \mathrm{s})$

c hrad = radiation heat transfer coefficient, $\mathrm{cal} / \mathrm{cm} 2 / \mathrm{s} / \mathrm{C}$

c htc = heat transfer coefficient, $\mathrm{cal} / \mathrm{cm} 2 / \mathrm{s} / \mathrm{C}$

$c$ htc2b = heat transfer coefficient for the liquid volume below the resin bed, c $\mathrm{cal} / \mathrm{cm} 2 / \mathrm{s} / \mathrm{C}$

c htc2t = heat transfer coefficient for the liquid volume above the resin bed, c $\mathrm{cal} / \mathrm{cm} 2 / \mathrm{s} / \mathrm{C}$

$c$ int = indicator for heat transfer to ambient air (iht =1) or to water-cooled

c jacket (iht=2) (A heat transfer coefficient is calculated for heat

c transfer to ambient air, and a surface temperature is specified for

c cooling by a water jacket.)

c ind2 = indicator for stage of process $(1=$ loading, 2 = washing, $3=$ elution $)$

$c$ iss = indicator that switches between implicit radial, explicit axial (iss=0)

c and explicit radial, implicit axial (iss=1) finite differencing

c ldown = depth of liquid in column below resin bea, $\mathrm{cm}$

c lup = height of liquid in column above resin bed, $\mathrm{cm}$

$c$ length $=$ column length, $\mathrm{cm}$

$c m=$ number of axial discretization nodes

c $\mathrm{n}=$ number of radial discretization nodes

c nu = Nusselt number for natural convection heat transfer to ambient air from c sides of column

c nu2 = Nusselt number for natural convection heat transfer to ambient air from

c top and bottom of column

c nu3 = Nusselt number for forced convection heat transfer to ambient air,

c assuming air velocity of $30 \mathrm{~cm} / \mathrm{s}$ (1 $\mathrm{ft} / \mathrm{s}$ )

$c$ phi = updated temperature, $\mathrm{K}$

c poszn = distance from top of resin bed, $\mathrm{cm}$

$c \mathrm{pr}=$ Prandtl number for ambient air 
$c$ pua = total amount of plutonium adsorbed on the resin beads, $g$

$c$ puf = ţotal amount of plutonium in the column, $g$

$c$ put $=$ amount of plutonium fed to the column, $g$

$c$ radius $=$ column radius, $\mathrm{cm}$

$c$ rayl = Rayleigh number for natural convection heat transfer to ambient air

c from sides of column

c rayl2 = Rayleigh number for natural convection heat transfer to ambient air

c from top and bottom of column

$c$ re $=$ Reynolds number for forced convection heat transfer to column, assuming

c an ambient air velocity of $30 \mathrm{~cm} / \mathrm{s}$ (1 $\mathrm{ft} / \mathrm{s}$ )

c rhcp = product of density and heat capacity for bulk resin bed, cal/cc/C

c rhcp2 = product of density and heat capacity for solution between

c resin beads, cal/cc/C

c rhcp $2 b=$ product of density and heat capacity for liquid volume below resin

c bed, cal/cc/C

$c$ rhcp2t = product of density and heat capacity for liquid volume above resin

c bed, cal/cc/C

c rho $=$ bulk density, g/cc

c rhoair = density of air at resin column surface, g/cc

c rhoamb = density of ambient air, g/cc

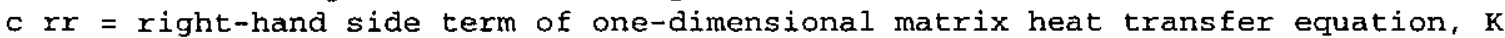

c $r x 1=$ right-hand side term of two-dimensional matrix heat transfer equation,

$\mathrm{K}$

c rra $=$ radial position of calculation node, $\mathrm{cm}$

c $r$ rn = radial position, $\mathrm{cm}$

$c$ rro = radial position, $\mathrm{cm}$

c rrr = radial position, $\mathrm{cm}$

c $\mathrm{rl}$ = radial position, $\mathrm{cm}$

c $\mathrm{r} 2$ = radial position, $\mathrm{cm}$

c qdot $=$ heat production rate due to plutonium loading, $\mathrm{cal} / \mathrm{cc} / \mathrm{s}$

c sigma = Boltzmann's constant, $\mathrm{cal} / \mathrm{cm} 2 / \mathrm{s} / \mathrm{K} 4$

c steml = temperature in the liquid volume above the resin bed, $\mathrm{K}$

$c$ stemla = change in temperature in the liquid volume above the resin bed, $k$

$c$ stemlc = temperature in the liquid volume above the resin bed, $C$

c stem2 = temperature in the liquid volume below the resin bed, $\mathrm{K}$

c stem $2 a=$ change in temperature in the liquid volume below the resin bed, $k$

c stem $2 c=$ temperature in the liquid volume below the resin bed, $C$

c stp = total number of calculation time steps

c sumf = total loading of plutonium on resin, gm

c svz2 = integrated volumetric flow rate out column, $\mathrm{cc} / \mathrm{s}$

c tamb = ambient temperature, $k$

c tau = time constant for loading plutonium on resin, $s$

c tău2 = time constant for eluting plutonium from resin, s

c $\operatorname{tcn} 1=$ thermal conductivity for nitric acid, cal/cm/s/C

c ton2 = thermal conductivity for water, $\mathrm{cal} / \mathrm{cm} / \mathrm{s} / \mathrm{C}$

c tcnm = thermal conductivity for bulk resin bed, $\mathrm{cal} / \mathrm{cm} / \mathrm{s} / \mathrm{C}$

c telut = time for elution, $s$

c temb = product of volumetric flow rate out of resin bed and temperature at

c bottom of resin bed, $\mathrm{K}-\mathrm{Cc} / \mathrm{s}$

$c$ temch = maximum temperature in column, $\mathrm{C}$

$c$ temc = temperature, $c$

$\mathrm{c}$ temp = temperature, $\mathrm{K}$

c time $=$ elapsed time after stage of process started, $\mathrm{m}$

c time2 = elapsed time after feeding started, $\mathbf{s}$

c tinte $=$ time interval for printing maximum resin bed temperatures, $s$

c tinte $=$ time for printing bed temperature profiles, s

c tload = time for loading, $s$

c trpt $=$ time to print out temperature matrix, s

c twash = time for washing, $s$

c tzero = initial temperature, $\mathrm{K}$

c tzero = temperature of solution entering column, $\mathrm{K}$

$\mathrm{c} u \mathrm{u}=$ vector containing solution to one-dimensional heat transfer equation, $\mathrm{K}$

$c$ vbot = volume of liquid below resin bed, $\mathrm{cc}$ 
c vel2 = velocity of ambient air, $\mathrm{cm} / \mathrm{s}$

c $v f i=$ volume fraction in resin bead pores, prior to adsorption of plutonium

c vfi2 = volume fraction in resin bead pores, after adsorption of plutonium

$c$ vfi3 = volume fraction in resin bead pores, adjusted for actual amount of

c plutonium adsorbed

c vfo = volume fraction occupied by flowing solution

c vis = liquid dynamic viscosity, $\mathrm{g} / \mathrm{cm} / \mathrm{s}$

c visair = dynamic viscosity of ambient air, $\mathrm{g} / \mathrm{cm} / \mathrm{s}$

$c$ vid = total volume of resin bed, $\mathrm{cc}$

c vr = superficial radial velocity, cm/s

c vtop = volume of liquid above resin bed, $\mathrm{cc}$

$c \mathrm{vz}=$ superficial axial velocity, $\mathrm{cm} / \mathrm{s}$

$c \mathrm{x}=$ fractional loading of plutonium on resin

c $x g=$ elution rate constant, $1 / \mathrm{s}$

c xkair $=$ thermal conductivity of ambient air, $\mathrm{cal} / \mathrm{cm} / \mathrm{s} / \mathrm{C}$

$c \times \times 1=$ mass fraction nitric acid in the solution between resin beads

$c \mathrm{xx} 1 \mathrm{~b}=$ mass fraction nitric acid in liquid volume below resin bed

c $x \times 1 t=$ mass fraction nitric acid in liquid volume above resin bed

c $y=$ bulk plutonium concentration in pore solution, $\mathrm{g} / \mathrm{cc}$

c yold = bulk plutonium concentration in pore solution at previous step, g/cc

c $y_{2}=$ bulk plutonium concentration in solution between resin beads, g/cc

c $\mathrm{y} 2 \mathrm{bot}=$ plutonium concentration in liquid volume below resin bed, g/cc

c y2feed = plutonium concentration in solution entering resin bed, g/cc

c $y 2 \max =$ maximum bulk plutonium concentration in solution between resin beads

c during elution, g/cc

c $\mathrm{y} 2 \mathrm{mx} 2=$ maximum bulk plutonium concentration in solution between resin beads

c during elapsed time during elution, g/cc

c $y 201 d=$ bulk plutonium concentration in solution between resin beads at

c previous time step, g/cc

$c \mathrm{x}=$ fractional loading of plutonium on resin

$c$ xarea $=$ cross-sectional area of resin bed, $\mathrm{cm} 2$

c $x o l d=$ fractional loading of plutonium on resin at previous time step

c zden = area-average liquid density at a given level, g/cc

c $\mathbf{z v z}=$ area-average superficial axial velocity at a given level, cm/s implicit double precision (a-z)

integer $i, j, m, m m 1, n, n n 1, q, r, s, s t p, i s k i p, i s 1, i s s, j 1 e v$,

1 ind2

character* $10 \mathrm{ch} 1$

dimension temc $(200,100), \operatorname{temp}(200,100), \operatorname{phi}(200,100)$

dimension dens $(200,100)$, zden (200), htc (200)

dimension vis $(200,100), y 2 m x 2(200)$

dimension area $(100), \operatorname{den} 1(200,100), \operatorname{den} 2(200,100)$

dimension $r h c p(200,100), \operatorname{rhcp} 2(200,100), \operatorname{caps}(200,100)$

dimension bz $(200,100), \operatorname{br}(200,100), \operatorname{br} 1(200,100), \operatorname{tcnm}(200,100)$

dimension aa (200), bb(200), cc (200)

dimension uu(200), rr (200), rra (100)

dimension aal $(200,100), \mathrm{bbl}(200,100), \mathrm{ccl}(200,100), \operatorname{rr} 1(200,100)$

character tab $/ 9 /$

dimension $c(200), \operatorname{cold}(200), f(200)$, fold $(200), x(200), x 01 d(200)$

dimension $y(200), y o l d(200), y 2(200), y 20 l d(200), f x(200)$

common /elut1/c, cold, f, fold, $x$, xold,y,yold, y2, y2old, cfeed,

ldt, tau, tau2, ffeed, anl, dpart, vz, dz, xg, vfi2, vfo,

2 y 2 feed, y $2 \max , y 2 \mathrm{mx} 2, \mathrm{c} 1$ feed

$c$ Input initial resin bed temperature in ${ }^{\circ} \mathrm{C}$.

read $\left(5,{ }^{*}\right)$ tzero

c Input ambient temperature in ${ }^{\circ} \mathrm{C}$. read $\left(5,{ }^{\star}\right)$ tamb

c Input indicator for air heat transfer (iht=1) or water jacket heat transfer

c (iht=2). read $(5, *)$ iht

c Input resin bed depth in centimeters. read $\left(5,{ }^{*}\right)$ length

c Input height above resin bed in centimeters. 
read $\left(5,{ }^{*}\right)$ lup

c Input depth below resin bed in centimeters. read $\left(5,{ }^{*}\right)$ ldown

$c$ Input column radius in centimeters. read $\left(5,{ }^{*}\right)$ radius

$c$ Input particle diameter in centimeters. read $\left(5,{ }^{*}\right)$ dpart

c Input pore diffusivity in $\mathrm{cm} 2 / \mathrm{sec}$. read $\left(5,{ }^{*}\right)$ depor

c Input particle diffusivity in $\mathrm{cm} 2 / \mathrm{sec}$. read $\left(5,{ }^{*}\right)$ dfprt

$c$ Input void fraction. read $(5, *)$ vfo

c Input $\mathrm{Pu}$ feed concentration, gm/cc. read $\left(5,{ }^{\star}\right)$ cfeed

c Input maximum $\mathrm{Pu}$ resin bed concentration, gm/cc. read $\left(5,{ }^{\star}\right)$ ffeed

c Input maximum $\mathrm{Pu}$ concentration during elution, gm/cc. read $\left(5,{ }^{*}\right)$ y $2 \max$

c Input radiolysis heat in $\mathrm{cal} / \mathrm{cc} / \mathrm{sec}$. read $\left(5,{ }^{\star}\right)$ qdot pi=4. *atan (1.) rho $=1.23$

$\mathrm{cp}=0.76$

tzero $=$ tzero +273.0

tamb $=\mathrm{tamb}+273.0$

grav $=980$.

$v f i=0.132$

vfi $2=0.160$

an $1=1 . /($ vfotvf $i)$

$\mathrm{pi}=4$. *atan (1.)

tau $=$ dpart**2/(4. $\left.{ }^{*} p i * 2\right) /$ dfprt

tau $2=$ dpart $* * 2 /\left(24 . * 0.75^{\star}\right.$ dfpor $)$

$\mathrm{xg}=4 .{ }^{\star} \mathrm{p} i * 2^{\star}{ }^{\star} \mathrm{dfpor} / \mathrm{dpart}{ }^{*}{ }^{*}{ }^{*}(1 .-\mathrm{vfo})$

$c$ Input \# steps in axial, radial directions. read $(5, *) \mathrm{m}, \mathrm{n}$

c Input \# of data points to skip between reading each concentration. read $\left(5,{ }^{*}\right)$ iskip

$\mathrm{dz}=$ length $/ \mathrm{m}$

dreradius $/ \mathrm{n}$

vtop $=p i{ }^{*}$ radius $* 2^{*}$ lup

vbot $=p i *$ radius $* \star 2 * 1$ down

vmid $=p i{ }^{\star}$ radius ${ }^{\star \star} 2 \star$ length

$\mathrm{m}=\mathrm{m}+1$

$\mathrm{n}=\mathrm{n}+1$

$\mathrm{mm} 1=\mathrm{m}-1$

$\mathrm{nn} 1=\mathrm{n}-1$

area $(1)=p i *(0.5 / \mathrm{nn} 1 *$ radius $) * * 2$

area $(n)=p i *(1 .-((n n l-0.5) / n n 1) * * 2) *$ radius**2

$\operatorname{rra}(1)=0$.

$i=2$

do while (i.le.nnl)

$r 1=(i-1.5) / n n 1 *$ radius

$r 2=(i-0.5) / n n 1 *$ radius

$\operatorname{area}(i)=p i *(r 2 \star \star 2-r 1 \star \star 2)$

$\operatorname{rra}(i)=r r a(i-1)+d r$

$i=i+1$

enddo

$\operatorname{rra}(n)=\operatorname{rra}(\mathrm{nn} 1)+d r$

areat $=\mathrm{pi}$ * radius ${ }^{\star} \star 2$

$i=1$

$\operatorname{sumf}=0$.

dvol $=p^{\star}{ }^{\star}$ radius ${ }^{\star}{ }^{\star}{ }^{\star} \mathrm{dz}$ 
do while (i.le.mml)

$\operatorname{sum} f=\operatorname{sum} f+0.5^{*}(f(i)+f(i+1))$

$i=i+1$

enddo

sumf $=$ sumf * dvol

c Input time increment in seconds.

read $\left(5,{ }^{*}\right) \mathrm{dt}$

$d t o=d t$

c Input number of time steps.

read $\left(5,{ }^{*}\right)$ stp

c Input loading time in sec.

read $\left(5,{ }^{*}\right)$ tload

$c$ Input washing time in sec. read $\left(5,{ }^{*}\right)$ twash

c Input elution time in sec. read $\left(5,{ }^{*}\right)$ telut

c Input time to print out temperature matrix in sec. read $(5, *)$ trpt

c Input time interval for printing output. read $\left(5,{ }^{*}\right)$ tinte

c Input time interval for printing maximum temperatures. read $\left(5,{ }^{*}\right)$ tinte 2

c Calculate material properties.

stem $1=$ tzero

stem $2=$ tzero

$\mathrm{cbot}=0$.

$\mathrm{y} 2 \mathrm{bot}=0$.

$\mathrm{y}^{2}$ feed $=0$.

clfeed $=0$.

stem $1 \mathrm{C}=$ stem $1-273$.

stem2c $=$ stem2 -273 .

den $1 t=1.6603-1.9894 \mathrm{e}-3^{*}$ stem1c

den $1 b=1.6603-1.9894 \mathrm{e}-3^{*}$ stem $2 \mathrm{c}$

$\operatorname{den} 2 t=0.99683-1.3010 e-4{ }^{\star}$ stem $1 c-2.4358 e-6 *$ stem $1 c * \star 2$

den $2 \mathrm{~b}=0.99683-1.3010 e-4{ }^{\star}$ stem $2 c-2.4358 e-6^{\star}$ stem $2 c^{\star \star} 2$

$x \times 1 t=\operatorname{den} 1 t^{*} \operatorname{cf} 30^{*}(1 .-\mathrm{c} 1$ feed $) /\left(\operatorname{den} 1 t^{\star} \operatorname{cf} 30^{*}(1 .-\mathrm{c} 1\right.$ feed $)+\operatorname{den} 2 t$

$1 *\left(1 .-\operatorname{cf} 30^{*}(1 .-c 1\right.$ feed $\left.)\right)$

$x \times 1 b=\operatorname{den} 1 b^{\star} \operatorname{cf} 30^{\star}(1 .-\operatorname{cbot}) /\left(\operatorname{den} 1 b^{\star} \operatorname{cf} 30^{*}(1 .-c 1\right.$ feed $)+\operatorname{den} 2 b$

$1 *(1,-\operatorname{cf} 30 *(1,-c b o t)))$

$\operatorname{cno} 3 t=(1 .-c 1$ feed $){ }^{*} \mathrm{cf} 30^{*}$ den $1 t * 1000 . / 63 .-4 .{ }^{*} \mathrm{y} 2$ feed ${ }^{*} 1000, / 238$.

$\mathrm{cno} 3 \mathrm{~b}=(1 .-\mathrm{cbot}){ }^{\star} \mathrm{c} f 300^{\star} \mathrm{den} 1 \mathrm{~b}^{\star} 1000 . / 63 .-4 .{ }^{*} y 2 \mathrm{bot}^{\star} 1000 . / 238$.

if (cno3t.lt.0.) $\operatorname{cno} 3 t=0$.

if (cno3b.lt.0.) cno $3 \mathrm{~b}=0$.

dens $t=\operatorname{den} 2 t+0.4277 * y 2$ feed $* 1000 . / 238 . / v$ fo $+0.031 * \operatorname{cno} 3 t$

dens $b=$ den $2 b+0.4277 * y 2 b o t * 1000 . / 238 . / v$ fo $+0.031^{\star} \mathrm{cno} 3 \mathrm{~b}$

capst $=1.0104-\left(1.419-0.3^{*}(\right.$ stem $\left.1 \mathrm{c}-20) / 80.\right) * x \times 1 t$

$1+(2.005-0.6 *($ stemlc -20.$) / 80) *. x \times 1 t * * 2$

$2-(1.147-0.3 *$ (stem $1 c-20) / 80.) * x \times 1 t * * 3$

$\mathrm{capsb}=1.0104-(1.419-0.3 *($ stem $2 \mathrm{c}-20) / 80). * \mathrm{xx} 1 \mathrm{~b}$

$1+(2.005-0.6 *($ stem $2 c-20) / 80) *. x \times 1 b * * 2$

$2-\left(1.147-0.3^{*}(\text { stem } 2 c-20 .) / 80 .\right)^{\star} \times x 1 b * * 3$

rhcp $2 t=$ denst* capst

rhcp $2 b=$ dens $b^{\star}$ capsb

$i=1$

do while (i.le.n)

$j=1$

do while (j.le.m)

$\operatorname{cold}(j)=0$.

$c(j)=0$.

temc $(j, i)=$ tzero -273 .

$\operatorname{den} 1(j, j)=1.6603-1.9894 \mathrm{e}-3^{*} \operatorname{temc}(j, i)$

$\operatorname{den} 2(j, i)=0.99683-1.3010 e-4 * \operatorname{tenc}(j, i)-2.4358 e-6 * \operatorname{tenc}(j, i) * * 2$

$x \times 1=\operatorname{den} 1(j, i){ }^{\star} \operatorname{cf} 30 *(1 .-c(j)) /(\operatorname{den} 1(j, i) * c f 30 *(1,-c(j))+\operatorname{den} 2(j, i)$ 
$1 *(1 .-\operatorname{cf} 30 *(1 .-\mathrm{c}(j))))$

$\operatorname{cno} 3=(1 .-c(j)) * \operatorname{cf} 30 * \operatorname{den} 1(j, i) * 1000 . / 63 .-4 .{ }^{*} y 2(j) * 1000$.

$1 / 238$. /vfo

if $(\mathrm{cno3} .1 \mathrm{t} .0.) \quad \mathrm{cno} 3=0$.

$\operatorname{dens}(j, i)=\operatorname{den} 2(j, i)+0.4277^{\star} y 2(j) * 1000 . / 238 . /$ vfo $+0.031 * \mathrm{cno} 3$

$\operatorname{tcn} 1=6.1388 \mathrm{e}-4+1.3951 \mathrm{e}-6^{*}$ temc $(j, i)$

$\operatorname{tcn} 2=1.3518 e-3+2.7903 e-6 * \operatorname{tenc}(j, i)$

$\operatorname{tanm}(j, i)=\operatorname{tcn} 1 * x \times 1+\operatorname{tcn} 2 \star(1 .-x \times 1)$

$\operatorname{tcnm}(j, i)=0.5 *(5 . e-4+\operatorname{tcnm}(j, i))$

$\operatorname{caps}(j, i)=1.0104-\left(1.419-0.3^{\star}(\operatorname{temc}(j, i)-20) / 80.\right) * x \times 1$

$1+(2.005-0.6 *(\operatorname{tenc}(j, i)-20) / 80.) \star x \times 1 * \star 2$

$2-(1.147-0.3 *(\operatorname{tenc}(j, i)-20) / 80) *. x \times 1 * \star 3$

$\operatorname{rhcp}(j, i)=0.5^{\star} 1.25^{\star} 0.52+0.5^{\star} \operatorname{dens}(j, i){ }^{\star} \operatorname{caps}(j, i)$

$\operatorname{rhcp} 2(j, i)=\operatorname{dens}(j, i) * \operatorname{caps}(j, i)$

alpha $=\operatorname{tcnm}(j, i) / \operatorname{rhcp}(j, i)$

$b z(j, i)=\left(a l p h a+2{ }^{\star} \operatorname{dpart}{ }^{\star} v z^{\star} \operatorname{rhcp} 2(j, i) / \operatorname{rhcp}(j, i)\right) \star d t / d z * \star 2$

$j=j+1$

enddo

$i=i+1$

enddo

$j=1$

do while (j.le.m)

alpha=tcnm $(j, 1) / \operatorname{rhcp}(j, 1)$

$\operatorname{br}(j, 1)=\left(\right.$ alpha+0.4*dpart* $\left.v z^{\star} \operatorname{rhcp} 2(j, 1) / \operatorname{rhcp}(j, 1)\right){ }^{\star} d t^{\star} 4 . / d r * \star 2$

$\operatorname{br} 1(j, 1)=0$.

$j=j+1$

enddo

$i=2$

rrr $=\mathrm{dr}$

rro $=0$.

do while (i.le.n)

$j=1$

do while (j.le.m)

alpha $=\operatorname{tcnm}(j, i) / \operatorname{rhcp}(j, i)$

$r \mathrm{rn}=\mathrm{rrr}+\mathrm{dr}$

$b r(j, i)=(a l p h a+0.4 * d p a r t * v z * \operatorname{rhcp} 2(j, i) / \operatorname{rhcp}(j, i)) * d t / d r * * 2$

$\operatorname{br} 1(j, i)=\left(\text { alpha+0.4*dpart }{ }^{\star} v z^{\star} \operatorname{rhcp} 2(j, i) / \operatorname{rhcp}(j, i)\right)^{\star} d t$

$1 / 2 . / \mathrm{dr} / \mathrm{rra}(i)$

$j=j+1$

enddo

rro $=$ rrr

rrr $=r r r+d r$

$i=i+1$

enddo

c Input initial volume fraction nitric acid.

read $\left(5,{ }^{*}\right) \operatorname{cf} 30$

c Input velocity in $\mathrm{cm} / \mathrm{sec}$.

read $(5, *) \mathrm{vz}$

c Write input variables to output.

write $(1,100)$ length, radius, $m, n$

write $(1,121)$ dpart, vfo

write $(1,101) \mathrm{dt}, \mathrm{htc}, \mathrm{htc2}$

write $(1,110)$ sumf

100 format ('L (CM) =', f7.3,2x,'R (CM) =', f7.3,2x,'AXIAL NODES =', 1 i $3,2 x$, 'RADIAL NODES $='$, i3)

101 format ('DT (S) =', f8.4,2x, 'HSID $\left(\mathrm{CAL} / \mathrm{CM} 2 / \mathrm{S} /{ }^{\circ} \mathrm{C}\right)=\cdot, \mathrm{f} 9.6$,

$\left.12 \mathrm{x}, \mathrm{HTOP}\left(\mathrm{CAL} / \mathrm{CM} 2 / \mathrm{S} /{ }^{\circ} \mathrm{C}\right)=+, \mathrm{f} 9.6\right)$

110 format ('PU CHARGE (GM) =',f11.4)

write $\left(2,{ }^{*}\right)$ 'TIME (MIN)', tab, 'TMAX $\left({ }^{\circ} \mathrm{C}\right)$ ', tab, 'VTOP (CC)',

$1 \mathrm{tab}$, 'VSGMAX (CM/S)'

121 format ('PART DIAM $(\mathrm{CM})=$ ', f8.4,2x, 'VOID FRACTION =', f7.4)

c Set all temperatures equal to uniform initial value. Initialize plutonium

$c$ and nitric acid concentrations. 
$\mathrm{q}=1$

do while (q.le.m)

$r=1$

do while (r.le.n)

temp $(q, r)=$ tzero

tem $1=$ tzero -273 .

$\operatorname{den} 1(q, r)=1.6603-1.9894 e-3^{*} \operatorname{tenc}(q, r)$

$\operatorname{den} 2(q, r)=0.99683-1.3010 e-4 * \operatorname{temc}(q, r)-2.4358 e-6 * \operatorname{tenc}(q, r) \star \star 2$

$r=r+1$

enddo

$\mathrm{fx}(\mathrm{q})=0$

fold $(q)=0$.

$\operatorname{yold}(q)=0$

$y 20 l d(q)=0$.

$y 2 m \times 2(q)=0$.

$\operatorname{cold}(q)=0$.

$q=q+1$

enddo

c Pexform transient calculations.

$s=1$

time $2=0$.

iss $=1$

do while (time2.le.tload+twash+telut+1.)

if (time2.le.tload) ind $2=1$

if (time2.gt.tload.and.time2.le.tload+twash) ind2=2

if (time2.gt.tload+twash) ind $2=3$

if (iss.eq.0) then

c Switch between implicit radial, explicit axial and explicit radial, implicit

c axial calculations.

$$
\begin{aligned}
& \text { iss }=1 \\
& \text { else } \\
& \text { iss }=0 \\
& \text { endif }
\end{aligned}
$$

c Calculate heat transfer coefficients

sigma $=1.356 \mathrm{e}-12$

emiss $=0.6$

$\mathrm{q}=1$

do while (q.le.m)

hrad $=e m i s s^{*}$ sigma $(\operatorname{temp}(q, n) * \star 3+\operatorname{temp}(q, n) * * 2 * \operatorname{tamb}$

$1+\operatorname{temp}(q, n) *$ tamb $\left.b^{\star} 2+\operatorname{tamb}^{\star \star} 3\right)$

cpair $=3.5 * 1.9872 * 29$.

xkair $=0.0262 / 100 * 0.2389$

visair $=0.00018$

pr=cpair*visair/xkair

rhoamb $=29 . / 82.057 /$ tamb

rhoair $=29 . / 82.057 / \operatorname{temp}(\mathrm{q}, \mathrm{n})$

ray $1=980$. * (length + lup +1 down $) * * 3 *$ rhoamb* (rhoamb-rhoair)

$1 /$ visair** $2^{\star}$ pr

if (rayl.gt.0.) then

nu $=0.59^{*}$ rayl ${ }^{* *} 0.25$

endif

if (nu.lt.1.) nu=1.

hconv $=n u^{*} \times k a i r /($ length +1 up + ldown $)$

vel $12=30.0$

re $=2 .{ }^{*}$ radius *vel2* rhoamb/visair

nu $3=0.683^{\star} \mathrm{re}^{\star \star} 0.466^{\star} \mathrm{pr}^{\star *}(1 . / 3$.

hconv $3=x k a i r *$ nu $3 / 2$. / radius

if (hconv.lt.hconv3) hconvehconv3

htc $(q)=$ hconv+hrad

$q=q+1$

enddo

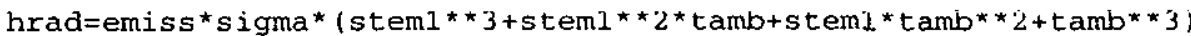

rhoai $x=29 . / 82.057 /$ stem 1 
rayl $=980 . *($ length + lup + ldown $) * * 3 *$ rhoamb* (rhoamb-rhoair)

$1 / \mathrm{visair}{ }^{\star} \star 2 * \mathrm{pr}$

if (rayl.gt.0.) then

$\mathrm{nu}=0.59{ }^{*}$ rayl ${ }^{*} 0.25$

endif

if (nu.1t.1.) nu=1.

hconv $=n u^{\star} x k a i r /($ length + lup + ldown)

ray $12=980 .{ }^{*}\left(2 .{ }^{*}\right.$ radius $) *{ }^{*}{ }^{*}$ rhoamb* (rhoamb-rhoair)/visair ${ }^{*} 2{ }^{*} p r$

if (rayl2.gt.0.) then

nu2 $=0.54^{\star}$ ray $12 \star \star 0.25$

endif

if (nu2.1t.1.) nu2=1.

hconv2=nu2 $2^{\star}$ xkair $/ 2$. / radius

hconv $=\left(2 .{ }^{*}\right.$ radius ${ }^{\star}$ lup ${ }^{\star}$ hconv+radius ${ }^{\star} 2{ }^{\star}$ hconv 2$) /\left(2 .{ }^{\star}\right.$ radius ${ }^{\star} l u p$

$1+$ radius $* \star 2)$

ve $12=30.0$

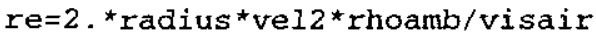

nu $3=0.683 * \mathrm{re}^{\star \star} 0.466^{\star} \mathrm{pr}^{\star \star}(1 . / 3$.

hconv $3=x k a i r \star n u 3 / 2$. /radius

if (hconv.1t.hconv3) hconv=hconv3

htc2t $=$ hrad+hconv

hrad=emiss * sigma * (stem $2 *$ * $3+$ stem $2 * * 2 *$ tamb+stem 2 *tamb** $2+$ tamb** 3 )

rhoair $=29 . / 82.057 /$ stem2

rayl $=980 . *$ (length +1 up + ldown $) * * 3 *$ rhoamb* (rhoamb-rhoair)

$1 /$ visair** $2 *$ pr

if (rayl.gt.0.) then

$\mathrm{nu}=0.59 * \operatorname{ray} 1 * \star 0.25$

endif

if (nu.1t.1.) nu=1.

hconv=nu*xkaix/(length+lup+ldown)

ray $12=980 . *\left(2 .{ }^{*}\right.$ radius $) * * 3 *$ rhoamb* (xhoamb-rhoair)/visair ${ }^{*}{ }^{*}$ *pr

if (rayl2.gt.0.) then

nu $2=0.27 *$ ray $12 * \star 0.25$

endif

if (nu2.1t.1.) nu2=1.

hconv2 $=$ nu $2{ }^{\star} x k a i r / 2 . /$ radius

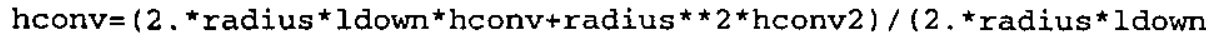

$1+$ radius $* * 2$ )

vel $2=30.0$

re $=2$. radius *ve12 ${ }^{\star}$ rhoamb/visair

nu $3=0.683 * r e * * 0.466^{*} \mathrm{pr}^{* *}(1.13$.

hconv $3=x k a i r \star n u 3 / 2$. /radius

if (hconv. 1t.hconv3) hconv=hconv3

htc $2 b=h r a d+h c o n v$

$c$ Calculate temperature changes in the spaces above and below the resin bed. stemla $=y 2$ feed* $0.8 *$ qdot $* d t /$ rhcp $2 t$

stem $2 \mathrm{a}=\mathrm{y} 2 \mathrm{bot}{ }^{\star} 0.8 *$ qdot ${ }^{\star} \mathrm{dt} / \mathrm{rhcp} 2 \mathrm{~b}$

$i=1$

do while (i.le.n)

stemla=stemla+bz $(1, i) * d z / v \operatorname{top} * \operatorname{area}(i) *(\operatorname{temp}(2, i)-\operatorname{temp}(1, i))$

stem $2 a=\operatorname{stem} 2 a+b z(m, i) * d z / v b o t * a r e a(i) *(\operatorname{temp}(m m 1, i)-\operatorname{temp}(m, i))$

stem $2 a=s \operatorname{tem} 2 a-v z * d t / \operatorname{vbot} * \operatorname{area}(i) *(\operatorname{stem} 2-\operatorname{temp}(m, i))$

$i=i+1$

enddo

stemla=stemla-vz*dt*areat/vtop* (steml-tzero)

stem $1 a=\operatorname{stem} 1 a+h t c 2 t * d t / \operatorname{rhcp}(1,1) /\left(\operatorname{vtop} /\left(\operatorname{areat}+2 .{ }^{*} p i{ }^{*} \operatorname{rra}(n)\right.\right.$ * $\left.\left.1 u p\right)\right)$

1 * (tamb-stem1)

stem $2 a=s$ tem $2 a+h t c 2 b * d t / r h c p(1,1) /($ vbot $/$

$1\left(\right.$ areat $+2 .{ }^{*} p i^{\star} \operatorname{rra}(n) \star 1$ down $\left.)\right)^{\star}($ tamb-stem 2$)$

c Calculate concentration changes in the space above the resin bed.

$\mathrm{y} 2$ feed $=\mathrm{y} 2$ feed +2 . $^{*}$ dpart ${ }^{*} \mathrm{vz}^{*} \mathrm{dt} / \mathrm{dz} / \mathrm{vtop}{ }^{*}$ areat $/ \mathrm{vfo}$

$1 *(y 201 d(2)-y 201 d(1))$

if (ind2.eq.1) then 


\section{- Revision 0}

y2 feed $=y^{2}$ feed $+v z^{\star}$ areat $/$ vtop ${ }^{\star} d t *(c$ feed $-y 2$ feed)

else

$y^{2}$ feed $=y 2$ feed $-v z^{\star}$ areat $/ v$ top ${ }^{\star} d t^{\star} y 2$ feed

endif

if (ind2.eq. 3) then

c1feed $=\mathrm{c} 1$ feed $+2 .^{*} \mathrm{dpart}{ }^{*} \mathrm{vz}{ }^{*} \mathrm{dt} / \mathrm{dz} / \mathrm{vtop} \operatorname{areat}^{*}(\operatorname{cold}(2)-\operatorname{cold}(1))$

$c 1$ feed $=c 1$ feed $+v z^{*}$ areat $/ v t o p * d t *(1 .-c 1$ feed $)$ endif

c Calculate temperature and concentration changes at top of column. $\operatorname{phi}(1,1)=\operatorname{temp}(1,1)+\mathrm{fx}(1) * 0.8^{\star} \operatorname{qdot}^{\star} \mathrm{dt} / \mathrm{rhcp}(1,1)$

if (iss.eq. 0 ) then

$\operatorname{rr} 1(1,1)=\operatorname{phi}(1,1)+\mathrm{bz}(1,1) *(\operatorname{stem} 1-\operatorname{temp}(1,1))$

$1+\mathrm{bz}(2,1) *(\operatorname{temp}(2,1)-\operatorname{temp}(1,1))$

$\operatorname{aal}(1,1)=0$.

bb1 $(1,1)=1 .+$ br $(1,1)$

$\operatorname{cc} 1(1,1)=-\operatorname{br}(1,1)$

else

$\operatorname{rr} 1(1,1)=\operatorname{phi}(1,1)+\operatorname{br}(1,1) *(\operatorname{temp}(1,2)-\operatorname{temp}(1,1))+b z(1,1) * \operatorname{stem} 1$

aal $(1,1)=0$.

$\mathrm{bb} 1(1,1)=1+\mathrm{bz}(1,1)+\mathrm{bz}(2,1)$

$\operatorname{ccl}(1,1)=-b z(2,1)$

endif

$\operatorname{rr} 1(1,1)=\operatorname{rr} 1(1,1)-v z^{\star} d t / d z *(\operatorname{temp}(1,1)-$ stem 1$)$

if (ind2.eq.1.or.ind2.eq. 2 ) then

call feeder $(1, \mathrm{~m}$, ind2)

else

call elut $(1, m)$

endif

$\operatorname{phi}(1, n)=\operatorname{temp}(1, n)+f x(1) * 0.8 * q d o t * d t / \operatorname{rhcp}(1, n)$

if (iss.eq.0) then

$\operatorname{rr} 1(1, n)=p h i(1, n)+b z(1, n) *(\operatorname{stem} 1-\operatorname{temp}(1, n))$

$1+b z(2, n) *(\operatorname{temp}(2, n)-\operatorname{temp}(1, n))+h t c(1) * d t / r h c p(1, n)$

$2 *(1 . / d r+1 . / 2 . / \operatorname{rra}(\mathrm{n})) *$ tamb

aal $(1, n)=-\operatorname{br}(1, n n 1)+\operatorname{br} 1(1, n)$

$\operatorname{bbl}(1, n)=1 .+\operatorname{br}(1, n n 1)-\operatorname{br} 1(1, n)+h t c(1) * d t / \operatorname{rhcp}(1, n)$

$1 *(1 . / d r+1 . / 2 . /$ rra $(n))$

$\operatorname{cc} 1(1, n)=0$.

else

$\operatorname{rr} 1(1, n)=\operatorname{phi}(1, n)-\operatorname{br}(1, n n 1) *(\operatorname{temp}(1, n)-\operatorname{temp}(1, n n 1))$

$1+\operatorname{br} 1(1, n) *(\operatorname{temp}(1, n)-\operatorname{temp}(1, n n 1))+h \operatorname{tc}(1) * d t / \operatorname{rhcp}(1, n)$

$2 *(1 . / d r+1 . / 2 . / \operatorname{rra}(n)) *(\operatorname{tamb}-\operatorname{temp}(1, n))+b z(1, n) * \operatorname{stem} 1$

$\operatorname{aa} 1(1, n)=0$.

$\mathrm{bb} 1(1, n)=1 .+b z(1, n)+b z(2, n)$

$\operatorname{cc} 1(1, n)=-b z(2, n)$

endif

$\operatorname{rr} 1(1, \mathrm{n})=\operatorname{rr} 1(1, \mathrm{n})-\mathrm{v} z^{\star} \mathrm{dt} / \mathrm{d} z^{*}(\operatorname{temp}(1, \mathrm{n})-\mathrm{stem} 1)$

$r=2$

do while (r.le.nn1)

$\operatorname{phi}(1, r)=\operatorname{temp}(1, r)+f x(1) * 0.8^{*} \operatorname{qdot}^{\star} d t / r h c p(1, r)$

if (iss.eq.0) then

$\operatorname{rrl}(1, r)=\operatorname{phi}(1, r)+b z(1, r) *(\operatorname{stem} 1-\operatorname{temp}(1, r))$

$1+b z(2, r) *(\operatorname{temp}(2, r)-\operatorname{temp}(1, r))$

aal $(1, r)=-\operatorname{br}(1, r-1)+\operatorname{br} 1(1, r)$

$\operatorname{bbl}(1, r)=1 .+\operatorname{br}(1, r)+\operatorname{br}(1, r-1)$

$\operatorname{ccl}(1, r)=-\operatorname{br}(1, r)-\operatorname{br} 1(1, r)$

else

$\operatorname{rrl}(1, r)=\operatorname{phi}(1, r)-\operatorname{br}(1, r-1) *(\operatorname{temp}(1, r)-\operatorname{temp}(1, r-1))$

$1+\operatorname{br}(1, r) *(\operatorname{temp}(1, r+1)-\operatorname{temp}(1, r-1))+\operatorname{br} 1(1, r)$

2 * $(\operatorname{temp}(1, r)-\operatorname{temp}(1, r-1))+b z(1, r){ }^{*}$ stem 1

aa $1(1, r)=0$.

$\mathrm{bbl}(1, x)=1 .+\mathrm{bz}(1, x)+\mathrm{bz}(2, \mathrm{r})$

$\mathrm{Ccl}(1, r)=-\mathrm{bz}(2, \mathrm{r})$

endif 
$\operatorname{rr} 1(1, r)=\operatorname{rrl}(1, r)-v z^{\star} d t / d z^{\star}(\operatorname{temp}(1, r)-s t e m 1)$

$r=r+1$

enddo

c Calculate temperature and concentration changes in middle of column.

$\mathrm{q}=2$

do while (q.le.mm1)

$\operatorname{phi}(q, 1)=\operatorname{temp}(q, 1)+f \times(q) * 0.8 * q d o t * d t / \operatorname{rhcp}(q, 1)$

if (iss.eq.0) then

$\operatorname{rr} 1(q, 1)=\operatorname{phi}(q, 1)+b z(q+1,1) *(\operatorname{temp}(q+1,1)-\operatorname{temp}(q, 1))$

$1+b z(q, 1) *(\operatorname{temp}(q-1,1)-\operatorname{temp}(q, 1))$

$\operatorname{aal}(q, 1)=0$.

$\operatorname{bb} 1(q, 1)=1 .+\operatorname{br}(q, 1)$

$\operatorname{cc} 1(q, 1)=-\operatorname{br}(q, 1)$

else

$\operatorname{rrl}(q, 1)=\operatorname{phi}(q, 1)+\operatorname{br}(q, 1) *(\operatorname{temp}(q, 2)-\operatorname{temp}(q, 1))$

aal $(q, 1)=-b z(q, 1)$

$\mathrm{bb} 1(\mathrm{q}, 1)=1 .+\mathrm{bz}(\mathrm{q}, 1)+\mathrm{bz}(\mathrm{q}+1,1)$

$\operatorname{cc} 1(q, 1)=-b z(q+1,1)$

endif

$\operatorname{rrl}(q, 1)=\operatorname{rrl}(q, 1)-v z^{\star} d t / d z^{*}(\operatorname{temp}(q, 1)-\operatorname{temp}(q-1,1))$

$\operatorname{phi}(q, n)=\operatorname{temp}(q, n)+f x(q) * 0.8^{*} q d o t * d t / r h c p(q, n)$

if (iss.eq.0) then

$\operatorname{rrl}(q, n)=p h i(q, n)+b z(q+1, n) *(\operatorname{temp}(q+1, n)-\operatorname{temp}(q, n))$

$1+b z(q, n) *(\operatorname{temp}(q-1, n)-\operatorname{temp}(q, n))+h t c(q) * d t / r h c p(q, n)$

$2 *(1 . / \mathrm{dr}+1 . / 2 . / \mathrm{rra}(\mathrm{n})) *$ tamb

aal $(q, n)=-b r(q, n n 1)+b r 1(q, n)$

$\mathrm{bb} 1(\mathrm{q}, \mathrm{n})=1 .+\mathrm{br}(\mathrm{q}, \mathrm{nn} 1)-\operatorname{br} 1(\mathrm{q}, \mathrm{n})+\mathrm{htc}(\mathrm{q}) * \mathrm{dt} / \mathrm{rhcp}(\mathrm{q}, \mathrm{n})$

$1 *(1 . / d r+1 . / 2 . / \operatorname{ra}(\mathrm{n}))$

$\operatorname{cc} 1(\mathrm{q}, \mathrm{n})=0$

else

$\operatorname{rr} 1(q, n)=p h i(q, n)-b r(q, n n 1) *(\operatorname{temp}(q, n)-\operatorname{temp}(q, n n 1))$

$1+\operatorname{br} l(q, n) *(\operatorname{temp}(q, n)-\operatorname{temp}(q, n n l))+h t c(q) * d t / \operatorname{rhcp}(q, n)$

$2 *(1 . / d r+1 . / 2 . / r r a(n)) *($ tamb-temp $(q, n))$

aal $(q, n)=-b z(q, n)$

$\mathrm{bbl}(\mathrm{q}, \mathrm{n})=1,+\mathrm{bz}(\mathrm{q}, \mathrm{n})+\mathrm{bz}(\mathrm{q}+1, \mathrm{n})$

$\operatorname{cc} 1(q, n)=-b z(q+1, n)$

endif

$\operatorname{rr} 1(q, n)=\operatorname{rr} 1(q, n)-v z * d t / d z *(\operatorname{temp}(q, n)-\operatorname{temp}(q-1, n))$

$q=q+1$

enddo

$\mathrm{q}=2$

do while (q.le.mm1)

$r=2$

do while (r.le.nnl)

$\operatorname{phi}(q, r)=\operatorname{temp}(q, r)+\mathrm{fx}(q) \star 0.8^{\star} q \mathrm{qdot}^{\star} \mathrm{dt} / \operatorname{rhcp}(q, r)$

if (iss.eq.0) then

$\operatorname{rrl}(q, r)=p h i(q, r)+b z(q+1, r) *(\operatorname{temp}(q+1, r)-\operatorname{temp}(q, r))$

$1+b z(q, r) *(\operatorname{temp}(q-1, r)-\operatorname{temp}(q, r))$

aal $(q, r)=-b r(q, r-1)+b r 1(q, r)$

$\mathrm{bbl}(\mathrm{q}, r)=1$. $\mathrm{br}(\mathrm{q}, \mathrm{r})+\mathrm{br}(\mathrm{q}, \mathrm{r}-1)$

$\operatorname{cc} 1(q, r)=-\operatorname{br}(q, r)-\operatorname{br} 1(q, r)$

else

$\operatorname{rr} 1(q, r)=p h i(q, r)-b r(q, r-1) *(t e m p(q, r)-t e m p(q, r-1))$

$1+\operatorname{br}(q, r) *(\operatorname{temp}(q, r+1)-\operatorname{temp}(q, r))+\operatorname{br} 1(q, r)$

$2 *(\operatorname{temp}(q, r+1)-\operatorname{temp}(q, r-1))$

aal $(q, r)=-b z(q, r)$

$b b 1(q, r)=1+b z(q, r)+b z(q+1, r)$

$\operatorname{ccl}(q, r)=-b z(q+1, r)$

endif

$\operatorname{rr} 1(q, r)=r r 1(q, r)-v z^{\star} d t / d z *(\operatorname{temp}(q, r)-\operatorname{temp}(q-1, r))$

$x=r+1$

endido

if (ind2.eq.1.or.ind2.eq.2) then 
call feeder $(q, m$, ind2)

else

call elut $(q, m)$

endif

$q=q+1$

enddo

c Calculate temperature and concentration changes at bottom of column. $\operatorname{phi}(\mathrm{m}, 1)=\operatorname{temp}(\mathrm{m}, 1)+\mathrm{fx}(\mathrm{m}) * 0.8^{*} \mathrm{qdot} * \mathrm{dt} / \mathrm{rhcp}(\mathrm{m}, 1)$

if (iss.eq.0) then

$\operatorname{rrl}(\mathrm{m}, 1)=\operatorname{phi}(\mathrm{m}, 1)+\mathrm{bz}(\mathrm{m}, 1) *(\operatorname{stem} 2-\operatorname{temp}(\mathrm{m}, 1))$

$1+b z(m, 1) *(\operatorname{temp}(m m 1,1)-\operatorname{temp}(m, 1))$

$\operatorname{aal}(\mathrm{m}, 1)=0$.

$\mathrm{bb} 1(\mathrm{~m}, 1)=1 .+\mathrm{br}(\mathrm{m}, 1)$

$\operatorname{cc} 1(m, 1)=-\operatorname{br}(m, 1)$

else

$\operatorname{rr} 1(m, 1)=\operatorname{phi}(m, 1)+\operatorname{br}(m, 1) *(\operatorname{temp}(m, 2)-\operatorname{temp}(m, 1))+b z(m, 1) * s t e m 2$

aal $(m, 1)=-b z(m, 1)$

$\mathrm{bb} 1(\mathrm{~m}, 1)=1 .+2 .{ }^{\star} \mathrm{bz}(\mathrm{m}, 1)$

$\operatorname{ccl}(m, 1)=0$.

endif

$\operatorname{rr} 1(m, 1)=\operatorname{rr} 1(m, 1)-v z^{*} d t / d z^{*}(\operatorname{temp}(m, 1)-\operatorname{temp}(m m 1,1))$

phi $(m, n)=\operatorname{temp}(m, n)+f x(m) * 0.8^{*} \operatorname{qdot}^{*} d t / \operatorname{rhcp}(m, n)$

if (iss.eq.0) then

$\operatorname{rr} 1(m, n)=p h i(m, n)+b z(m, n) *($ stem $2-\operatorname{temp}(m, n))$

$1+b z(m, n) *(\operatorname{temp}(m n 1, n)-\operatorname{temp}(m, n))+h t c(m) \star d t / r h c p(m, n)$

$2 *(1 . / \mathrm{dr}+1 . / 2 . / \operatorname{rra}(\mathrm{n})) *$ tamb

aal $(m, n)=-\operatorname{br}(m, n n 1)+b r 1(m, n)$

bbl $(m, n)=1 .+b r(m, n n l)-b r l(m, n)+h t c(m) * d t / r h c p(m, n)$

$1 *(1 . / d r+1 . / 2 . /$ rra $(n))$

$\operatorname{ccl}(m, n)=0$.

else

$\operatorname{rrl}(m, n)=\operatorname{phi}(m, n)-b r(m, n n 1) *(\operatorname{temp}(m, n)-\operatorname{temp}(m, n n 1))$

$1+\operatorname{br} 1(m, n) *(\operatorname{temp}(m, n)-\operatorname{temp}(m, n n 1))+h t c(m) * d t / \operatorname{rhcp}(m, n)$

$2 *(1 . / d r+1 . / 2 . / \operatorname{rra}(n)) *(\operatorname{tamb}-\operatorname{temp}(m, n))+b z(m, n) * s t e m 2$

aal $(m, n)=-b z(m, n)$

$\mathrm{bb} 1(m, n)=1 .+2 .{ }^{\star} \mathrm{b} z(m, n)$

$\operatorname{ccl}(m, n)=0$.

endif

$\operatorname{rr} 1(m, n)=\operatorname{rrl}(m, n)-v z^{\star} d t / d z^{\star}(\operatorname{temp}(m, n)-\operatorname{temp}(m m 1, n))$

$r=2$

do while (r.le.nnl)

$\operatorname{phi}(\mathrm{m}, \mathrm{r})=\operatorname{temp}(\mathrm{m}, \mathrm{r})+\mathrm{fx}(\mathrm{m}) \star 0.8^{\star} \operatorname{qdot}{ }^{\star} \mathrm{dt} / \mathrm{rhcp}(\mathrm{m}, \mathrm{r})$

if (iss.eq.0) then

$\operatorname{rr} 1(m, r)=p h i(m, r)+b z(m, r) *($ stem2 $-\operatorname{temp}(m, r))$

$1+b z(m, r) *(\operatorname{temp}(m m 1, r)-\operatorname{temp}(m, r))$

aal $(m, r)=-\operatorname{br}(m, r-1)+\operatorname{br} 1(m, r)$

$\mathrm{bb} 1(m, r)=1 .+\mathrm{br}(m, r)+\mathrm{br}(m, r-1)$

$\operatorname{ccl}(m, r)=-b r(m, r)-b r 1(m, r)$

else

$\operatorname{rrl}(m, r)=\operatorname{phi}(m, r)-\operatorname{br}(m, r-1) *(\operatorname{temp}(m, r)-\operatorname{temp}(m, r-1))$

$1+b r(m, r) *(\operatorname{temp}(m, r+1)-\operatorname{temp}(m, r))$

$2+\operatorname{br} 1(m, r) *($ temp $(m, r+1)-\operatorname{temp}(m, r-1))+b z(m, r)$ *stem 2

aal $(m, r)=-b z(m, r)$

$\mathrm{bb} 1(\mathrm{~m}, \mathrm{r})=1 .+2{ }^{\star} \mathrm{bz}(\mathrm{m}, \mathrm{r})$

$\operatorname{cc} 1(m, r)=0$.

endif

$\operatorname{rr} 1(m, r)=\operatorname{rr} 1(m, r)-v z * d t / d z^{*}(\operatorname{temp}(m, r)-t e m p(m m 1, r))$

$r=r+1$

enddo

if (ind2.eq.1.or.ind2.eq.2) then

call feeder $(m, m$, ind 2$)$

else

call elut $(m, m)$ 
endif

if (iss.eq.0) then

$j=1$

do while (j.le.m)

$i=1$

do while (i.le.n)

aa $(i)=\operatorname{aal}(j, i)$

$\mathrm{bb}(i)=\mathrm{bbl}(j, i)$

$\operatorname{cc}(i)=\operatorname{ccl}(j, i)$

$\operatorname{rr}(i)=\operatorname{rr} 1(j, i)$

$i=i+1$

enddo

call tridag (aa,bb,cc,rr, uu, n)

$i=1$

do while (i.le.n)

$\operatorname{phi}(j, i)=u u(i)$

$i=i+1$

enddo

$j=j+1$

endido

else

$i=1$

do while (i.le.n)

$j=1$

do while (j.le.m)

aa $(j)=\operatorname{aal}(j, i)$

$\mathrm{bb}(j)=\mathrm{bb} 1(j, i)$

$\operatorname{cc}(j)=\operatorname{cc1}(j, i)$

$\operatorname{rr}(j)=\operatorname{rr} 1(j, i)$

$j=j+1$

enddo

call tridag (aa,bb,cc, rr, uu, m)

$j=1$

do while (j.le.m)

$\operatorname{phi}(j, i)=u u(j)$

$j=j+1$

enddo

$i=i+1$

enddo

endif

c Calculate concentration changes in the liquid volume below the resin bed. $y 2$ bot $=y 2$ bot $+2 .{ }^{*} d p a r t{ }^{\star} v z^{\star} d t / d z /$ vbot ${ }^{\star}$ areat $/$ vfo

$1 *(y 201 d(m m 1)-y 201 d(m))$

y2bot $=y 2$ bot $+v z^{*}$ areat $/$ vbot* $(y 2 o l d(m) / v f o-y 2 b o t)$

cbot $=c b o t+v z^{*}$ areat $/ v b o t *(\operatorname{cold}(m)-c b o t)$

$c$ Update temperatures and concentrations. Calculate densities and viscosities. stem $1=\operatorname{stem} 1+\operatorname{stem} 1 a$

stem $2=$ stem $2+$ stem $2 a$

$j=1$

do while (j.le.m)

$\operatorname{yold}(j)=y(j)$

$y 2 o l d(j)=y^{2}(j)$

$\operatorname{xold}(j)=x(j)$

$\operatorname{cold}(j)=c(j)$

if (ind2.eq.1.or.ind2.eq.2) fold $(j)=f(j)$

if (ind2.eq.1.or.ind2.eq.2) $f x(j)=f(j)+y 2(j)$

if (ind2.eq. 3 ) $f x(j)=f(j)+y 2(j)+y(j)$

$j=j+1$

enddo

stem $1 \mathrm{c}=$ stem $1-273$.

stem $2 \mathrm{c}=$ stem $2-273$.

$\operatorname{den} 1 t=1.6603-1.9894 \mathrm{e}-3^{*}$ stem $1 \mathrm{c}$

den $1 b=1.6603-1.9894 e-3^{*}$ stem $2 c$ 
$\operatorname{den} 2 t=0.99683-1.3010 e-4^{\star}$ stem $1 c-2.4358 e-6^{*}$ stem $1 c * * 2$

$\operatorname{den} 2 b=0.99683-1.3010 e-4^{\star} s \operatorname{ten} 2 c-2.4358 e-6^{*} \operatorname{stem} 2 c^{*} 2$

$x \times 1 t=\operatorname{den} 1 t^{\star} \operatorname{cf} 30^{\star}(1 .-\operatorname{clfeed}) /\left(\operatorname{den} 1 t^{\star} \operatorname{cf} 30^{*}(1 .-\cos 1\right.$ feed $)+\operatorname{den} 2 t$

$1 *(1 .-\operatorname{cf} 30 *(1 .-\operatorname{cifeed})))$

$x \times 1 b=\operatorname{den} 1 b^{*} c f 30 *(1 .-c b o t) /\left(\operatorname{den} 1 b^{*} \operatorname{cf} 30 *(1 .-c 1\right.$ feed $)+\operatorname{den} 2 b$

$1 *(1 .-\operatorname{cf} 30 *(1 .-\mathrm{cbot})))$

$\operatorname{cno} 3 t=(1 .-c 1$ feed $){ }^{\star} \operatorname{cf} 30 * \operatorname{den} 1 t * 1000 . / 63 .-4 .{ }^{*} y 2$ feed $* 1000 . / 238$.

$\mathrm{cno} 3 \mathrm{~b}=(1,-\mathrm{cbot}){ }^{\star} \mathrm{cf} 30^{\star} \operatorname{den} 1 \mathrm{~b} * 1000 . / 63 .-4{ }^{\star}{ }^{*} \mathrm{y} 2 \mathrm{bot} * 1000 . / 238$.

if $(\mathrm{cno} 3 \mathrm{t} .1 \mathrm{t} .0.) \operatorname{cno} 3 \mathrm{t}=0$.

if $(\mathrm{cno} 3 \mathrm{~b} .1 \mathrm{t} .0.) \mathrm{cno} 3 \mathrm{~b}=0$.

dens $t=\operatorname{den} 2 t+0.4277 * y 2$ feed ${ }^{\star} 1000 . / 238 . / v f o+0.031 * \mathrm{cno} 3 t$

densb $=$ den $2 b+0.4277 * y 2 b o t * 1000 . / 238 . /$ vfo $+0.031 * \mathrm{cno} 3 \mathrm{~b}$

capst $=1.0104-(1.419-0.3 *$ (stem $1 \mathrm{c}-20) / 80.) * \mathrm{x} \times 1 \mathrm{t}$

$1+\left(2.005-0.6^{\star}(\right.$ stemlc -20.$\left.) / 80.\right){ }^{\star} x \times 1 t * \star 2$

$2-\left(1.147-0.3^{*}(\right.$ stemlc -20.$\left.) / 80.\right) * x \times 1 t^{*} \star 3$

capsb $=1.0104-\left(1.419-0.3^{*}(\right.$ stem $\left.2 c-20) / 80.\right) * x \times 1 b$

$1+\left(2.005-0.6^{\star}(\right.$ stem $\left.2 c-20) / 80.\right) * x \times 1 b * \star 2$

$2-\left(1.147-0.3^{\star}(\right.$ stem $\left.2 c-20) / 80.\right) * x \times 1 b^{\star \star} 3$

rhcp $2 t=$ denst $*$ capst

rhcp $2 b=$ densb ${ }^{\star}$ capsb

$i=1$

do while (i.le.n)

$j=1$

do while (j.le.m)

temp $(j, i)=\operatorname{phi}(j, i)$

if (iht.eq. 2 . and. $i$.eq.n) temp $(j, i)=$ tamb

temc $(j, i)=\operatorname{phi}(j, i)-273.0$

if (iht.eq.2 and.i.eq.n) temc $(j, i)=$ tamb-273.0

$\operatorname{den} 1(j, i)=1.6603-1.9894 e-3^{\star} \operatorname{tenc}(j, i)$

$\operatorname{den} 2(j, i)=0.99683-1.3010 e-4 * \operatorname{tenc}(j, i)-2.4358 e-6^{\star} \operatorname{tenc}(j, i) * * 2$

$\operatorname{xx} 1=\operatorname{den} 1(j, i){ }^{\star} \operatorname{cf} 30^{*}(1 .-c(j)) /\left(\operatorname{den} 1(j, i){ }^{\star} c f 30 *(1,-c(j))\right.$

$1+\operatorname{den} 2(j, i) *(1,-\operatorname{cf} 30 *(1 .-c(j))))$

$\operatorname{cno} 3=(1 .-c(j)){ }^{\star} \operatorname{cf} 30 \star \operatorname{den} 1(j, i) * 1000 . / 63 .-4 .{ }^{\star} y 2(j) \star 1000$.

$1 / 238 . / v$ fo

if $(\mathrm{cno} 3.1 \mathrm{t} .0.) \mathrm{cno} 3=0$.

$\operatorname{dens}(j, i)=\operatorname{den} 2(j, i)+0.4277 * y 2(j) \star 1000 . / 238 . / \mathrm{vfo}+0.031 * \mathrm{cno} 3$

$\operatorname{tcn} 1=6.1388 e-4+1.3951 e-6^{\star} \operatorname{tenc}(j, i)$

$\operatorname{tcn} 2=1.3518 e-3+2.7903 e-6^{\star} \operatorname{temc}(j, i)$

$\operatorname{tcn} \pi(j, i)=\tan 1 * x \times 1+\operatorname{tcn} 2 *(1 .-x \times 1)$

$\operatorname{tcnm}(j, i)=0.5^{*}(\operatorname{tcoum}(j, i)+5 . e-4)$

$\operatorname{caps}(j, i)=1.0104-(1.419-0.3 *(\operatorname{tenc}(j, i)-20) / 80) * x \times$.

$1+\left(2.005-0.6^{*}(\operatorname{temc}(j, i)-20) / 80.\right) * x \times 1 * \star 2$

$2-(1.147-0.3 *(\operatorname{temc}(j, i)-20) / 80) *. x \times 1 * \star 3$

$\operatorname{rhcp}(j, i)=0.5 * 1.25 * 0.52+0.5 * \operatorname{dens}(j, i) \star \operatorname{caps}(j, i)$

$\operatorname{rhcp} 2(j, i)=\operatorname{dens}(j, i){ }^{*} \operatorname{caps}(j, i)$

alpha $=\operatorname{tcnm}(j, i) / \operatorname{rhcp}(j, i)$

$b z(j, i)=\left(a l p h a+2 .{ }^{*} d p a r t * v z * r h c p 2(j, i) / \operatorname{rhcp}(j, i)\right) * d t / d z * \star 2$

vis $\{j, i)=0.01002 * 10 . * *(\{1.3272 *\{20$. $-\operatorname{temc}(j, i\})-0.001053 *$

$1(\operatorname{temc}(j, i)-20.) \star \star 2) /(\operatorname{tenc}(j, i)+105)$.

$j=j+1$

enddo

$i=i+1$

enddo

$j=1$

do while (j.le.m)

alpha $=\operatorname{tcnm}(j, 1) / \operatorname{rhcp}(j, 1)$

$\operatorname{br}(j, 1)=\left(\operatorname{alpha}+0.4{ }^{*} \operatorname{dpart}{ }^{\star} v z^{*} \operatorname{rhcp} 2(j, 1) / \operatorname{rhcp}(j, 1)\right) \operatorname{dt}^{\star} 4 . / \mathrm{dr}{ }^{\star \star} 2$

$j=j+1$

enddo

$i=2$

$\operatorname{rrr}=\mathrm{d} r$

rro $=0$.

do while (i.le.nn1) 


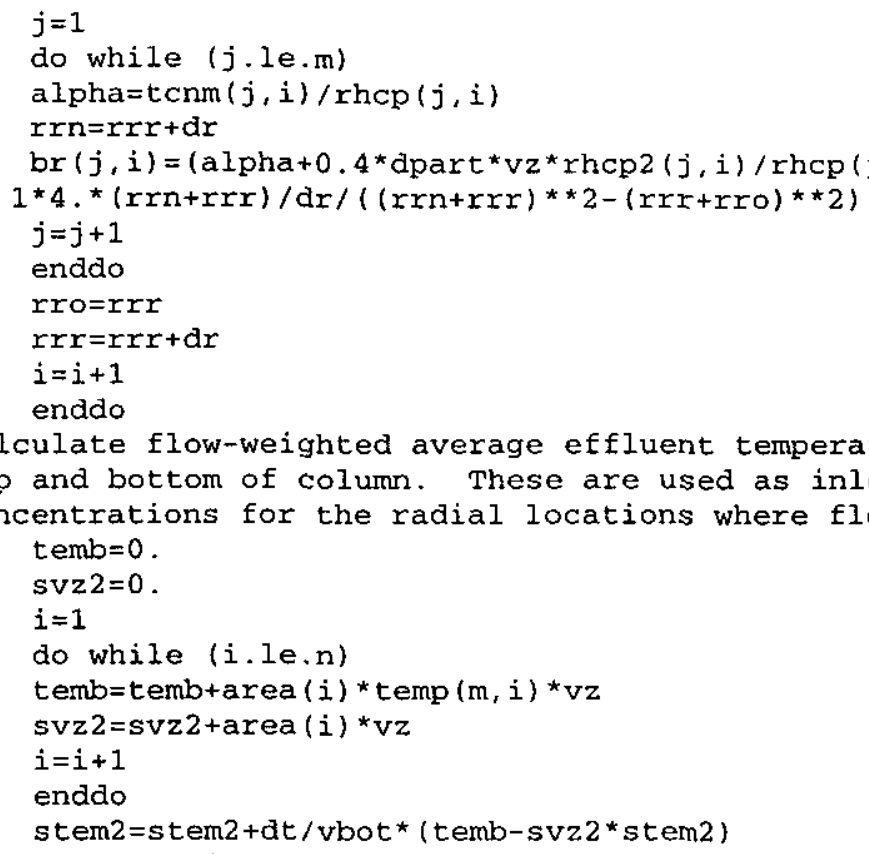

c Calculate maximum plutonium concentrations at each axial location. $j=1$

c Integrate $\mathrm{Pu}$ concentration profile and compare with amount loaded. $\mathrm{pi}=4 .{ }^{*} \mathrm{atan}(1$.

c Write transient temperatures and velocities to output files. time $2=t i m e 2+d t$

if (time2.1t.tload) time=time2/60.

if (time2.ge.tload.and.time2.2t.tload+twash)

$1 \mathrm{time}=($ time2-tload $) / 60$.

if (time2.ge.tload+twash)

1 time $=(t$ ime2-tload-twash $) / 60$.

if (abs (nint (time/tinte)-time/tinte).1t.0.0001

1.or abs ((time2-tload)/tinte).1t.0.0001

2.or.abs ( (time2-tload-twash)/tinte). 1t.0.0001

3.or.abs ((time2-tload-twash-telut)/tinte).1t.0.0001) then

c Write headers for output files.

write $\left(1,{ }^{*}\right.$ ) 'TIME (MIN)', tab,'POS (CM)', tab, 'LOAD', tab,

1 'TCEN $\left({ }^{\circ} \mathrm{C}\right) '$, tab, 'TMID $\left({ }^{\circ} \mathrm{C}\right) \cdot$, tab, 'TOUT $\left({ }^{\circ} \mathrm{C}\right)$ '

write (6,*) 'TIME (MIN)', tab, 'LENGTH (CM)', tab, 'ELU (VF)', tab,

1 'ADS $(G / C C) \cdot, t a b, \cdot L I Q(G / C C)$, tab, 'POR (G/CC)', tab, 'TOT (G/CC)' $j=1$

stem1m=stem $1-273$.

write $(1,102)$ time, tab, -1, tab, $0 ., t a b$, stemim, tab, stemim, $1 \mathrm{tab}$, stem1m 


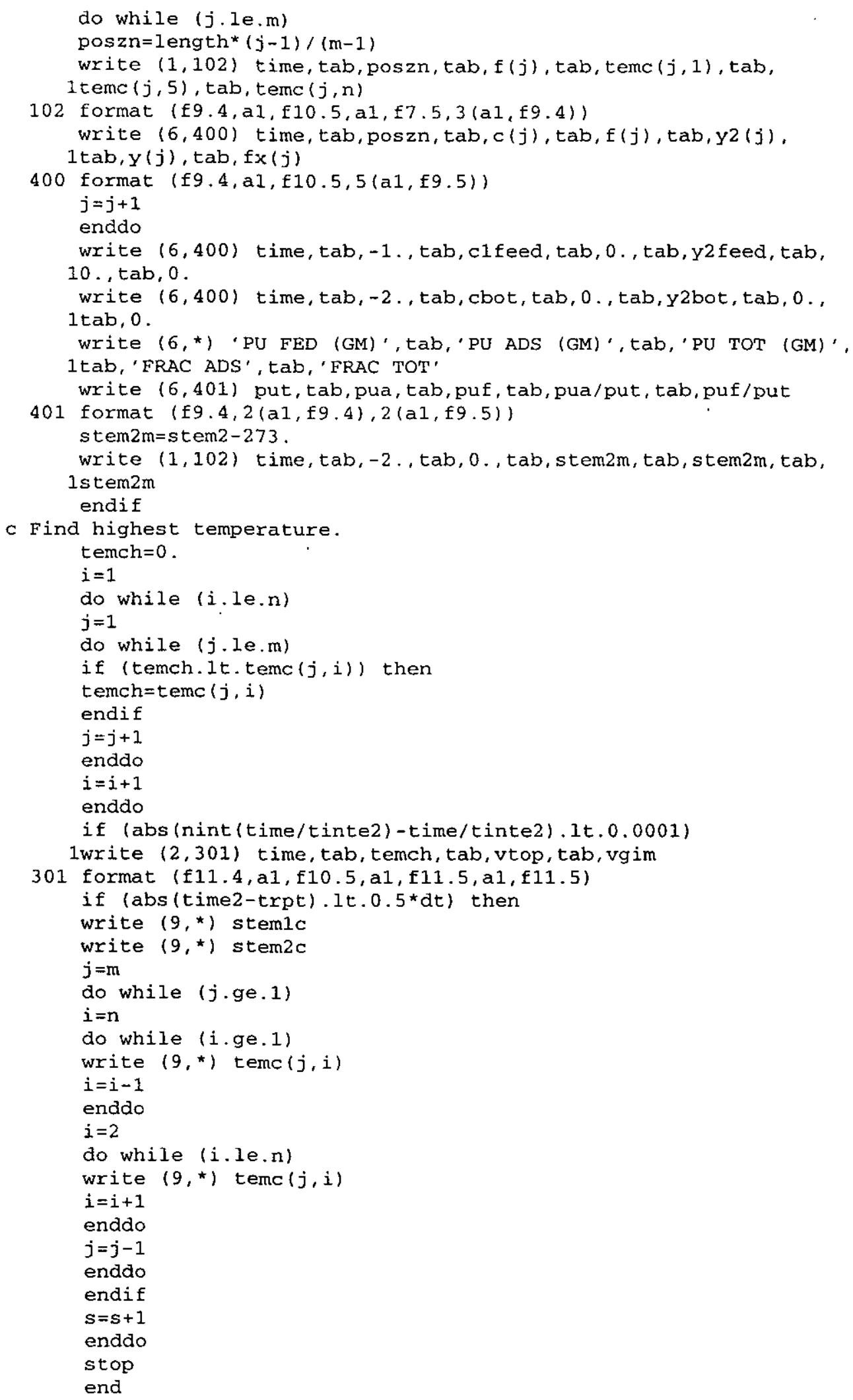

c This is a subroutine that uses LU decomposition to solve a set of equations 
c that is tridiagonal. This subroutine was copies from Press, Teukolsky, $c$ Vetterling, and Flannery, Numerical Recipes in FORTRAN: The Art of Scientific

c Computing, 2nd ed., Cambriage University Press (New York), 1986, p. 43. subroutine tridag $(a, b, c, r, u, n)$

implicit double precision $(a-h, o-z)$

dimension $a(n), b(n), c(n), r(n), u(n)$

dimension gam(400)

bet $=\mathrm{b}(1)$

$u(1)=r(1) /$ bet

$j j j=2$

do while (jjj.le.n)

$\operatorname{gam}(j j j)=c(j j j-1) /$ bet

bet $=b(j j j)-a(j j j) \star \operatorname{gam}(j j j)$

$u(j j j)=(r(j j j)-a(j j j) \star u(j j j-1)) /$ bet

$j j j=j j j+1$

enddo

$j j j=n-1$

do while (jjj.ge.1)

$u(j j j)=u(j j j)-\operatorname{gam}(j j j+1) \star u(j j j+1)$

$j j j=j j j-1$

enddo

return

end

subroutine feeder ( $i, m$, ind2)

c Compute changes in the plutonium concentrations during feeding or washing.

implicit double precision $(a-z)$

integer $i, m$, ind2

dimension $c(200)$, cold $(200), f(200)$, fold $(200), x(200), x o l d(200)$,

$1 y(200), y o l d(200), y 2(200), y 20 l d(200), y 2 m x 2(200)$

common /elut1/c, cold, f, fold, $x$, xold, $y, y \circ 1 d, y 2, y 201 d$, feed,

1dt, tau, tau2, ffeed, an1, dpart, vz, dz, xg,vfi2, vfo,

$2 \mathrm{y} 2$ feed, y2max, y $2 \mathrm{mx} 2, \mathrm{c} 1$ feed

if (i.eq. 1 .and.ind2.eq.1) dy $2=v z / v$ fo*dt/dz* $\left(v f o^{\star} y 2\right.$ feed $-y 201 d(1)$ )

$1+2 .{ }^{*} \mathrm{dpart} * \mathrm{vz} \mathrm{dt}^{\mathrm{d}} / \mathrm{dz}$ * $2^{*}(\mathrm{y} 201 \mathrm{~d}(2)-\mathrm{y} 201 \mathrm{~d}(1))$

if (i.eq.1.and.ind2.eq. 2$)$ dy $2=-\left(2 .{ }^{\star}\right.$ dpart ${ }^{\star} v z^{\star} \mathrm{dt} / \mathrm{d} z^{\star \star} 2$

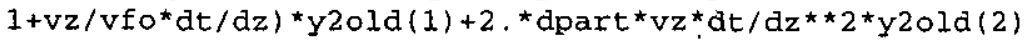

if (i.gt.1.and.i.lt.m)

Idy $2=\left(2 .{ }^{*}\right.$ dpart* $\left.z^{*} d t / d z * * 2+v z / v f o * d t / d z\right) * y 2 o l d(i-1)$

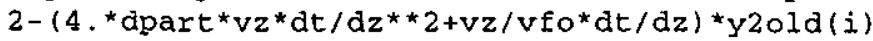

$3+2 .{ }^{\star} \mathrm{dpart} \mathrm{v}^{\star} \mathrm{z}^{\star} \mathrm{dt} / \mathrm{dz}{ }^{\star *}{ }^{*}{ }^{*} \mathrm{y} 2 \mathrm{old}(i+1)$

if (i.eq.m) dy $2=\left(2 .{ }^{*}\right.$ dpart $\left.{ }^{\star} v z^{\star} d t / d z * * z+v z / v f o^{*} d t / d z\right)$

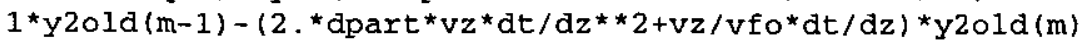

if $\left(y^{2}(i)+d y 2.1 t .0\right.$.) $d y 2=-y 2$ (i)

$x y 2=y 20 l d(i) / y^{2}$ feed

if (xold(i).1t.1.) then

if (xold (i).gt.1.d-3)

$1 x(i)=x o l d(i)+d t / t a u^{\star} x y 2 * \operatorname{xol} d(i) \star \star 2 /(\log ((1 .+\operatorname{xold}(i)) /$

$\left.2(1 .-\operatorname{xold}(i)))-2 .{ }^{\star} \operatorname{xold}(i)\right)$

if (xold(i).le.1.d-3, and.xold(i).gt.1.d-8)

$1 x(i)=x o l d(i)+d t / \operatorname{tau}^{*} x y^{2}{ }^{*} 1.5 / \operatorname{xold}(i)$

if $(x(i) . g t .1) \quad x.(i)=1$.

if $(x(i) .1 t \cdot x o l d(i)$ and.i.gt. 1$) x(i)=x o l d(i)$

if $(y 2 m x 2(i) \cdot g t .1 \cdot d-3)$ then

$d f=f f e e d *(x(i)-x o l d(i)) * y 2 o l d(i) / y 2 m \times 2(i)$

else

$d f=f f^{*} d^{*}(x(i)-x o l d(i))$

endif

if $\left(y^{2} \circ\right.$ ld $\left.(\mathrm{i})+\mathrm{dy} 2 \cdot \mathrm{ge} \cdot \mathrm{y}^{2} \mathrm{mx} 2(\mathrm{i})\right)$ then

if (df.gt.dy2) then

$\mathrm{df}=\mathrm{dy} 2$

dy $2=0$. 
else

$d y^{2}=d y 2-d f$

endif

if $(\operatorname{xold}(i) \cdot \operatorname{le}, 1 \cdot d-8)$ then

$\mathrm{df}=\mathrm{dy} 2$

dy $2=0$.

endif

else

if $\left(y^{2}(i)+d y 2-d f .1 t .0.\right)$ then

$\mathrm{df}=\mathrm{y} 2(i)+\mathrm{dy} 2$

dy $2=-y^{2}$ (i)

else

$d y 2=d y 2-d f$

endif

endif

endif

if (ind2.eq.1.and.xold(i).ge.1.) df=0.

if (ind2.eq. 2. and.xold(i).ge.1.) then

$\mathrm{df}=0$.

if $\left(y^{2}(i)+d y 2\right.$. lt. 0.$)$ dy $2=-y 2(i)$

endif

$f(i)=f(i)+d e$

$y^{2}(i)=y 2(i)+d y 2$

$x(i)=x o l d(i)+d E / f$ feed

return

end

subroutine elut (i,m)

$c$ Compute changes in nitric acid and plutonium concentrations for elution.

implicit double precision $(a-z)$

integer $i, m$

dimension $c(200), \operatorname{cold}(200), f(200)$, fold $(200), x(200)$, xold $(200)$,

Iy $(200), y 01 d(200), y 2(200), y 20 l d(200), y 2 m x 2(200)$

common /elut1/c, cold,f, fold, $x$, xold,y,yold,y $2, y 2 o l d$, cfeed,

1dt, tau, tau2, ffeed, an1, dpart, vz, dz, xg,vfi2, vfo,

$2 \mathrm{y} 2$ feed, y2max, y2mx2, c1feed

if (i.eq.1) $c(1)=\operatorname{cold}(1)+\operatorname{an} 1 *(v z * d t / d z *(c 1$ feed-cold (1))

$1+2 .{ }^{*}$ dpart $\left.{ }^{\star} \mathrm{vz}^{\star} \mathrm{dt} / \mathrm{dz} \mathrm{z}^{*} 2^{\star}(\operatorname{cold}(2)-\operatorname{cold}(1))\right)$

if (i.gt.1.and.i.lt.m) $c(i)=\operatorname{cold}(i)+\operatorname{an} 1 *$

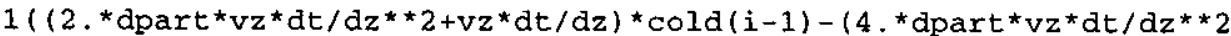

$\left.\left.2+v z^{\star} d t / d z\right){ }^{\star} \operatorname{col} d(i)+2 .{ }^{\star} d p a r t * v z{ }^{\star} d t / d z * * 2{ }^{*} \operatorname{col} d(i+1)\right)$

if $(i$.eq. $m) c(m)=\operatorname{cold}(m)+\operatorname{an} 1^{\star}\left(v z^{\star} d t / d z\right.$

$\left.1^{\star}(\operatorname{cold}(m-1)-\operatorname{cold}(m))+2 .{ }^{\star} d p a r t * d t / d z^{\star \star} 2^{\star}(\operatorname{col} d(m-1)-\operatorname{cold}(m))\right)$

if (fold(i).gt.0.) then

if (y2old(i).gt.1.d-8.and.cold(i).gt.1.d-8) then

if $(y 2 o l d(i) / y 2 \max .1 t . \operatorname{col} d(i))$ then

$f f c x=(\operatorname{cold}(i)-y 201 d(i) / y 2 \max ) * \star 0.5$

$f c x=f f c x /(f f c x+(y 20 l d(i) / y 2 \max ) \star \star 0.5)$

else

$f c x=1 .-\operatorname{cold}(i)$

endif

else

$\mathrm{fcx}=1$.

endif

if (f(i).gt.0. and.y2old(i). It.y2max) then

$\mathrm{df}=-1 . /\left(1 .-0.8^{*}(\right.$ fold $(i) / \mathrm{f}(i)) \star *(1 . / 3)-.0.2 *(\mathrm{fold}(i) / \mathrm{f}(i)) * \star 2$

$1-1, d-8)^{*} \operatorname{cold}(i) \star d t /$ tau2 ${ }^{\star}$ fold $(i){ }^{*} \mathrm{fcx}$

if $\left(\mathrm{df} . \mathrm{gt} .\left(3 .{ }^{\star} \operatorname{cold}(i){ }^{\star} \mathrm{dt} / \mathrm{tau} 2^{\star} \mathrm{fcx}\right) \star \star 0.5^{*}\right.$ fold $\left.(i)\right)$

1 then

$d f=\left(3 .{ }^{*} \operatorname{cold}(i) * d t / \operatorname{tau} 2 * f c x\right) * * 0.5 *$ fold $(i)$

endif

else

df $=0$. 
endif

if ( $f(i)-d f .1 t .0$.$) then$

$\mathrm{d} f=f(i)$

$E(i)=0$.

else

$f(i)=f(i)-d f$

endif

else

$\mathrm{d} f=0$.

endif

if $\left(y^{2}\right.$ old $\left.(i) .1 t \cdot y^{2} \max \right)$ then

if (fold(i).gt.0.) then

$\operatorname{vfi} 3=\operatorname{vfi} 2 *(1 .-f(i) /$ fold $(i)) * * 0.5$

else

vfi3=vfi2

endif

if (vfi3.1t.1. d-8) vfi3=1.d-8

if (yold(i).gt.1.d-8) then

if (y2old(i).gt.0.) then

$y 2 \max 1=\left(y 2 \max { }^{*} y 20 l d(i)\right) * * 0.5$

else

$y 2 \max 1=0$.

endif

if (abs (y2max1/vfo-yold(i)/vfi3).gt.1.d-8.and.

labs (y2max 1$) \cdot g t .1 . d-8)$ then

$\mathrm{dg}=\mathrm{xg} \mathrm{dt}^{*}(\mathrm{yold}(\mathrm{i}) / \mathrm{vfi} 3) \star \star 2 *((\mathrm{y} 2 \max 1 / \mathrm{vfo}) \star \star 2$

$1-(y o l d(i) / v f i 3) * * 2) /\left(2 .{ }^{*} y o l d(i) / v f i 3 *(y 2 m a x 1 / v f o) * \star 2\right.$

$2-y 2 \max 1 / v f o *((y 2 \max 1 / v f o) * * 2-(y o l d(i) / v f i 3) * * 2)$

$3 * \log ((y 2 \max 1 / v$ fo+yold $(i) / v f i 3) /(a b s(y 2 \max 1 / v f o-$

4yold(i)/Vfi3))l)

else

$d g=x g * d t *(y 2 \max 1 / v f o-y o l d(i) / v f i 3)$

endif

else

if (y2old(i).gt.0.) then

$d g=\left(1.5{ }^{\star} y 2 \max ^{*} y 201 d(i) * x g * d t\right) * \star 0.5$

else

$\mathrm{dg}=0$.

endif

endif

if (yold (i) $+d g .1 t .0$.$) then$

$\mathrm{dg}=-$ yold $(i)$

$y(i)=0$.

else

$y(i)=y \circ 1 d(i)+d g$

endif

else

$\mathrm{dg}=0$.

endif

if (i.eq. 1) y2(i)=y2old(i)-vz/vfo*dt/dz

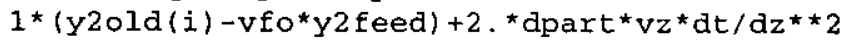

2 * $(y 2 o l d(i+1)-y 2 o l d(i))+d f-d g$

if (i.gt.1.and.i.lt.m)

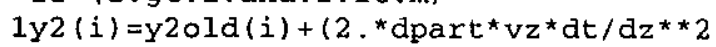

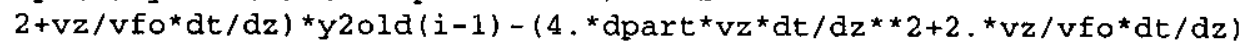

$3^{\star} y 201 d(i)+2 .{ }^{*} d p a r t t^{*} v z^{\star} d t / d z * 2{ }^{\star} y 201 d(i+1)+d f-d g$

if (i.eq.m) $y^{2}(m)=y 2 o l d(m)-v z / v f o * d t / d z$

$1 *(y 2 o l d(m)-y 2 o l d(m-1))+2 . * d p a r t * v z * d t / d z * \star 2$

$2^{\star}(y 2 \circ l d(m-1)-y 2 o l d(m))+d f-d g$

if $\left(y^{2}(i) .1 t .0.\right)$ then

$y(i)=y(i)+y^{2}(i)$

$y 2(i)=0$.

endif 
return

end

\section{Sample Input Listing for Thermal Analysis during Normal Operation}

25.
25.
1
34.1
2.54
2.54
3.73
0.04
0.0000012
0.0000012
0.33
0.163
0.062
0.0263
0.13384
48.24
0
0.02
18250
29.
149.
187.
29.
0.25
0.05
0.274
0.458

\section{Sample Output Listing for Thermal Analysis during Normal Operation}

TIME (MIN)
0.0500
0.1000
0.1500
0.2000
0.2500
0.3000
0.3500
0.4000
0.4500
0.0500
0.1000
0.1500
0.2000
0.2500
0.3000
0.3500
0.4000
0.4500
0.5000
0.5500
0.6000
0.6500

$\operatorname{TMAX}\left({ }^{\circ} \mathrm{C}\right)$
25.00786
25.02581
25.04540
25.06753
25.09177
25.11744
25.14420
25.17226
25.20083
25.25032
25.28031
25.30669
25.32948
25.34950
25.36851
25.38752
25.40708
25.42714
25.44761
25.46842
25.48939
25.51030

VTOP (CC)

111.02001

111.02001

111.02001

111.02001

111.02001

111.02001

111.02001

111.02001

111.02001

111.02001

111.02001

111.02001

111.02001

111.02001

111.02001

111.02001

111.02001

111.02001

111.02001

111.02001

111.02001

111.02001

VSGMAX (CM/S)
0.00000
0.00000
0.00000
0.00000
0.00000
0.00000
0.00000
0.00000
0.00000
0.00000
0.00000
0.00000
0.00000
0.00000
0.00000
0.00000
0.00000
0.00000
0.00000
0.00000
0.00000
0.00000

VSGMAX (CM/S)

0.00000

0.00000

0.00000

0.00000

0.00000

0.00000

0.00000

0.00000

0.00000

0.00000

0.00000

0.00000

0.00000

0.00000 
WSRC-TR-99-00027

Revision 0

\begin{tabular}{|c|c|}
\hline 0.7000 & 25.53093 \\
\hline 0.7500 & 25.55119 \\
\hline 0.8000 & 25.57023 \\
\hline 0.8500 & 25.58779 \\
\hline 0.9000 & 25.60306 \\
\hline 0.9500 & 25.61562 \\
\hline 1.0000 & 25.62243 \\
\hline 1.0500 & 25.62660 \\
\hline 1.1000 & 25.62596 \\
\hline 1.1500 & 25.62155 \\
\hline 1.2000 & 25.61445 \\
\hline 1.2500 & 25.60563 \\
\hline 1.3000 & 25.59593 \\
\hline 1.3500 & 25.58602 \\
\hline 1.4000 & 25.57640 \\
\hline 1.4500 & 25.56744 \\
\hline 1.5000 & 25.55936 \\
\hline 1.5500 & 25.55226 \\
\hline 1.6000 & 25.54620 \\
\hline 1.6500 & 25.54113 \\
\hline 1.7000 & 25.53699 \\
\hline 1.7500 & 25.53368 \\
\hline 1.8000 & 25.53107 \\
\hline 1.8500 & 25.52907 \\
\hline 1.9000 & 25.52755 \\
\hline 1.9500 & 25.52642 \\
\hline 2.0000 & 25.52559 \\
\hline 2.0500 & 25.52500 \\
\hline 2.1000 & 25.52457 \\
\hline 2.1500 & 25.52427 \\
\hline 2.2000 & 25.52406 \\
\hline 2.2500 & 25.52392 \\
\hline 2.3000 & 25.52382 \\
\hline 2.3500 & 25.52376 \\
\hline 2.4000 & 25.52371 \\
\hline 2.4500 & 25.52368 \\
\hline 0.0000 & 25.52367 \\
\hline 0.0500 & 25.52366 \\
\hline 0.1000 & 25.52365 \\
\hline 0.1500 & 25.52365 \\
\hline 0.2000 & 25.52365 \\
\hline 0.2500 & 25.52365 \\
\hline 0.3000 & 25.52366 \\
\hline 0.3500 & 25.52364 \\
\hline 0.4000 & 25.52355 \\
\hline 0.4500 & 25.52318 \\
\hline 0.5000 & 25.52231 \\
\hline 0.5500 & 25.52030 \\
\hline 0.6000 & 25.51642 \\
\hline 0.6500 & 25.51000 \\
\hline 0.7000 & 25.50064 \\
\hline 0.7500 & 25.48829 \\
\hline 0.8000 & 25.47319 \\
\hline 0.8500 & 25.45579 \\
\hline 0.9000 & 25.43655 \\
\hline 0.9500 & 25.41591 \\
\hline 1.0000 & 25.39429 \\
\hline 1.0500 & 25.37207 \\
\hline 1.1000 & 25.34961 \\
\hline 1.1500 & 25.32727 \\
\hline 1.2000 & 25.30540 \\
\hline 1.2500 & 25.28431 \\
\hline 1.3000 & 25.26428 \\
\hline
\end{tabular}

111.02001

111.02003

111.02001

111.02001

111.02001

111.02001

111.02001

111.02001

111.02001

111.02001

111.02001

111.02001

111.02001

111.02001

111.02001

111.02001

111.02001

111.02001

111.02001

111.02001

111.02001

111.02001

111.02001

111.02001

111.02001

111.02001

111.02001

111.02001

111.02001

111.02001

111.02001

111.02001

111.02001

111.02001

111.02001

111.02001

111.02001

111.02001

111.02001

111.02001

111.02001

111.02001

111.02001

111.02001

111.02001

111.02001

111.02001

111.02001

111.02001

111.02001

111.02001

111.02001

111.02001

111.02001

111.02001

111.02001

111.02001

111.02001

111.02001

111.02001

111.02001

111.02001

111.02001
0.00000

0.00000

0.00000

0.00000

0.00000

0.00000

0.00000

0.00000

0.00000

0.00000

0.00000

0.00000

0.00000

0.00000

0.00000

0.00000

0.00000

0.00000

0.00000

0.00000

0.00000

0.00000

0.00000

0.00000

0.00000

0.00000

0.00000

0.00000

0.00000

0.00000

0.00000

0.00000

0.00000

0.00000

0.00000

0.00000

0.00000

0.00000

0.00000

0.00000

0.00000

0.00000

0.00000

0.00000

0.00000

0.00000

0.00000

0.00000

0.00000

0.00000

0.00000

0.00000

0.00000

0.00000

0.00000

0.00000

0.00000

0.00000

0.00000

0.00000

0.00000

0.00000

0.00000 
WSRC-TR-99-00027

Revision 0
1.3500
1.4000
1.4500
1.5500
1.6000
1.7000
1.7500
1.8500

25.24551

25.22817

25.21230

25.19793

25.18499

25.17340

25.16303

25.15376

25.14545

25.13800

25.13128

25.12519

25.11966

25.11460

25.10997

25.10569

25.10174

25.09808

25.09467

25.09148

25.08850

25.08571

25.08308

25.08061

25.07828

25.07608

25.07399

25.07201

25.07013

25.06835

25.06665

25.06503

25.06349

25.06202

25.06061

25.05926
0.00000
0.00000
0.00000
0.00000
0.00000
0.00000
0.00000
0.00000
0.00000
0.00000
0.00000
0.00000
0.00000
0.00000
0.00000
0.00000
0.00000
0.00000
0.00000
0.00000
0.00000
0.00000
0.00000
0.00000
0.00000
0.00000
0.00000
0.00000
0.00000
0.00000
0.00000
0.00000
0.00000
0.00000
0.00000
0.00000

\section{Source Code Listing for Thermal Analysis during a Flow Stoppage}

c This program calculates the temperature transient following a flow

$c$ interruption during elution of an ion exchange column. It includes the

$c$ effects of thermal conduction to the column walls and natural convection due

$c$ to temperature and concentration gradients in the bulk solution. The effect

$c$ of plutonium and nitric acid on the bulk solution density is included. The

$c$ program solves finite difference energy balance equations with forward time c differencing, donor cell differencing for convection terms, and centered space

c differencing for conduction terms. A list of variable definitions follows. $\mathrm{c}$

$c$ aa = parameter for calculation of saturated plutonium concentration

$c a b=$ parameter for calculation of saturated nitrate concentration

$c$ afl = area factor for inward radial flow, $1 / \mathrm{cm}$

$c$ af 2 = area factor for outward radial flow, $1 / \mathrm{cm}$

c alpha = thermal diffusivity, $\mathrm{cm} 2 / \mathrm{s}$

$c$ an1 = fraction of void volume that lies between resin beads

c area = partial cross-sectional area of resin bed for calculation node, cm2

$c$ areat = total cross-sectional area of resin bed, $\mathrm{cm} 2$

$\mathrm{c} b r=$ nondimensional radial dispersion coefficient for heat transfer equation

$c$ bre = nondimensional radial dispersion coefficient for acid mass transfer

c equation

c brcl = nondimensional radial dispersion coefficient for acid mass transfer 
c equation, due to area change with radius

c bry = nondimensional radial dispersion coefficient for pu mass transfer c equation

c bryl = nondimensional radial dispersion coefficient for Pu mass transfer

c equation, due to area change with radius

$c$ br 1 = nondimensional radial dispexsion coefficient for heat transfer

equation,

c due to area change with radius

$\mathrm{c} b z=$ nondimensional axial dispersion coefficient for heat transfer equation

$c$ bzc = nondimensional axial dispersion coefficient for acid mass transfer

c equation

c bzy = nondimensional axial dispersion coefficient for Pu mass transfer equation

$c$ = volume fraction acid in solution between resin beads

c cold = volume fraction acid in solution between resin beads at previous time step

c cond $=$ thermal conductivity of resin, $\mathrm{cal} / \mathrm{cm} / \mathrm{s} / \mathrm{C}$

c caps = heat capacity of $1 \mathrm{iquid}, \mathrm{cal} / \mathrm{g} / \mathrm{C}$

c capsb = heat capacity of liquid in volume below resin bed, $\mathrm{cal} / \mathrm{g} / \mathrm{c}$

$c$ capst $=$ heat capacity of liquid in volume above resin $\mathrm{bed}, \mathrm{cal} / \mathrm{g} / \mathrm{C}$

c cfeed = plutonium concentration in feed solution, g/cc

c $\operatorname{cf} 30=$ volume fraction of feed solution occupied by HNO3

c $\operatorname{cmax} 2$ = maximum total nitrate concentration for a saturated plutonium nitrate

c solution, gmole/lit

c $\operatorname{cmx} 2=1$ - nitric acid concentration/nitric acid concentration at saturation

c cno3 = nitric acid concentration, gmole/lit

c cno3b = nitric acid concentration in liquid volume below resin bed, gmole/lit

c cno3t = nitric acid concentration in liquid volume above resin bed, gmole/lit

c cno32 = saturation nitrate concentration, calculated as a function of

$\mathrm{C}$

$\mathrm{c} \mathrm{cp}=$ heat capacity, cal/g/C

$c \mathrm{cpu}=$ local plutonium concentration in solution between resin beads, gmole/1it

c cpu2 = saturation plutonium concentration, calculated as a function of acid

c concentration, gmole/lit

c $\operatorname{cpair}=$ heat capacity of ambient air, cal/g/C

c cond $=$ thermal conductivity

c dca = change in volume fraction acid in solution between resin beads at each

c calculation node

c den 1 = density of pure HNO3, g/cc

c den $1 \mathrm{~b}=$ density of pure $\mathrm{HNO} 3$ in liquid volume below resin bed, $\mathrm{g} / \mathrm{cc}$

$c$ denlt = density of pure HNO3 in liquid volume above resin bed, g/cc

c den2 = density of pure $\mathrm{H} 2 \mathrm{O}, \mathrm{g} / \mathrm{Cc}$

$\mathrm{c}$ den $2 \mathrm{~b}=$ density of pure $\mathrm{H} 2 \mathrm{O}$ in liquid volume below resin $\mathrm{bed}, \mathrm{g} / \mathrm{cc}$

$\mathrm{c}$ den2t = density of pure $\mathrm{H} 20$ in liquid volume above resin bed, g/cc

c dens = liquid density, g/cc

$c$ densb = liquid density in volume below resin bed, g/cc

$c$ denst $=$ liquid density in volume above resin bed, $\mathrm{g} / \mathrm{cc}$

c dfpor $=$ pore diffusivity, $\mathrm{cm} 2 / \mathrm{s}$

c dfprt = particle diffusivity, $\mathrm{cm} 2 / \mathrm{s}$

$c \mathrm{df}=$ change in adsorbed plutonium concentration during feeding and elution, c $\mathrm{g} / \mathrm{Cc}$

c diffc = molecular diffusivity of $\mathrm{HNO} 3, \mathrm{~cm} 2 / \mathrm{s}$

c diffcb = molecular diffusivity of HNO3 in volume below resin bed, cm2/s

c diffct = molecular diffusivity of HNO3 in volume above resin bed, cm2/s

c diffy = molecular diffusivity of $\mathrm{Pu}, \mathrm{cm} 2 / \mathrm{s}$

c diffyb = molecular diffusivity of $\mathrm{Pu}$ in volume below resin bed, $\mathrm{cm} 2 / \mathrm{s}$

$\mathrm{c}$ diffyt = molecular diffusivity of Pu in volume above resin bed, cm2/s

c dpart = resin bead diameter, $\mathrm{cm}$

c dr = radial discretization step size, cm

c $d t=$ time step, s

c $d z=$ axial discretization step size, cm

c $d_{y} 2=$ change in plutonium concentration in solution between resin beads, g/cc 
c dy $2 \mathrm{a}=$ change in plutonium concentration in solution between resin beads at

c each calculation node, g/cc

c emiss = surface emissivity for column

c $f=$ plutonium loading on resin, $g / c c$

c fact 1 = factor for iterative calculation of modified stream function

c fact2 = factor for iterative calculation of modified stream function

c fact 3 = factor for iterative calculation of modified stream function

c fact 4 = factor for iterative calculation of modified stream function

c fact5 = factor for iterative calculation of modified stream function

c fcx = weighting factor for elution of plutonium by acid dilution

c ffac = multiplying factor for rate of adsorption of plutonium by resin,

c added to prevent adsorption rate from exceeding rates of convection

$c$ numerically and dispersion mass transfer and thereby making calculation

c unstable

c ffcx = weighting factor for elution of plutonium by acid dilution

c ffeed = maximum plutonium resin bed concentration, g/cc

c fold = plutonium loading on resin at previous time step, g/cc

c $\mathrm{fpu}=$ multiplier used to maintain constant plutonium content in column

c $\mathrm{fx}=$ total bulk plutonium concentration, $\mathrm{g} / \mathrm{cc}$

c grav = gravitational acceleration, $\mathrm{cm} / \mathrm{s} 2$

c $\mathrm{gzn}=$ update value of modified stream function, $\mathrm{cc} / \mathrm{s}$

c $g z o=$ value of stream function for previous iteration, $\mathrm{cc} / \mathrm{s}$

$c$ hconv = coefficient for natural convection heat transfer to sides of column, also overall convective heat transfer coefficient, $\mathrm{cal} / \mathrm{cm} 2 / \mathrm{s} / \mathrm{C}$

$c$ hconv2 = coefficient for natural convection heat transfer to top and bottom c of column, $\mathrm{cal} / \mathrm{cm} 2 / \mathrm{s} / \mathrm{C}$

c hconv2b = overall coefficient for natural convection heat transfer to liquid c volume at bottom of column, cal/cm $2 / \mathrm{s} / \mathrm{C}$

c hconv2t = overall coefficient for natural convection heat transfer to liquid c volume at top of column, cal/cm2/s/C

c hconv3 = coefficient for forced convection heat transfer to column, assuming c an ambient air velocity of $30 \mathrm{~cm} / \mathrm{s}(1 \mathrm{ft} / \mathrm{s})$

$c$ hrad = radiation heat transfer coefficient, cal/cm2/s/C

$c$ htc $=$ heat transfer coefficient, $\mathrm{cal} / \mathrm{cm} 2 / \mathrm{s} / \mathrm{C}$

c htc2b = overall heat transfer coefficient for liquid volume below resin bed, c cal/cm2/s/C

c htc2t = overall heat transfer coefficient for liquid volume above resin bed, c $\mathrm{cal} / \mathrm{cm} 2 / \mathrm{s} / \mathrm{C}$

c iht = indicator for heat transfer to ambient air (iht=1) or to water-cooled c jacket (iht=2) (A heat transfer coefficient is calculated for heat

c transfer to ambient air, and a surface temperature is specified for c cooling by a water jacket.)

$c$ indk = indicator that tells whether rate of adsorption of plutonium exceeds

$c$ rate of mass transfer due to convection and dispersion. If true,

c indk=1 and adsorption rate is halved. If false, indk=0.

$c$ ind 3 = indicator that tells whether solution between the resin beads is

c saturated with plutonium (If ind $=1$, solution is saturated and program

$c$ is directed to loading rate calculations in subroutine feeder; if

ind $=0$,

c solution is not saturated and program is directed to elution rate

c calculations in subroutine elut.)

c ldown = depth of liquid in column below resin bed, $\mathrm{cm}$

c lup = height of liquid in column above resin bed, $\mathrm{cm}$

c length $=$ column length, $\mathrm{cm}$

$\mathrm{c} \mathrm{m}=$ number of axial discretization nodes

$c$ mlen = effective mixing length for axial dispersion coefficient, ratio of

c dispersion coefficient to mixing velocity, $\mathrm{cm}$

c mlen2 = mixing cell height for axial dispersion due to Benard cell mixing, cm

$\mathrm{c} \mathbf{n}=$ number of radial discretization nodes

$c$ nu $=$ Nusselt number for natural convection heat transfer to ambient air from

c sides of column

c nu2 = Nusselt number for natural convection heat transfer to ambient air from 
c top and bottom of column

c nu3 = Nusselt number for forced convection heat transfer to ambient air, assuming air velocity of $30 \mathrm{~cm} / \mathrm{s}(1 \mathrm{ft} / \mathrm{s})$

$\mathrm{C}$ phi = updated temperature, $\mathrm{K}$

$c$ poszn = distance from top of resin bed, $\mathrm{cm}$

c $\mathrm{pr}=$ Prandtl number for ambient air

$c$ pua = total amount of plutonium adsorbed on the resin beads, $g$

c puao = initial total amount of plutonium adsorbed on the resin beads, $g$

$c$ puf = total amount of plutonium in the column, $g$

c pusn = total amount of plutonium in solution, $g$

c pusno = initial total amount of plutonium in solution, $g$

c put = amount of plutonium fed to the column, $g$

c gdot $=$ heat production rate due to plutonium loading, $\mathrm{cal} / \mathrm{cc} / \mathrm{s}$

c radius $=$ column radius, $\mathrm{cm}$

$c$ rayl = Rayleigh number for natural convection heat transfer to ambient air c from sides of column

c rayl2 = Rayleigh number for natural convection heat transfer to ambient air

c from top and bottom of column

c re = Reynolds number for forced convection heat transfer to column, assuming

c an ambient air velocity of $30 \mathrm{~cm} / \mathrm{s}$ (1 $\mathrm{ft} / \mathrm{s})$

c rhcp = product of density and heat capacity for bulk resin bed, cal/cc/c

c rhcp2 = product of density and heat capacity for solution between

c resin beads, cal/cc/C

$c$ rhcp $2 b=$ product of density and heat capacity for liquid volume below resin

c bed, $\mathrm{cal} / \mathrm{cc} / \mathrm{C}$

c rhcp2t = product of density and heat capacity for liquid volume above resin

c bed, $\mathrm{cal} / \mathrm{Cc} / \mathrm{C}$

c rho = bulk density, g/cc

c rhoair = density of air at resin column surface, g/cc

$\mathrm{c}$ rhoamb = density of ambient air, $\mathrm{g} / \mathrm{cc}$

c rrn = updated radial position, used in radial integrations of flow rates and

c temperatures, cm

c rro = second previous radial position, $\mathrm{cm}$

c rrr = previous radial position, $\mathrm{cm}$

c $\operatorname{rrl}=$ radial position of calculation node, $\mathrm{cm}$

c $r 1$ = radial position, $\mathrm{cm}$

c $\mathrm{r} 2$ = radial position; $\mathrm{cm}$

c gdot $=$ heat production rate due to plutonium loading, cal/cc/s

c scl = volume fraction acid in solution in liquid volume at top of column

c scla = change in volume fraction acid in solution in liquid volume at top of column

sc2 = volume fraction acid in solution in liquid volume at bottom of column

c sc2a = change in volume fraction acid in solution in liquid volume at bottom c of column

c $\mathbf{s f}=$ stream function for superficial velocities in resin bed, $\mathrm{cm} 2 / \mathrm{s}$

c sigma = Boltzmann's constant, cal/cm2/s/K4

c stem 1 = temperature in the liquid volume above the resin bed, $K$

c stemla = change in temperature in the liquid volumn above the resin bed, $K$

c stemlc = tempexature in the liquid volumn above the resin bed, $c$

$c$ stem2 = temperature in the liquid volume below the resin bed, $\mathrm{K}$

$c$ stem $2 \mathrm{a}=$ change in temperature in the liquid volume below the resin bed, $\mathrm{K}$

c stem2c = temperature in the liquid volume below the resin bed, $c$

c stp = total number of calculation time steps

c sumsf = integration parameter for stream function calculation, cc/s

c svz2 = integrated volumetric flow rate out column, $\mathrm{cc} / \mathrm{s}$

c sy21 = plutonium concentration in liquid volume at top of column, g/cc

c syzla = change in plutonium concentration in liquid volume at top of colum,

c $\mathrm{g} / \mathrm{cc}$

c sy22 = plutonium concentration in liquid volumn at bottom of column, g/cc

c sy22a = change in plutonium concentration in liquid volume at bottom of

c column, g/cc

c tamb = ambient temperature, $\mathrm{K}$

c tau = time constant for loading plutonium on resin, s 
c tau2 = time constant for eluting plutonium from resin, $s$

$c \operatorname{tcn} 1=$ thermal conductivity for nitric acid, cal $/ \mathrm{cm} / \mathrm{s} / \mathrm{C}$

$c$ tcnlb = thermial conductivity for nitric acid in volume below resin bed,

c cal/cm/s/C

$c$ tcnlt $=$ thermal conductivity for nitric acid in volume above resin bed,

c $\mathrm{cal} / \mathrm{cm} / \mathrm{s} / \mathrm{C}$

c $\operatorname{tcn} 2=$ thermal conductivity for water, $\mathrm{cal} / \mathrm{cm} / \mathrm{s} / \mathrm{C}$

$c \operatorname{tcn} 2 b=$ thermal conductivity for water in volume below resin bed, cal/cm/s/c

$c t c n 2 t=$ thermal conductivity for water in volume above resin bed, cal/cm/s/c

$c$ tcnm = thermal conductivity for bulk resin bed, $\mathrm{cal} / \mathrm{cm} / \mathrm{s} / \mathrm{C}$

$\mathrm{c}$ tcmmb = thermil conductivity for liquid in volume below resin bed, cal/cm/s/C

$\mathrm{c}$ tcont = thermal conductivity for liquid in volume above resin bed, cal/cm/s/c

$c$ telut $=$ time for elution, s

$c$ temb = product of volumetric flow rate out of resin bed and temperature at

$c$ bottom of resin bed, $\mathrm{K}-\mathrm{cc} / \mathrm{s}$

$c$ temch = maximum temperature in column, $\mathrm{C}$

$c$ temc = temperiture, $\mathrm{C}$

c temp = temperature, $\mathrm{K}$

c time = elapsed time after flow is interrupted, $m$

c time2 = elapsed time after flow is interrupted, $s$

c tinte $=$ time interval for printing maximum resin bed temperatures, $s$

c tinte2 = time for printing bed temperature profiles, $s$

$c$ tload = time for loading, s

c twash = time for washing, $s$

c tzero = initial temperature, $\mathrm{K}$

$\mathrm{c}$ tzero = temperature of solution entering column, $\mathrm{K}$

$\mathrm{c}$ vbot $=$ volume of liquid below resin bed, $\mathrm{cc}$

c vel2 = velocity of ambient air, $\mathrm{cm} / \mathrm{s}$

c vfi = volume fraction in resin bead pores, prior to adsorption of plutonium

c vfi2 = volume fraction in resin bead pores, after adsorption of plutonium

c vfi3 = volume fraction in resin bead pores, adjusted for actual amount of

c plutonium adsorbed

c vfo = volume fraction occupied by flowing solution

$c$ vis = liquid dynamic viscosity, $\mathrm{g} / \mathrm{cm} / \mathrm{s}$

c visb = dynamic viscosity for liquid volume below resin bed, $\mathrm{g} / \mathrm{cm} / \mathrm{s}$

c vist = dynamic viscosity for liquid volume above resin $\mathrm{bed}, \mathrm{g} / \mathrm{cm} / \mathrm{s}$

c visair = dynamic viscosity of: ambient air, $g / \mathrm{cm} / \mathrm{s}$.

c vmid = total volume of resin bed, cc

c vr = superficial radial veloc:ity, cm/s

$c$ vtop $=$ volume of liquid above resin bed, cc

$c \mathrm{vz}=$ superficial axial velocity, $\mathrm{cm} / \mathrm{s}$

c vzsum = integration parameter for integration of axial velocity profile, cc/s

$c$ wf = weighting factor for axial dispersion coefficient, based on distance

c over which density difference for natural convection velocity is based

$\mathrm{c} x$ = fractional loading of plutonium on resin

c $\mathrm{xg}=$ elution rate constant, $1 . / \mathrm{s}$

c $x$ kair $=$ thermal conductivity of ambient air, cal $/ \mathrm{cm} / \mathrm{s} / \mathrm{C}$

c xold = fractional loading of plutonium on resin at previous time step

c $\mathbf{x x 1}=$ mass fraction nitric acid in the solution between resin beads

$\mathrm{c} \times \mathrm{x}$ - $=$ mass fraction nitric acid in liquid volume below resin bed

c $x \times 1 t=$ mass fraction nitric acid in liquid volume above resin bed

c $y=$ bulk plutonium concentration in pore solution, g/cc

c yold = bulk plutonium concentration in pore solution at previous step, g/cc

c y2 = bulk plutonium concentration in solution between resin beads, g/cc

c y2feed = plutonium concentration in solution entering resin bed, g/cc

c $y 2 \max =$ maximum bulk plutonium concentration in solution between resin beads

c duririg elution, g/cc

c y $2 \max 2=$ maximum plutonium concentration for a saturated plutonium nitrate

c solution, gmole/lit

c y $2 \mathrm{mx} 2=$ maximum bulk plutonilum concentration in solution between resin beads

c durirg elapsed time during elution, g/cc

c $y^{2}$ old $=$ bulk plutonium concentration in solution between resin beads at

c previous time step, g/cc 


\section{Revision 0}

c zden = area-average liquid density at a given level, g/cc

c $\mathbf{z v z}=$ area-average superficial axial velocity at a given level, $\mathrm{cm} / \mathrm{s}$ implicit double precision $(a-z)$

integer $i, j, m, m m 1, n, n n 1, q, r, s, s t p, s t p 2, i s k i p, i s 1, m m 2, m m 3, j l e v$,

1 ind, istt, istc, ind $3, k, n c t, n c t 2, n c t 3, n l a s t, j 4, j \max , j \min , \operatorname{mm} 4, m m 5$,

2 indk, $k 2$

character ${ }^{10} \operatorname{ch} 1$

dimension temc $(200,100), \operatorname{temp}(200,100), \operatorname{phi}(200,100)$

dimension $v r(200,100), v z(200,100)$, dens $(200,100), z$ den $(200)$

dimension vis $(200,100), z v z(200)$

dimension area $(100), \operatorname{den} 2(200,100), \operatorname{br} 1(200,100), \operatorname{brc} 1(200,100)$

dimension $\operatorname{rhcp}(200,100), \operatorname{tcnm}(200,100)$

dimension $\mathrm{bz}(200,100), \mathrm{br}(200,100), \mathrm{fx}(200,100)$

dimension $\operatorname{rr} 1(100), \operatorname{bzc}(200,100), \operatorname{brc}(200,100)$

dimension bzy $(200,100)$, bry $(200,100)$, bryl $(200,100)$

dimension rhcp $2(200,100)$, diffy $(200,100)$, diffc $(200,100)$

dimension alpha $(200,100), g z 0(200,100), \operatorname{gzn}(200,100)$

dimension dy2a $(200,100)$, dca $(200,100)$

dimension afl(100), af2(100), $\operatorname{vzm}(200)$

dimension $c(200,100), \operatorname{cold}(200,100), f(200,100)$, fold $(200,100)$,

$1 \mathrm{x}(200,100), \mathrm{xold}(200,100), \mathrm{y} 2(200,100), y 201 \mathrm{~d}(200,100)$,

$2 \operatorname{den} 1(200,100)$, ind $3(200,100), \operatorname{cmx} 2(200,100)$,

$3 y 2 \max (200,100)$

character tab /9/

comonon /elut1/c, cold, f, fold, $x, x o l d, y 2, y 2 o l d, d e n 1$,

$2 y 2 \max , y 2 \max 2, \max 2$, ind $3, \operatorname{cmx} 2$, cfeed, dt, tau, tau2, ffeed, an1,

3 dpart, dz, xg, vfi2, vfo, ind

$c$ Input ambient temperature in ${ }^{\circ} \mathrm{C}$.

read $\left(5,{ }^{*}\right)$ tamb

c Input indicator for air heat transfer (iht=1) or water jacket heat transfer

c $($ ih $t=2)$.

read $\left(5,{ }^{\star}\right)$ int

c Input resin bed depth in centimeters. read $\left(5,{ }^{*}\right)$ length

$c$ Input height above resin bed in centimeters. read $(5, *)$ lup

c Input depth below resin bed in centimeters. read $(5, *)$ ldown

$c$ Input colum radius in centimeters. read $\left(5,{ }^{*}\right)$ radius

c Input particle diameter in centimeters. read $\left(5,{ }^{*}\right)$ dpart

c Input pore diffusivity in $\mathrm{cm} 2 / \mathrm{sec}$. read $\left(5,{ }^{*}\right)$ dfpor

c Input particle diffusivity in $\mathrm{cm} 2 / \mathrm{sec}$. read $\left(5,{ }^{\star}\right)$ dfprt

c Input void fraction. read $\left(5,{ }^{\star}\right)$ vfo

$c$ Input maximum resin bed concentration. read $(5, *)$ ffeed

$c$ Input radiolysis heat in $\mathrm{cal} / \mathrm{cc} / \mathrm{sec}$. read $\left(5,{ }^{*}\right)$ qdot

c Input initial volume fraction nitric acid. read $\left(5,{ }^{*}\right) \operatorname{cf} 30$

pi $=4$. *atan (1.)

c Input parameters for mixing model.

rho $=1.23$

$\mathrm{cp}=0.76$

tzero $=$ tzero +273.0

tamb $=$ tamb +273.0

grav $=980$.

vf $i=0.132$

vfi $2=0.160$ 
an $1=1 . /($ vfo $+v f i)$

mlen $=0.48^{*}$ radius

mlen $2=1.6^{\star}$ radius

tau $=$ dpart ${ }^{\star \star} 2 /\left(4 .{ }^{\star} p i{ }^{\star}{ }^{\star} 2\right) /$ dfprt

tau2 $=$ dpart ${ }^{\star} \star 2 /(24 . * 0.75 *$ dfpor $)$

$\mathrm{xg}=4 .{ }^{\star} \mathrm{pi}{ }^{\star} \star 2 \star \mathrm{d}$ fpor $/ \mathrm{dpart}{ }^{\star} \star 2$ * $(1 .-\mathrm{vfo})$

$\mathrm{a} a=1$.

$\mathrm{k}=1$

do while (k.le.8)

$a a=a a-(a a * * 5-2.9 * * 4 * 0.26 *(4 .-a a) *(1 .-a a) * * 4)$

$1 /\left(4 .{ }^{\star} a a^{\star \star} 4+2.9 * \star 4 * 0.26 *\left((1 .-a a) * \star 4+4 .{ }^{\star}(4 .-a a) *(1,-a a) \star \star 3\right)\right)$

$\mathrm{k}=\mathrm{k}+1$

enddo

y $2 \max 2=a a / 2.9 /(4,-a a) /(1,-a a)$

$\operatorname{cmax} 2=4 .{ }^{\star} y 2 \max 2$

$c$ Input \# steps in axial, radial directions. read $\left(5,{ }^{*}\right) \mathrm{m}, \mathrm{n}$

$c$ Input \# of data points to skip between reading each concentration. read $\left(5,{ }^{*}\right)$ iskip

c Input starting line for reading concentration profile.

read $\left(5,{ }^{*}\right)$ istc

$m=m+1$

$\mathrm{n}=\mathrm{n}+1$

$\mathrm{mml}=\mathrm{m}-1$

$\mathrm{nn} 1=\mathrm{n}-1$

$\mathrm{mm} 2=\mathrm{m}+1$

$\mathrm{mm} 3=\mathrm{m}+2$

$\mathrm{mm} 4=\mathrm{m}-2$

$m \mathrm{~m} 5=m-3$

$c$ Read in temperatures.

read $\left(9,{ }^{*}\right)$ stem $1 \mathrm{c}$

read $\left(9,{ }^{*}\right)$ stem $2 \mathrm{c}$

stem $1=$ stem $1 c+273$.

stem $2=$ stem $2 c+273$.

$j=m$

do while (j.ge.1)

$i=n$

do while (i.ge.1)

$\operatorname{read}(9, *) \operatorname{temp}(j, i)$

$\operatorname{temp}(j, i)=\operatorname{temp}(j, i)+273$.

$i=i-1$

enddo

$i=2$

do while (i.le.n)

$\operatorname{read}(9, *) \operatorname{temc}(j, i)$

$\operatorname{temp}(j, i)=\operatorname{temc}(j, i)+273$.

$i=i+1$

enddo

$j=j-1$

enddo

$c$ Read in concentrations.

istc $=$ istc -1

$\mathrm{k}=1$

do while (k.le.istc)

read $(8, *)$

$\mathrm{k}=\mathrm{k}+1$

enddo

$j=1$

do while (j.le.m)

$\operatorname{read}\left(8,{ }^{*}\right)$ tim, $1 n, x c 1, x c 2, x c 3, x c 4, x c 5$

$i=1$

do while (i.le.n)

$c(j, i)=\operatorname{cf} 30^{\star}(1 .-x c 1)$ 
$\operatorname{cold}(j, i)=c(j, i)$

$f(j, i)=x c 2$

fold $(j, i)=x c 2$

$y 2(j, i)=x c 3+x c 4$

$y 20 l d(j, i)=x c 3+x c 4$

$\operatorname{xold}(j, i)=x c 2 /$ ffeed

$\mathrm{fx}(j, i)=x \subset 5$

$i=i+1$

enddo

$j=j+1$

enddo

read $\left(8,{ }^{*}\right)$ tim, $1 \mathrm{n}, \mathrm{xc} 1, \mathrm{xc} 2, \mathrm{xc} 3, \mathrm{xc} 4, \mathrm{xc5}$

$\operatorname{sc} 1=\operatorname{cf} 30 *(1 .-x c 1)$

sy $21=x c 3$

read $\left(8,{ }^{*}\right)$ tim, $l n, x \subset 1, x c 2, x c 3, x c 4, x c 5$

$\operatorname{sc} 2=\operatorname{cf} 30 *(1 .-x c 1)$

sy $22=x c 3$

$\mathrm{dz}=$ length/dfloat (mm1)

$\mathrm{dr}=$ radius/dfloat (nnl)

vtop $=p i *$ radius * $* 2 * 1$ up

vbot $=p i$ *adius $* * 2 * 1$ down

vmid $=\mathrm{pi}$ * radius ${ }^{\star} \star 2 \star 1$ eng th

area $(1)=p i *(0.5 /$ dfloat $(\mathrm{nn} 1) *$ radius $) * * 2$

area $(n)=p i *(1 .-((\operatorname{dfloat}(\mathrm{nn} 1)-0.5) / \operatorname{dfloat}(\mathrm{nn} 1)) \star \star 2)$ *adius $* * 2$

$i=2$

do while (i.le.nnl)

$r 1=($ dfloat $(i)-1.5) /$ dfloat $(\mathrm{nn} 1) *$ radius

$r 2=(\operatorname{dfloat}(i)-0.5) / \operatorname{dfloat}(\mathrm{nn} 1) \star$ radius

area $(i)=p i *(r 2 * * 2-r 1 * * 2)$

$i=i+1$

enddo

areat $=\mathrm{pi}$ * radius ${ }^{\star * 2}$

$c$ Input starting time increment in seconds. read $\left(5,{ }^{*}\right)$ dts

$c$ Input later time increment in seconds.

read $(5, *)$ dtf

c Input number of time steps for starting time increment. read $\left(5,{ }^{\star}\right) \operatorname{stp} 2$

$c$ Input total number of time steps. read $(5, *)$ stp

c Initialize radial positions. $\operatorname{rrl}(1)=0$.

$i=2$

do while (i.le.n)

$\operatorname{rrl}(i)=\operatorname{rr} 1(i-1)+d r$

$i=i+1$

enddo

af $1(1)=0$.

$\operatorname{af} 2(1)=0$.

$i=2$

do while (i.le.nn1)

af $1(i)=2{ }^{*} \operatorname{rr} 1(i) /(\operatorname{rr} 1(i) \star \star 2-\operatorname{rr} 1(i-1) * \star 2)$

af $2(i)=2{ }^{*} \operatorname{rr} 1(i) /(\operatorname{rr} 1(i+1) * \star 2-\operatorname{rr} 1(i) * \star 2)$

$i=i+1$

enddo

c Initialize physical properties.

stemlc $=$ stem1-273.

stem $2 c=$ stem $2-273$.

$\operatorname{den} 1 t=1.6603-1.9894 \mathrm{e}-3^{\star} s t e m 1 c$

den $1 b=1.6603-1.9894 e-3 *$ stem $2 c$

den $2 t=0.99683-1.3010 e-4^{\star} s \operatorname{sen} 1 c-2.4358 e-\sigma^{\star} s t e m 1 c * \star 2$

den $2 b=0.99683-1.3010 e-4^{\star} s t e m 2 c-2.4358 e^{-6 *}$ stem $2 c^{*}{ }^{*} 2$

$x \times 1 t=\operatorname{den} 1 t^{\star} \operatorname{sc} 1 /\left(\operatorname{den} 1 t^{*} \operatorname{sc} 1+\operatorname{den} 2 t *(1 .-\operatorname{sc} 1)\right)$ 
$x \times 1 b=\operatorname{den} 1 b^{*} \operatorname{sc} 2 /\left(\operatorname{den} 1 b^{*} \operatorname{sc} 2+\operatorname{den} 2 b *(1,-s c 2)\right)$

cno3t $=s c 1 * \operatorname{den} 1 t * 1000 . / 63 .-4 .{ }^{*} \operatorname{sy} 21 * 1000 . / 238$. $\mathrm{cno} 3 \mathrm{~b}=\mathrm{sc} 22^{\star} \operatorname{den} 1 \mathrm{~b} * 1000 . / 63 .-4 .{ }^{\star} \operatorname{sy} 22 \star 1000 . / 238$. if $(\mathrm{cno} 3 \mathrm{t} .1 \mathrm{t} .0.) \mathrm{cno} 3 \mathrm{t}=0$. if (cno3b. $1 \mathrm{t} .0.) \quad \mathrm{cno} 3 \mathrm{~b}=0$.

dens $t=\operatorname{den} 2 t+0.4277 * \operatorname{sy} 21 * 1000 . / 238 .+0.031 * \mathrm{cno} 3 t$ densb $=$ den $2 b+0.4277 * s y 22 * 1000 . / 238 .+0.031 *$ cno $3 b$ caps $\mathrm{t}=1.0104-\left(1.419-0.3^{*}(\right.$ stem $\left.1 \mathrm{c}-20) / 80.\right) * \mathrm{xx} 1 \mathrm{t}$ $1+(2.005-0.6 *($ stem1c -20.$) / 80.){ }^{*} \times x 1 t * * 2$ $2-\left(1.147-0.3^{*}(\operatorname{stem} 1 c-20) / 80.\right){ }^{*} x \times 1 t * * 3$ capsb $=1.0104-(1.419-0.3 *($ stem $2 c-20) / 80) * x x$. $1+(2.005-0.6 *($ stem $2 c-20) / 80) *. x \times 1 b * * 2$

$2-\left(1.147-0.3^{*}(\right.$ stem $\left.2 c-20) / 80.\right) * x \times 1 b * * 3$ rhcp $2 t=$ denst $t^{*}$ capst $x h \mathrm{cp} 2 \mathrm{~b}=$ densb* $\mathrm{capsb}$ $\operatorname{tcn} 1 t=6.1388 e-4+1.3951 e-6^{*}$ stemlc $\operatorname{tcn} 2 t=1.3518 e-3+2.7903 e-6^{\star}$ stem $1 c$ $\operatorname{tcn} 1 \mathrm{~b}=6.1388 \mathrm{e}-4+1.3951 \mathrm{e}-6^{\star}$ s tem $2 \mathrm{c}$ $\operatorname{tcn} 2 b=1.3518 e-3+2.7903 e-6^{\star}$ stem $2 c$ tcnmt $=\operatorname{tcn} 1 t^{\star} \times x 1 t+\operatorname{ten} 2 t^{\star}(1,-x \times 1 t)$ $t c n m b=t \operatorname{cn} 1 b^{*} \times x 1 t+\operatorname{tcn} 2 b^{*}(1 .-x \times 1 t)$ vist $=0.01002 * 10 . * *\left(\left(1.3272 *(20 .-s t e m 1 c)-0.001053^{\star}\right.\right.$ $1($ stem $1 c-20). * \star 2) /($ stem $1 c+105)$. visb $=0.01002 * 10 . * \star((1.3272 *(20 .-$ stem $2 c)-0.001053 *$

$1($ stem $2 c-20) * * 2.) /($ stem $2 c+105)$. diffyt $=8.314 / 96500 * 2 * \operatorname{stem} 1 *(1 . / 1 .+1 . / 3) /.(1 . / 69.5$

$1+1 . / 71.4)$ diffct $=8.314 / 96500 * * 2 * \operatorname{stem} 1 *(1 . / 1 .+1 . / 1) /.(1 . / 349.8$ $1+1 . / 71.4)$

diffyb $=8.314 / 96500 * * 2 *$ stem $2 *(1 . / 1 .+1 . / 3) /.(1 . / 69.5$

$1+1 . / 71.4)$

diffcb $=8.314 / 96500^{*} 2^{\star}$ stem $2 *(1 . / 1 .+1 . / 1) /.(1 . / 349.8$

$1+1 . / 71.4)$

$i=1$ do while (i.le.n)

$j=1$

do while $(j . l e . m)$

$\operatorname{temc}(j, i)=\operatorname{temp}(j, i)-273$.

$\operatorname{den} 1(j, i)=1.6603-1.9894 \mathrm{e}-3 * \operatorname{tenc}(j, i)$

$\operatorname{den} 2(j, i)=0.99683-1.3010 e-4 * \operatorname{tenc}(j, i)-2.4358 e-6 * \operatorname{tenc}(j, i) * * 2$

$x \times 1=\operatorname{den} 1(j, i){ }^{\star} c(j, j) /(\operatorname{den} 1(j, i) * c(j, i)+\operatorname{den} 2(j, i) *(1,-c(j, i)))$ $c n 03=c(j, i){ }^{\star} \operatorname{den} 1(j, i) * 1000.163 .-4 .{ }^{\star} y 2(j, i) \star 1000 . / 238 . /$ vfo if $(\mathrm{cno} 3.1 \mathrm{t} .0.) \quad \mathrm{cno} 3=0$.

$\operatorname{dens}(j, i)=\operatorname{den} 2(j, i)+0.4277^{\star} y^{2}(j, i){ }^{*} 1000 . / 238 . / v f o+0.031^{\star} \operatorname{cno} 3$

$\operatorname{tcn} 1=6.1388 \mathrm{e}-4+1.3951 \mathrm{e}-6^{*} \operatorname{temc}(j, i)$

$\operatorname{tcn} 2=1.3518 e-3+2.7903 e-6 * \operatorname{tenc}(j, i)$

$\operatorname{tanm}(j, i)=\tan 1{ }^{*} x \times 1+\tan 2 *(1 .-x \times 1)$

$\tan (j, i)=0.5^{\star}(5 . e-4+\operatorname{tanm}(j, i))$

caps $=1.0104-\left(1.419-0.3^{*}(\operatorname{temc}(j, i)-20) / 80.\right) * x \times 1$

$1+(2.005-0.6 *(\operatorname{tenc}(j, i)-20) / 80) *. x \times 1 * * 2$

$2-(1.147-0.3 *(\operatorname{temc}(j, i)-20) / 80) *. x \times 1 * * 3$

$\operatorname{rhcp}(j, i)=0.5 * 1.25 * 0.52+0.5 * \operatorname{dens}(j, i) * \operatorname{caps}$

$\operatorname{rhcp} 2(j, i)=$ dens $(j, j) * \operatorname{caps}$

$\operatorname{vis}(j, i)=0.01002 * 10 * \star((1.3272 *(20 .-\operatorname{temc}(j, i))-0.001053 *$

$1(\operatorname{temc}(j, i)-20) * * 2.) /(\operatorname{tenc}(j, i)+105)$.

$\operatorname{alpha}(j, i)=\operatorname{tcnm}(j, i) / \operatorname{rhcp}(j, i)$

$\operatorname{diff} Y(j, i)=8.314 / 96500 * * 2 * \operatorname{temp}(j, i) *(1 . / 1 .+1 . / 3) /.(1 . / 69.5$

$1+1 . / 71.4)$

$\operatorname{diffc}(j, i)=8.314 / 96500 * \star 2 * \operatorname{temp}(j, i) \star(1 . / 1 .+1 . / 1) /.(1 . / 349.8$

$1+1 . / 71.4)$

$b z(j, i)=\left(\operatorname{alpha}(j, i)+2{ }^{*} \operatorname{dpart} \operatorname{abs}(v z(j, i)) \star \operatorname{rhcp} 2(j, i) / \operatorname{rhcp}(j, i)\right)$

$1 \star d t / d z \star \star 2$

$b z y(j, i)=\left(\operatorname{diffy}(j, i)+2{ }^{\star} \operatorname{dpart} \operatorname{abs}(v z(j, i))\right) \star d t / d z \star \star 2$ 


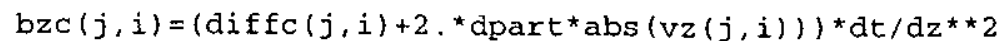

$j=j+1$

enddo

$i=i+1$

enddo

$j=1$

do while $(j . l e . m)$

$\operatorname{br}(j, 1)=\left(\operatorname{alpha}(j, 1)+0.4^{\star} \operatorname{dpart}{ }^{\star} \operatorname{abs}(v z(j, 1))^{\star} \operatorname{rhcp} 2(j, 1) / \operatorname{rhcp}(j, 1)\right)$

$1 * d t^{\star} 4 . / d r^{\star *} 2$

$\operatorname{br} 1(j, 1)=0$.

$\operatorname{bry}(j, 1)=\left(\operatorname{diffy}(j, 1)+0.4^{\star} \operatorname{dpart} \operatorname{abs}^{*}(v z(j, 1))\right) * \mathrm{dt}^{\star} 4 . / \mathrm{dr} r^{\star} 2$

$\operatorname{bry} 1(j, 1)=0$.

$\operatorname{brc}(j, 1)=\left(\operatorname{diffc}(j, 1)+0.4{ }^{\star} \operatorname{dpart} \operatorname{abs}(\operatorname{vz}(j, 1))\right) * \operatorname{dt}^{\star} 4 . / \operatorname{dr} r^{\star} 2$

$\operatorname{brcl}(j, 1)=0$.

$j=j+1$

enddo

$i=2$

do while (i.le.n)

$j=1$

do while (j.le.m)

$\operatorname{br}(j, i)=\left(a l p h a(j, i)+0.4^{\star} \operatorname{dpart} \operatorname{abs}(v z(j, i))^{\star} \operatorname{rhcp} 2(j, i)\right.$

$1 / \operatorname{rhcp}(j, i)) * d t / d r * \star 2$

$\operatorname{br} 1(j, i)=\left(\operatorname{alpha}(j, i)+0.4^{\star} \operatorname{dpart}{ }^{\star} \operatorname{abs}(v z(j, i)){ }^{*} \operatorname{rhcp} 2(j, i)\right.$

$1 / \operatorname{rhcp}(j, i))^{\star} \mathrm{dt} / \mathrm{dr} / \operatorname{xr} 1(i) / 2$.

$\operatorname{bry}(j, i)=\left(\operatorname{diffy}(j, i)+0.4 * \operatorname{dpart} \operatorname{abs}^{*}(v z(j, i))\right) \star d t / d r * \star 2$

$\operatorname{bryl}(j, i)=(\operatorname{diffy}(j, i)+0.4 * \operatorname{dpart} \operatorname{abs}(v z(j, i))) \star \operatorname{dt} / \operatorname{dr} / \operatorname{rr} 1(i) / 2$.

$\operatorname{brc}(j, i)=\left(\operatorname{diffc}(j, i)+0.4^{\star} \operatorname{dpart} \operatorname{abs}(\mathrm{vz}(j, i))\right) \star \mathrm{dt} / \mathrm{dr} r^{\star} 2$

$\operatorname{brcl}(j, i)=(\operatorname{diffc}(j, i)+0.4 * \operatorname{dpart} \operatorname{abs}(\mathrm{v} z(j, i))) \star \operatorname{dt} / \operatorname{dr} / \operatorname{rr} 1(i) / 2$.

$j=j+1$

enddo

$i=i+1$

endao

c Write input variables to output.

write $(1,100)$ length, radius, $m, n$

write $(1,121)$ dpart,vfo

write $(1,101)$ dt, htc, htc2

$\mathrm{C}$

write $(1,110)$ sumf

100 format ('L (CM) $=$ ', f7.3,2x,'R (CM) =',f7.3,2x,'AXIAL NODES =',

$1 i 3,2 x, '$ RADIAL NODES $=\prime, i 3)$

101 format ('DT (S) $=$ ', f $8.4,2 \mathrm{x}$, ' $\mathrm{HSID}\left(\mathrm{CAL} / \mathrm{CM} 2 / \mathrm{S} /{ }^{\circ} \mathrm{C}\right)=\cdot, \mathrm{f} 9.6$,

$12 \mathrm{x}$, 'HTOP $\left.\left(\mathrm{CAL} / \mathrm{CM} 2 / \mathrm{S} /{ }^{\circ} \mathrm{C}\right)=', \mathrm{f} 9.6\right)$

c 110 format ('PU CHARGE (GM) =', 111.4 )

write $\left(2,{ }^{*}\right)$ 'TIME (MIN)', tab, 'TMAX $\left({ }^{\circ} \mathrm{C}\right)$ ', tab, 'PUA (GM)',

1 tab, 'PUT (GM)'

121 format ('PART DIAM $(\mathrm{CM})=$ ', $\mathrm{f} 8.4,2 \mathrm{x}$, 'VOID FRACTION $=1, f 7.4$ )

c Find highest temperature.

temch $=0$.

$j=1$

do while (j.le.m)

$i=1$

do while (i.le.n)

if (temch.lt.temc $(j, i))$ then

temch $=$ temc $(j, i)$

endif

$i=i+1$

enddo

$j=j+1$

enddo

c Calculate total amounts of plutonium and plutonium adsorbed.

pua $=0$.

puf =areat* $\left(1\right.$ up $^{\star}$ sy $21+1$ down ${ }^{\star}$ sy 22$)$

pusn=areat * $\left(1\right.$ up $^{*}$ sy $21+1$ down* sy 22$)$

$i=1$ 
do while (i.le.n)

pua $=$ pua $+0.5^{\star} \mathrm{dz}$ *area $(i) *(f(1, i)+f(m, i))$

puf $=$ puf $+0.5^{\star} d z^{\star}$ area $(i) *(\operatorname{fx}(1, i)+f x(m, i))$

pusn=pusn $+0 \cdot 5^{\star} d z^{\star} \operatorname{area}(i) *\left(y^{2}(1, i)+y 2(m, i)\right)$

$i=i+1$

enddo

$j=2$

do while (j.le.mm1)

$i=1$

do while (i.le.n)

pua $=p u a+d z * f(j, i)$ *area $(i)$

puf $=p u f+d z * f x(j, i) * \operatorname{area}(i)$

pusn=pusn $+d z^{*} y 2(j, i) * \operatorname{area}(i)$

$i=i+1$

enddo

$j=j+1$

enddo

puao=pua

pusno=pusn

time $=0$.

if (abs (nint (time/2)-time/2).1t.0.001)

1write $(2,301)$ time, tab, temch, tab, pua, tab, puf

$c$ Set initial velocities equal to zero.

$j=1$

do while (j.le.m)

$\operatorname{vzm}(j)=0$.

$i=1$

do while $(i, 1$ e.n)

$v z(j, i)=0$.

$\operatorname{vr}(j, i)=0$.

$i=i+1$

enddo

$j=j+1$

endao

$i=1$

c Write initial concentrations and temperatures.

write $(1, *)$ 'TIME (MIN)', tab, 'POS (CM)', tab, 'LOAD', tab,

1 'TCEN $\left({ }^{\circ} \mathrm{C}\right) \cdot$, tab, 'TMID $\left({ }^{\circ} \mathrm{C}\right) \cdot$, tab, 'TOUT $\left({ }^{\circ} \mathrm{C}\right) \cdot$

write $\left(6,{ }^{*}\right)$ 'TIME (MIN)', tab, 'LENGTH (CM)', tab, 'ELU (VF)', tab,

1 'ADS $(\mathrm{G} / \mathrm{CC}) \cdot, \mathrm{tab}$, 'LIQ (G/CC)', tab, 'TOT (G/CC)'

$j=1$

write $(1,102)$ time, tab, -1, tab, 0., tab, stemlc, tab, stemlc,

1 tab, stem $1 \mathrm{c}$

do while (j.le.m)

poszn=length * $(j-1) /(m-1)$

write $(1,102)$ time, tab, poszn, tab, $f(j, 1), t a b, t e m c(j, 1), t a b$,

1 temc $(j, 5), t a b, \operatorname{temc}(j, n)$

write $(6,400)$ time, tab, poszn, tab, $c(j, 1), t a b, f(j, 1), t a b, y 2(j, 1)$,

$1 \mathrm{tab}, \mathrm{fx}(j, 1)$

$j=j+1$

enddo

write $(1,102)$ time, tab, -2, tab, 0., tab, stem $2 c, t a b, s t e m 2 c, t a b$,

$1 s \operatorname{tem} 2 \mathrm{c}$

c Perform transient calculations.

ind $k=1$

$\mathrm{s}=1$

time $2=0$.

$\mathrm{dt}=\mathrm{dt} \mathrm{s}$

do while (s.le.stp.and.vtop.gt.5.)

if (s.gt.stp2) $d t=d t f$

c Calculate heat transfer coefficients

sigma $=1.356 \mathrm{e}-12$

emiss $=0.6$ 
tavg $=0$.

$q=1$

do while (q.le.m)

$\operatorname{tavg}=\operatorname{tavg}+\operatorname{temp}(q, n)$

$q=q+1$

endoo

$\mathrm{tavg}=\mathrm{tavg} / \mathrm{m}$

hrad=emiss sigma $^{\star}$ ( tavg $* * 3+$ tavg $* 2 *$ tamb

$1+$ tavg $*$ tamb** $2+$ tamb**3)

cpair $=3.5 * 1.9872 * 29$.

$\mathrm{xkair}=0.0262 / 100 * 0.2389$

visair $=0.00018$

pr=cpair*visair/xkair.

rhoamb $=29.182 .057 /$ tamb

rhoair $=29.182 .057 /$ tavg

rayl $=g_{\text {rav }}$ (length+lup+ldown) $* 3^{*}$ rhoamb* (rhoamb-rhoair)

$1 /$ visair $* \star 2 * \mathrm{pr}$

if (rayl.gt.o.) then

nu $=0.59 *$ rayl ${ }^{*} 0.25$

endif

if (nu.1t.1.) nu=1.

hconv=nu*xkair / (length+lup+ldown)

vel $2=30.0$

re $=2 .{ }^{*}$ radius *vel2. ${ }^{*}$ rhoamb/visair

nu $3=0.683^{\star} \mathrm{re}^{\star \star} 0.466^{*} \mathrm{pr}{ }^{*}(1 . / 3$.

hconv $3=x k a i x^{\star}$ nu $3 / 2$. / radius

if (hconv. It.hconv3) hconv=hconv3

htc $=$ hconv+hrad

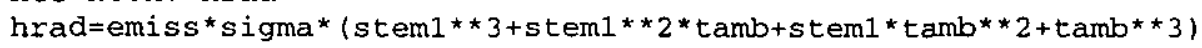

rhoair $=29 . / 82.057 /$ stem $]$

rayl $=\operatorname{grav}^{*}($ length +1 up +1 down $) * * 3 * r h o a m b *$ (rhoamb-rhoair)

$1 /$ visair**2*pr

if (rayl.gt.0.) then

$\mathrm{nu}=0.59 *$ ray $1 * * 0.25$

endif

if (nu. It.1.) nu=1.

hconv $=n u^{\star} \times k a i r /$ (length +1 up + ldown)

ray $12=\operatorname{grav}^{*}\left(2 .{ }^{*}\right.$ radius $) *{ }^{*}{ }^{\star}$ rhoamb* (rhoamb-rhoair) $/$ visair ${ }^{\star}{ }^{*}{ }^{*}$ pr

if (rayl2.gt.0.) then

nu $2=0.54 *$ ray $12 * \star 0.25$

endif

if (nu2.1t.1.) nu2=1.

hconv $2=n u 2{ }^{\star} x k a i r / 2$. /radius

hconv $2 t=\left(2 .{ }^{\star}\right.$ radius ${ }^{*} l$ up ${ }^{*}$ hconv + radius ${ }^{\star}{ }^{*} 2$ hconv 2$) /\left(2 .{ }^{*}\right.$ radius ${ }^{\star}$ lup

$1+$ radius $* 2$ )

vel $2=30.0$

re $=2 .{ }^{\star}$ radius ${ }^{*}$ vel2 ${ }^{*}$ rhoamb/visair

nu $3=0.683^{\star} r e^{\star \star} 0.466^{\star} \mathrm{pr}^{\star \star}(1 . / 3$.

hconv $3=x k a i r *$ nu $3 / 2$. / radius

if (heonv2t. It.heonv3) heonv2t=hconv 3

htc $2 \mathrm{t}=\mathrm{hrad}+\mathrm{hconv} 2 \mathrm{t}$

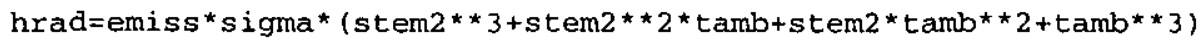

rhoair $=29.182 .057 /$ stem2

rayl $=g \operatorname{rav}^{*}$ (length+lup+ldown)**3*rhoamb* (rhoamb-rhoair)

$1 /$ visair**2*pr

if (rayl.gt.0.) then

$\mathrm{nu}=0.59 *$ rayl $1 * 0.25$

endif

if (nu.1t.1.) nu=1.

hconv $=n u^{*} \times k a i r /$ (length + lup + ldown $)$

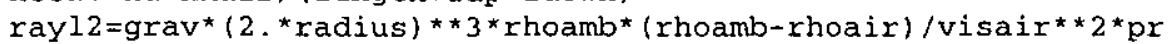

if (rayl2.gt.0.) then

nu2 $=0.27 *$ ray $12 * * 0.25$ 
endif

if (nu2.1t.1.) nu2=1.

hconv2 $=$ nu $2 * x k a i r / 2 . /$ radius

hconv $2 \mathrm{~b}=\left(2 .{ }^{\star}\right.$ radius ${ }^{\star} 1$ down ${ }^{\star}$ hconv+radius ${ }^{\star} 2^{\star}$ hconv 2$) /\left(2 .{ }^{*}\right.$ radius ${ }^{\star}$ ldown

$1+$ radius $* 2$ )

ve $12=30.0$

re $=2$. radius *ve12* rhoamb/visair

nu $3=0.683 * \mathrm{re}^{\star *} 0.466^{\star} \mathrm{pr}^{\star *}(1 . / 3$.

hconv $3=x k a i r * n u 3 / 2 . /$ radius

if (hconv $2 b .1 t . h c o n v 3$ ) hconv $2 b=h$ conv 3

$h t c 2 b=h r a d+h c o n v 2 b$

$c$ Calculate changes in temperatures and concentrations in the liquid volumes

$c$ above and below the resin bed.

sy $21 a=0$.

sy $22 a=0$.

$\operatorname{scla}=0$.

$\operatorname{sc} 2 a=0$.

stem $1 a=s y 21 * 0.8 *$ qdot ${ }^{*} d t /$ rhcp $2 t$

stem $2 a=\operatorname{sy} 22^{*} 0.8 *$ qdot ${ }^{*} d t / \operatorname{rhcp} 2 b$

$i=1$

do while (i.le.n)

stemla=stem $1 a+(b z(1, i) * d z / 1 u p+v z m(1) * d t / 1 u p / d z)$

$1 *$ area (i) / areat* (temp $(2, i)-$ stem 1$)$

stem $2 a=s \operatorname{tem} 2 a+(b z(m, i) \star d z / 1 d o w n+v z m(m) \star d t / 1 d o w n / d z)$

1 *area (i) /areat* (temp (mm1,i)-stem2)

sy2la $=$ sy $2 l a+(b z y(1, i) \star d z / l u p+v z m(1) \star d t / l u p / d z)$

$I^{*}$ area (i)/areat* $(y 20 l d(2, i) / v f o-s y 21)$

sy $22 a=s y 22 a+(b z y(m, i) * d z / 1 d o w n+v z m(m) * d t / 1 d o w n / d z)$

1 *area (i)/areat* (y2old (mm1,i)/vfo-sy22)

$\operatorname{scla}=\operatorname{scla}+(b z c(1, i) * d z / 1 u p+v z m(1) * d t / 1 u p / d z)$

1 *area (i) /areat* $(\operatorname{cold}(2, i)-s c 1)$

$\operatorname{sc} 2 a=s c 2 a+(b z c(m, i) * d z / l$ down $+v z m(m) * d t / 1 d o w n / d z)$

$1^{\star}$ area $(i) /$ areat* $\{$ cold $\{\operatorname{mn} 1, i\}-\operatorname{sc} 2\}$

$i=i+1$

enddo

stem $1 a=s t e m 1 a+h t c 2 t *$ (radius * $2+2, * 1$ up radius $) / 1$ up $/$ radius $* * 2$

$1 \star d t / r h c p 2 t *(t a m b-s t e m 1)$

stem $2 \mathrm{a}=$ stem $2 \mathrm{a}+\mathrm{htc} 2 \mathrm{~b}^{*}$ (radius $* 2+2 .{ }^{*}$ ldown $*$ radius) / ldown/radius $* 2$

$1^{\star} \mathrm{dt} / \mathrm{rhcp} 2 \mathrm{~b}^{*}(\mathrm{tamb}-\mathrm{stem} 2)$

c Initialize changes in concentrations.

$j=1$

do while (j.le.m)

$i=1$

do while (i.le.n)

$d y 2 a(j, i)=0$.

$\operatorname{dca}(j, i)=0$.

$i=i+1$

enddo

$j=j+1$

enddo

$c$ Calculate temperature and concentration changes in middle of column.

$q=2$

do while (q.le.mml)

$\operatorname{phi}(q, n)=\operatorname{temp}(q, n)+f x(q, n) \star 0.8^{*} q \operatorname{dot}{ }^{\star} d t / r h c p(q, n)$

$\operatorname{phi}(q, n)=p h i(q, n)+b z(q, n) *\left(\operatorname{temp}(q+1, n)+\operatorname{temp}(q-1, n)-2 .{ }^{*} \operatorname{temp}(q, n)\right)$

$1+h t c^{\star} d t / \operatorname{rhcp}(q, n) *(1 . / d r+1 . / 2 . / \operatorname{rr} 1(n)) *(\operatorname{tamb}-\operatorname{temp}(q, n))$

$2+b r(q, n n 1) *(\operatorname{temp}(q, n n 1)-\operatorname{temp}(q, n))$

$3+2 . * \operatorname{br} 1(q, n) *(\operatorname{temp}(q, n)-\operatorname{temp}(q, n n 1))$

$4+v z m(q) * \operatorname{rhcp} 2(q, n) / \operatorname{rhcp}(q, n) \star d t / d z^{\star \star} 2^{\star}(\operatorname{temp}(q+1, n)+\operatorname{temp}(q-1, n)$

$\left.5-2 .{ }^{*} \operatorname{temp}(q, n)\right)$

dy $2 a(q, n)=d y 2 a(q, n)+b z y(q, n) / v f o^{*}(y 2 o l d(q+1, n)+y 2 o l d(q-1, n)$

$\left.1-2 .{ }^{*} \mathrm{y} 2 \mathrm{old}(\mathrm{q}, \mathrm{n})\right)$

$2+\operatorname{bry}(q, n n 1) / v_{0} *(y 2 o l d(q, n n 1)-y 2 o l d(q, n))$ 
$3+2{ }^{\star} \operatorname{bry} 1(q, n) / v f o^{*}(y 2 o l d(q, n)-y 2 o l d(q, n n 1))$

$4+v z m(q) / v f o * d t / d z * * 2 *\left(y 2 \circ l d(q+1, n)+y 2 \circ l d(q-1, n)-2{ }^{\star} y 2 \circ l d(q, n)\right)$

$\operatorname{dca}(q, n)=\operatorname{dca}(q, n)+\operatorname{an} 1 *(b z c(q, n) *(\operatorname{cold}(q+1, n)+\operatorname{cold}(q-1, n)$

$\left.1-2 .{ }^{*} \operatorname{col} d(q, n)\right)$

$2+\operatorname{brc}(q, n n 1) *(\operatorname{col} d(q, n n 1)-\operatorname{cold}(q, n))$

$3+2 \cdot{ }^{*} \operatorname{brcl}(q, n) *(\operatorname{col} d(q, n)-\operatorname{cold}(q, n n l))$

$\left.4+v z m(q) \star d t / d z * \star 2 *\left(\operatorname{cold}(q+1, n)+\operatorname{cold}(q-1, n)-2 .{ }^{*} \operatorname{col} \alpha(q, n)\right)\right)$

if $(v z(q, n) . g t .0$.$) then$

phi $(\mathrm{q}, \mathrm{n})=\operatorname{phi}(\mathrm{q}, \mathrm{n})-\mathrm{vz}(\mathrm{q}, \mathrm{n}) * d t / d z * \operatorname{rhcp} 2(\mathrm{q}, \mathrm{n}) / \operatorname{rhcp}(\mathrm{q}, \mathrm{n})$

1 * $(\operatorname{temp}(q, n)-\operatorname{temp}(q-1, n))$

dy $2 a(q, n)=d y 2 a(q, n)-v z(q, n) * d t / d z / v f o *(y 2 o l d(q, n)-y 2 o l d(q-1, n))$

$\operatorname{dca}(q, n)=\operatorname{dca}(q, n)-\operatorname{anl} 1^{*} v z(q, n) \star d t / d z^{\star}(\operatorname{cold}(q, n)-\operatorname{cold}(q-1, n))$

endif

if $(v z(q, n) . l t .0$.$) then$

$\operatorname{phi}(q, n)=p h i(q, n)-v z(q, n) * d t / d z * \operatorname{rhcp} 2(q, n) / \operatorname{rhcp}(q, n)$

$1 *(\operatorname{temp}(q+1, n)-\operatorname{temp}(q, n))$

dy2a $(q, n)=d y 2 a(q, n)-v z(q, n) * d t / d z / v f o *(y 2 o l d(q+1, n)-y 2 o l d(q, n))$

$\operatorname{dca}(q, n)=d c a(q, n)-\operatorname{anl} 1^{*} v z(q, n) \star d t / d z *(\operatorname{col} d(q+1, n)-\operatorname{cold}(q, n))$

endif

$q=q+1$

endio

$q=2$

do while (q.le.mm1)

$r=2$

do while (r.le.nnl)

$\operatorname{phi}(q, r)=\operatorname{temp}(q, r)+f x(q, r) \star 0.8^{\star} q d o t^{*} d t / r h c p(q, r)$

phi $(q, r)=p h i(q, r)+b z(q, r) *\left(\operatorname{temp}(q+1, r)+\operatorname{temp}(q-1, r)-2 \cdot{ }^{\star} \operatorname{temp}(q, r)\right)$

$1+\operatorname{br}(q, r-1) *(\operatorname{temp}(q, r-1)-\operatorname{temp}(q, r))$

$2+\operatorname{br}(q, r) *(\operatorname{temp}(q, r+1)-\operatorname{temp}(q, r))$

$3+\operatorname{br} l(q, r) *(\operatorname{temp}(q, r+1)-\operatorname{temp}(q, r-1))$

$4+\operatorname{vzm}(q) \star \operatorname{rhcp} 2(q, r) / r h c p(q, r) \star d t / d z^{\star \star} 2^{\star}(\operatorname{temp}(q+1, r)+\operatorname{temp}(q-1, r)$

5-2. * temp $(q, r))$

dy $2 a(q, r)=d y 2 a(q, r)+b z c(q, r) / v f o^{*}(y 2 o l d(q+1, r)+y 2 o l d(q-1, r)$

$\left.1-2 .{ }^{*} y 201 d(q, r)\right)$

$2+\operatorname{bry}(q, r-1) /$ vfo* $(y 2 o l d(q, r-1)-y 2 o l d(q, r))$

$3+\operatorname{bry}(q, r) / v f o *\left(y 2 o l d(q, r+1)-y^{2} \circ l d(q, r)\right)$

$4+\operatorname{bry} 1(q, r) / v f o *(y 2 o l d(q, r+1)-y 2 o l d(q, r-1))$

$5+v z m(q) / v f o * d t / d z * \star 2 *\left(y 2 \circ l d(q+1, r)+y 2 \circ l d(q-1, r)-2 .{ }^{*} y 2 o l d(q, x)\right)$

$\operatorname{dca}(q, r)=\operatorname{dca}(q, r)+\operatorname{an} 1 *(b z c(q, r) *(\operatorname{cold}(q+1, r)+\operatorname{cold}(q-1, r)$

$\left.1-2 .{ }^{*} \operatorname{col} d(q, r)\right)$

$2+\operatorname{brc}(q, r-1) *(\operatorname{cold}(q, r-1)-\operatorname{cold}(q, r))$

$3+\operatorname{brc}(q, r) *(\operatorname{cold}(q, r+1)-\operatorname{cold}(q, r))$

$4+\operatorname{brcl}(q, r) *(\operatorname{cold}(q, r+1)-\operatorname{cold}(q, r-1))$

$\left.5+\operatorname{vzm}(q) * d t / d z * \star 2 *\left(\operatorname{col} d(q+1, r)+\operatorname{col} d(q-1, r)-2 .{ }^{*} \operatorname{col} d(q, r)\right)\right)$

if $(v z(q, r) . g t .0$.$) then$

$\operatorname{phi}(q, r)=p h i(q, r)-v z(q, r) \star d t / d z * r h c p 2(q, r) / r h c p(q, r)$

$I^{*}(\operatorname{temp}(q, r)-\operatorname{temp}(q-1, r))$

$d y 2 a(q, r)=d y 2 a(q, r)-v z(q, r) \star d t / d z / v f o *(y 2 o l d(q, r)-y 2 o l d(q-1, r))$

$\operatorname{dca}(q, r)=\operatorname{dca}(q, r)-\operatorname{an} 1 * v z(q, r) * d t / d z *(\operatorname{col} d(q, r)-\operatorname{col} d(q-1, r))$

endif

if $(v z(q, r) .1 t, 0$.$) then$

$\operatorname{phi}(q, r)=\operatorname{phi}(q, r)-v z(q, r) \star d t / d z * r h c p 2(q, r) / r h c p(q, r)$

$1 *(\operatorname{temp}(q+1, r)-\operatorname{temp}(q, r))$

$\mathrm{dy} 2 \mathrm{a}(q, r)=\mathrm{dy} 2 \mathrm{a}(\mathrm{q}, r)-\mathrm{vz}(\mathrm{q}, \mathrm{r}) * \mathrm{dt} / \mathrm{dz} / \mathrm{vfo} *(\mathrm{y} 201 \mathrm{~d}(q+1, r)-\mathrm{y} 201 \mathrm{~d}(\mathrm{q}, \mathrm{r}))$

$\operatorname{dca}(q, r)=\operatorname{dca}(q, r)-\operatorname{an} 1 * v z(q, r) \star d t / d z *(\operatorname{cold}(q+1, r)-\operatorname{cold}(q, r))$

endif

if $(\operatorname{vr}(q, r) . g t .0$.$) then$

$\operatorname{phi}(q, r+1)=p h i(q, r+1)-v r(q, r) \star d t * a f 2(r)^{\star} \operatorname{rhcp} 2(q, r) / r h c p(q, r)$

$1 *(\operatorname{temp}(q, r+1)-\operatorname{temp}(q, r))$

$d y 2 a(q, r+1)=d y 2 a(q, r+1)-v r(q, r) * d t * a f 2(r) / v f o$

$1 *(y 201 d(q, r+1)-y 201 d(q, r))$

$\operatorname{dca}(q, r+1)=\operatorname{dca}(q, r+1)-\operatorname{an} 1 * \operatorname{vr}(q, r) * d t * a f 2(r)$

$1 *(\operatorname{col} \alpha(q, r+1)-\operatorname{col} \alpha(q, r))$ 
endif

if $(\operatorname{vr}(q, r) .1 t .0$.$) then$

$\operatorname{phi}(q, r-1)=\operatorname{phi}(q, r-1)-v r(q, x) \star d t^{\star} \operatorname{afl}(r) \star \operatorname{rhcp} 2(q, r) / \operatorname{rhcp}(q, r)$

1 * $(\operatorname{temp}(q, r)-\operatorname{temp}(q, r-1))$

dy $2 a(q, r-1)=d y 2 a(q, r-1)-v r(q, r) * d t * a f 1(r) / v$ fo

$1 *(y 20 l d(q, r)-y 201 d(q, r-1))$

$\operatorname{dca}(q, x-1)=\operatorname{dca}(q, r-1)-\operatorname{an} 1 * \operatorname{vr}(q, r) \star d t \star a f 1(r)$

$1 *(\operatorname{cold}(q, r)-\operatorname{col} d(q, r-1))$

endif

$r=r+1$

enddo

$\mathrm{q}=\mathrm{q}+1$

enddo

$j=1$

do while (j.le.m)

$i=1$

do while (i.le.n)

if $(y 20 l d(j, i)+d y 2 a(j, i) .1 t .0$.$) then$

$d y 2 a(j, i)=-y 201 d(j, i)$

endif

$i=i+1$

enddo

$j=j+1$

enddo

c Calculate changes in plutonium concentrations due to adsorption.

C This is accomplished by calling the subroutine crite to determine if the bulk

c solution is saturated with plutonium. If the solution is saturated, the

$c$ subroutine feeder is called to calculate the adsorption rate.

$q=2$

do while (q.le.mm1)

$r=2$

do while (r.le.n)

call crite $(q, r, m)$

$r=r+1$

enddo

$q=q+1$

enddo

C Calculate the amount of plutonium adsorbed by calling subroutine feeder. A

$c$ check is added to ensure that the rate of adsorption does not exceed the

c rate of mass transfer by convection and dispersion. If this should occur,

c numerical instabilities would result.

indk $=1$

ffac $=1$.

$k 2=1$

do while (k2.le.20.and.indk.eq.1)

$q=2$

do while (q.le.mml)

$r=2$

do while (r.le.n)

$\mathrm{dy} 2=d y 2 \mathrm{a}(\mathrm{q}, \mathrm{r})$

$\mathrm{dc}=\mathrm{dca}(\mathrm{q}, \mathrm{r})$

if $(\operatorname{ind} 3(q, r)$. eq.1) then

call feeder $(q, r, m, d y 2, d c, d f, f f a c)$

endif

$f(q, r)=f o l d(q, r)+d f$

$y^{2}(q, r)=y 2 o l d(q, r)+d y 2$

$c(q, r)=\operatorname{cold}(q, r)+d c$

$x(q, r)=\operatorname{xol} d(q, r)+d f / f$ feed

$r=r+1$

enddo

$q=q+1$

enddo

indk $=0$ 
$i=2$

do while (i.le.n)

$j=1$

do while $(j .1$ le.m-3)

if $\left(y^{2}(j, i) \cdot 1 t \cdot y^{2}(j+1, i)\right.$ and $y 2(j+1, i) \cdot g t \cdot y^{2}(j+2, i)$.and.

$\left.1 y^{2}(j+2, i) \cdot 1 t \cdot y 2(j+3, i)\right)$ ind $k=1$

if $\left(y 2(j, i) \cdot g t \cdot y 2(j+1, i)\right.$ and $y^{2}(j+1, i) \cdot l t \cdot y 2(j+2, i)$ and.

1y $2(j+2, i) \cdot g t \cdot y 2(j+3, i))$ ind $k=1$

if $(c(j, i) .1 t \cdot c(j+1, i)$. and $c(j+1, i) \cdot g t \cdot c(j+2, i)$. and.

$1 c(j+2, i) .1 t . c(j+3, i))$ ind $k=1$

if $(c(j, i) \cdot g t \cdot c(j+1, i)$. and $c(j+1, i) \cdot 1 t \cdot c(j+2, i)$. and.

$1 c(j+2, i) \cdot g t \cdot c(j+3, i))$ indk $=1$

$j=j+1$

enddo

$i=i+1$

enddo

if (indk.eq.1) ffac $=f f a c / 2$.

$k 2=k 2+1$

enddo

c Update conditions in liquid layers at top and bottom of resin bed.

stem $1=$ stem $1+$ stem 1 a

sy $21=$ sy $21+$ sy $21 a$

sc1 $1=\operatorname{sc} 1+\operatorname{scla}$

stem $2=$ stem $2+$ stem $2 \mathrm{a}$

sy $22=\operatorname{sy} 22+\operatorname{sy} 22 a$

$s c 2=s c 2+\operatorname{sc} 2 a$

c Specify symmetry condition at column center.

$j=1$

do while (j.le.m)

$\operatorname{phi}(j, 1)=\operatorname{phi}(j, 2)$

temp $(j, 1)=\operatorname{temp}(j, 2)$

$\operatorname{temc}(j, 1)=\operatorname{temc}(j, 2)$

$c(j, 1)=c(j, 2)$

$\operatorname{cold}(j, 1)=\operatorname{cold}(j, 2)$

$y 2(j, 1)=y^{2}(j, 2)$

$y 201 d(j, 1)=y 2 o l d(j, 2)$

$f(j, 1)=f(j, 2)$

fold $(j, 1)=f o l d(j, 2)$

$f x(j, 1)=f x(j, 2)$

$\operatorname{xold}(j, 1)=\operatorname{xold}(j, 2)$

$j=j+1$

enddo

c Specify top and bottom conditions.

$i=1$

do while (i.le.n)

$\operatorname{phi}(1, i)=$ stem 1

y $2(1, i)=s y 21 *$ vo

$c(1, i)=s c 1$

phi $(\mathrm{m}, \mathrm{i})=$ stem 2

$y 2(m, i)=s y 22^{\star}$ vfo

$c(m, i)=s c 2$

$i=i+1$

enddo

c Update temperatures and concentrations. Calculate densities and viscosities.

stem $1 \mathrm{c}=$ stem $1-273$.

stem2 $\mathrm{c}=$ stem $2-273$.

$\operatorname{den} 1 t=1.6603-1.9894 \mathrm{e}-3^{*}$ stem $1 c$

den $1 b=1.6603-1.9894 \mathrm{e}-3^{*}$ stem $2 \mathrm{c}$

den $2 t=0.99683-1.3010 e-4^{*}$ stem $1 c-2.4358 e-6^{\star}$ stem $1 c^{\star *} 2$

den $2 \mathrm{~b}=0.99683-1.3010 \mathrm{e}-4^{\star} \mathrm{s} \operatorname{ten} 2 \mathrm{c}-2.4358 \mathrm{e}-6^{\star} \mathrm{stem} 2 \mathrm{c}{ }^{\star}{ }^{*}$

$x \times 1 t=\operatorname{den} 1 t^{\star} \operatorname{sc} 1 /\left(\operatorname{den} 1 t^{\star} \operatorname{sc} 1+\operatorname{den} 2 t^{\star}(1 .-\operatorname{sc} 1)\right)$

$\mathrm{xx} 1 \mathrm{~b}=\operatorname{den} 1 \mathrm{~b}^{\star} \mathrm{sc} 2 /\left(\operatorname{den} 1 \mathrm{~b}^{\star} \mathrm{sc} 2+\operatorname{den} 2 \mathrm{~b}^{\star}(1,-\mathrm{sc} 2)\right)$

cno3t $=s c 1{ }^{\star} \operatorname{den} 1 t * 1000 . / 63 .-4 .{ }^{\star} \operatorname{sy} 21 * 1000 . / 238$. 
cno $3 b=s c 2 * \operatorname{den} 1 b \star 1000 . / 63 .-4 .{ }^{\star} s y 22 * 1000 . / 238$.

if (cno3t.lt.0.) cno3t $=0$.

if (cno3b.lt.0.) $c$ no $3 b=0$.

dens $t=\operatorname{den} 2 t+0.4277^{\star} \operatorname{sy} 21 * 1000 . / 238 .+0.031 * \operatorname{cno} 3 t$

dens $b=\operatorname{den} 2 b+0.4277 * s y 22 * 1000 . / 238 .+0.031 * \mathrm{cno} 3 b$

capst $=1.0104-(1.419-0.3 *($ stemlc -20.$) / 80) *. x \times 1 t$

$1+(2.005-0.6 *($ stem1c -20.$) / 80) *. x \times 1 t * \star 2$

$2-\left(1.147-0.3^{*}(\right.$ stem $\left.1 c-20) / 80.\right){ }^{*} x \times 1 t * \star 3$

capsb $=1.0104-\left(1.419-0.3^{*}(\right.$ stem $\left.2 c-20) / 80.\right) * x \times 1 b$

$1+(2.005-0.6 *($ stem $2 c-20) / 80) *. x \times 1 b * * 2$

$2-(1.147-0.3 *($ stem $2 c-20) / 80) *. x \times 1 b^{* *} 3$

rhcp $2 t=$ denst* capst

rhcp $2 b=$ densb* capsb

$\operatorname{tcn} 1 t=6.1388 e-4+1.3951 e-6^{*}$ stem $1 c$

$\operatorname{tcn} 2 t=1.3518 e-3+2.7903 e-6^{*}$ stem $1 c$

$\operatorname{tcn} 1 \mathrm{~b}=6.1388 \mathrm{e}-4+1.3951 \mathrm{e}-6^{\star}$ stem $2 \mathrm{c}$

$\operatorname{tcn} 2 b=1.3518 e-3+2.7903 e-6^{*} \operatorname{stem} 2 c$

tcnmt $=\operatorname{tcn} 1 t^{*} \times x 1 t+t \operatorname{cn} 2 t^{*}(1 .-x \times 1 t)$

$t c n m b=\operatorname{tcn} 1 b^{*} x \times 1 t+t \operatorname{cn} 2 b^{*}(1 .-x \times 1 t)$

vist $=0.01002 * 10 . * *((1.3272 *(20 .-$ stem $1 c)-0.001053 *$

$1($ stem $1 c-20.) \star \star 2) /($ stem $1 c+105)$.

visb $=0.01002 * 10 . \star *((1.3272 *(20 .-$ stem $2 c)-0.001053 *$

$1($ stem $2 c-20). * \star 2) /($ stem $2 c+105)$.

diffyt $=8.314 / 96500 * * 2 * \operatorname{stem} 1 *(1 . / 1 .+1 . / 3) /.(1 . / 69.5$

$1+1 . / 71.4)$

diffct $=8.314 / 96500^{\star *} 2^{\star} \operatorname{stem} 1 *(1 . / 1 .+1 . / 1) /.(1 . / 349.8$

$1+1 . / 71.4)$

diffyb $=8.314 / 96500 * 2 * \operatorname{sten} 2 *(1 . / 1 .+1 . / 3) /.(1 . / 69.5$

$1+1 . / 71.4)$

diff $\mathrm{cb}=8.314 / 96500 * * 2 *$ stem $2 *(1 . / 1 .+1 . / 1) /.(1 . / 349.8$

$1+1 . / 71.4)$

$i=1$

do while (i.le.n)

$j=1$

do while $(j .1 \mathrm{e} . \mathrm{m})$

$\operatorname{temp}(j, i)=\operatorname{ph} i(j, i)$

if (iht.eq. 2 and. $i . e q . n)$ temp $(j, i)=$ tamb

$\operatorname{temc}(j, i)=\operatorname{phi}(j, i)-273.0$

if (iht.eq. 2 .and. $i . e q . n$ ) temc $(j, i)=$ tamb-273.0

$\operatorname{cold}(j, i)=c(j, i)$

fold $(j, i)=f(j, i)$

$y 20 l d(j, i)=y 2(j, i)$

$f x(j, i)=f(j, i)+y 2(j, i)$

$x o l d(j, i)=x(j, i)$

$\operatorname{den} 1(j, i)=1.6603-1.9894 \mathrm{e}-3 * \operatorname{tenc}(j, i)$

$\operatorname{den} 2(j, i)=0.99683-1.3010 e-4^{*} \operatorname{temc}(j, i)-2.4358 e-6^{*} \operatorname{tenc}(j, i) * * 2$

$x \times 1=\operatorname{den} 1(j, i){ }^{*} c(j, i) /(\operatorname{den} 1(j, i) * c(j, i)+\operatorname{den} 2(j, i) *(1 .-c(j, i)))$

$c n o 3=c(j, i) * \operatorname{den} 1(j, i) \star 1000 . / 63 .-4 . * y 2(j, i) * 1000 . / 238$. /vfo

if $(\mathrm{cno} .1 \mathrm{t} .0.) \quad \mathrm{cno} 3=0$.

dens $(j, i)=\operatorname{den} 2(j, i)+0.4277 * y 2(j, i) * 1000 . / 238 . / \mathrm{vfo}+0.031 * \mathrm{cno} 3$

$\operatorname{tcn} 1=6.1388 e-4+1.3951 e-6 * \operatorname{temc}(j, i)$

$\operatorname{tcn} 2=1.3518 \mathrm{e}-3+2.7903 e-6 *$ temc $(j, i)$

$\operatorname{tcnm}(j, i)=\tan 1{ }^{\star} \times x 1+\operatorname{tcn} 2 \star(1 .-x \times 1)$

$\operatorname{tcnm}(j, i)=0.5^{\star}(\operatorname{tcnm}(j, i)+5 . e-4)$

caps $=1.0104-(1.419-0.3 *(\operatorname{temc}(j, i)-20) / 80) * x \times$.

$1+\left(2.005-0.6^{*}(\right.$ temc $\left.(j, i)-20) / 80.\right) * x \times 1 * \star 2$

$2-\left(1.147-0.3^{*}(\right.$ temc $\left.(j, i)-20) / 80.\right) * x \times 1 * * 3$

$\operatorname{rhcp}(j, i)=0.5 * 1.25^{\star} 0.52+0.5^{\star}$ dens $(j, i)^{\star} \mathrm{caps}$

$\operatorname{rhcp} 2(j, i)=\operatorname{dens}(j, i) *$ caps

$\operatorname{vis}(j, i)=0.01002^{\star} 10{ }^{\star \star}\left(\left(1.3272^{\star}(20 .-\operatorname{temc}(j, i))-0.001053^{\star}\right.\right.$

$1(\operatorname{temc}(j, i)-20.) \star * 2) /(\operatorname{temc}(j, i)+105)$.

alpha $(j, i)=\operatorname{tanm}(j, i) / \operatorname{rhcp}(j, i)$

$\operatorname{diff} Y(j, i)=8.314 / 96500 * * 2 * \operatorname{temp}(j, i) *(1 . / 1 .+1 . / 3) /.(1 . / 69.5$ 


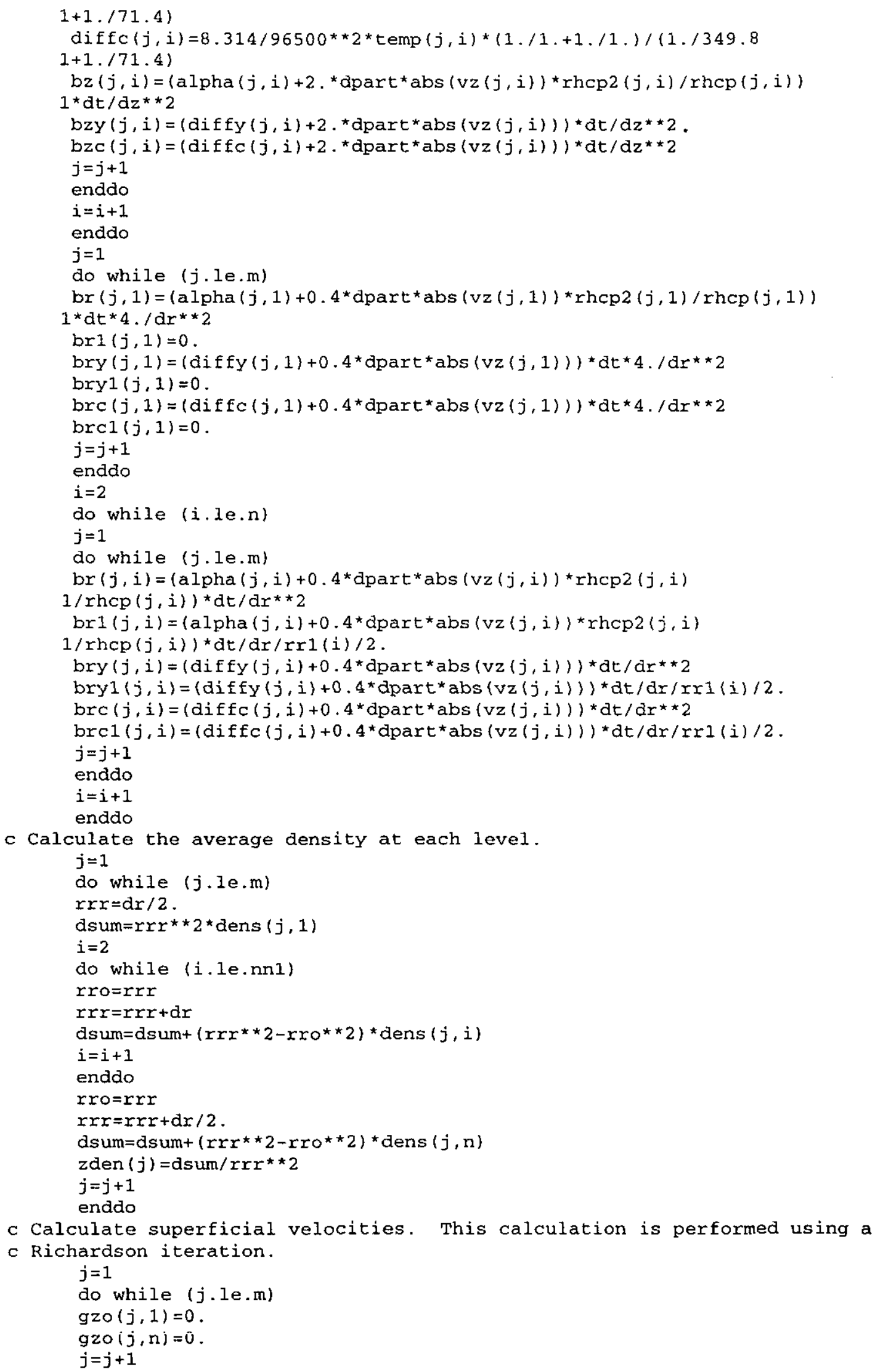




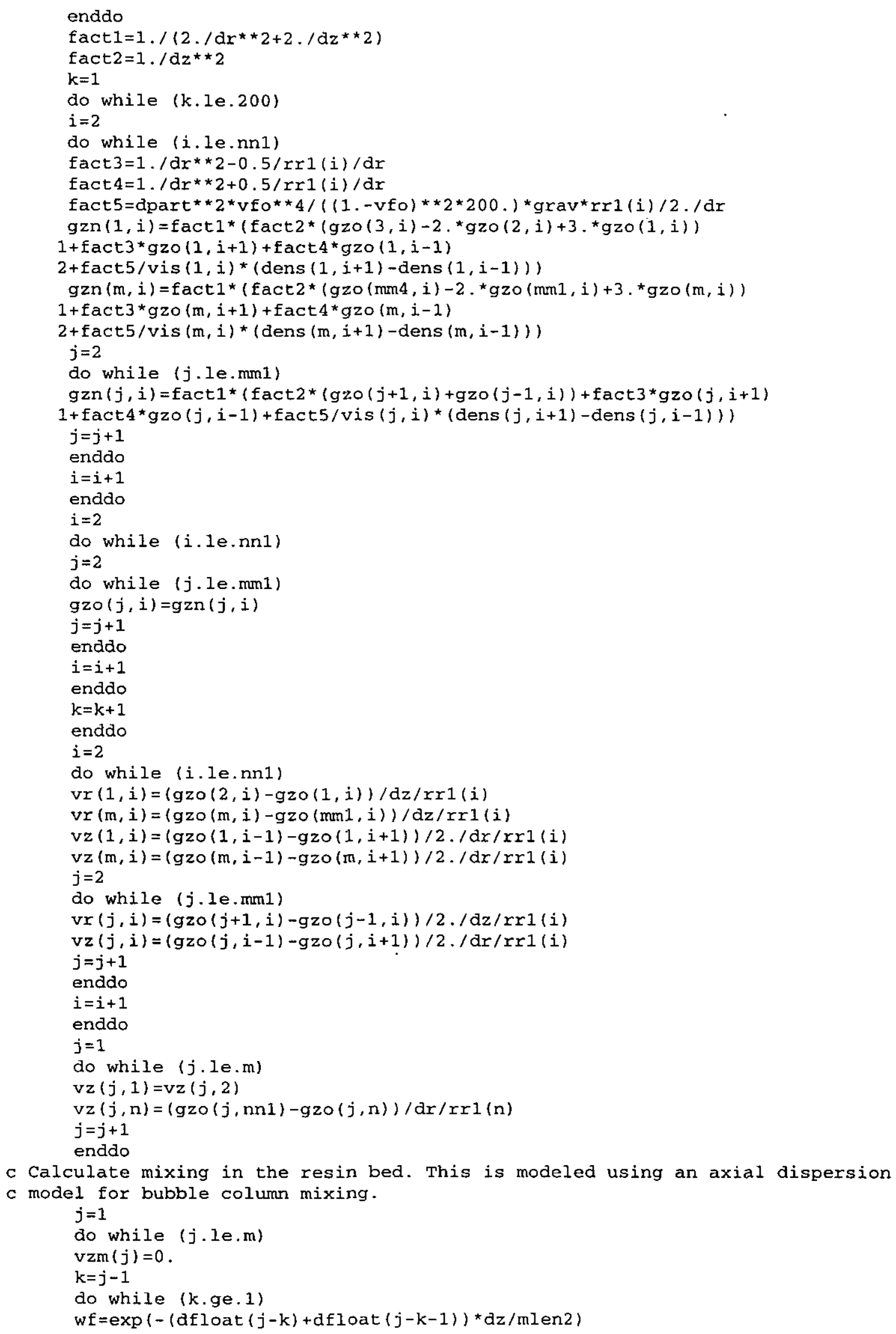


if $(z \operatorname{den}(k) \cdot g t \cdot z \operatorname{den}(j))$ then

$\operatorname{vzm}(j)=\operatorname{vzm}(j)+d$ part $* \star 2 * v f o * * 4 /\left((1,-v f o) * \star 2 * 400 .{ }^{*} \operatorname{vis}(k, 1)\right)$

$1 *(z \operatorname{den}(k)-z \operatorname{den}(j)){ }^{*} \operatorname{grav}^{\star} \mathrm{mlen}{ }^{\star} w \mathrm{w}$

endif

$k=k-1$

endido

$k=j+1$

do while (k.le.m)

$w f=\exp (-(d f l o a t(k-j)+d f l o a t(k-j-1)) * d z /$ mlen 2$)$

if (zden $(k) .1 t . z \operatorname{den}(j))$ then

$\operatorname{vzm}(j)=\operatorname{vzm}(j)+\operatorname{dpart}{ }^{\star} 2^{*} \operatorname{vfo} 0^{\star} 4 /\left((1 .-\operatorname{vfo}) \star * 2 * 400 .{ }^{*} \operatorname{vis}(k, 1)\right)$

$1^{\star}(\operatorname{zden}(j)-z \operatorname{den}(k)){ }^{\star} \operatorname{grav}^{\star} m l e{ }^{\star} w f$

endif

$\mathrm{k}=\mathrm{k}+1$

enddo

$j=j+1$

enddo

c Calculate total amounts of plutonium and plutonium adsorbed. Renormalize to

c ensure that the total amount of plutonium is conserved.

pua $=0$.

puf=areat * $\left(1\right.$ up $^{*}$ sy $21+1$ down* sy22)

pusn=areat* (1up*sy21+1down* sy22)

$i=1$

do while (i.le.n)

pua $=$ pua $+0.5^{\star} d z^{\star}$ area $(i) *(f(1, i)+f(m, i))$

puf $=$ puf $+0.5^{\star} d z^{*}$ area $(i) *(f x(1, i)+f x(m, i))$

pusn=pusn $+0 \cdot 5^{\star} d z^{*}$ area $(i) *(y 2(1, i)+y 2(m, i))$

$i=i+1$

enddo

$j=2$

do while (j.le.mml)

$i=1$

do while (i.le.n)

pua $=$ pua $+d z^{\star} f(j, i) *$ area $(i)$

puf $=p u f+d z * f x(j, i) *$ area $(i)$

pusn $=$ pusn $+d z * y 2(j, i) * a r e a(i)$

$i=i+1$

enddo

$j=j+1$

enddo

fpu $=($ pusno-pua + puao $) /$ pusn

sy $21=$ sy 21 * fpu

sy $22=$ sy 22 * fpu

$i=1$

do while (i.le.n)

$j=1$

do while (j.le.m)

$y 201 d(j, i)=y 201 d(j, i) \star E p u$

$y 2(j, i)=y 2(j, i) * \mathrm{fpu}$

$j=j+1$

enddo

$i=i+1$

enddo

c Write transient temperatures and velocities to output files.

time2 $=t i m e 2+d t$

time $=$ time2 $/ 60$.

if (abs (nint (time/30.)-time/30.).lt.dt/2./1800.) then

c Write headers for output files.

write $\left(1,{ }^{*}\right)$ 'TIME (MIN)', tab, 'POS (CM)', tab, 'LOAD', tab,

1 'TCEN $\left({ }^{\circ} \mathrm{C}\right) \cdot$, tab, 'TMID $\left({ }^{\circ} \mathrm{C}\right) '$, tab, 'TOUT $\left({ }^{\circ} \mathrm{C}\right)$ '

write $\left(6,{ }^{*}\right)$ 'TIME (MIN)', tab, 'LENGYH (CM)', tab, 'ELU (VF)', tab,

1 'ADS (G/CC)', tab, 'LIQ (G/CC)', tab, 'TOT (G/CC)'

write $\left(10,{ }^{*}\right)$ 'TIME (MIN)', tab, 'LENGTH (CM)', tab, 'IND', tab, 
1 'VFA', tab, 'VFAM'

$j=1$

write $(1,102)$ time,tab, 1 , tab, 0, tab, stem $1 c$, tab, stem $1 c$,

1 tab, stem $1 \mathrm{c}$

do while (j.le.m)

poszn=length* $(j-1) /(m-1)$

write $(1,102)$ time, tab, poszn, tab, $f(j, 1), t a b, t e m c(j, 1), t a b$,

1 temc $(j, 5), t a b, \operatorname{temc}(j, n)$

102 format ( $f 9.4, a 1, £ 10.5, a 1, f 7.5,3(a 1, f 9.4)$ )

write $(6,400)$ time, tab, poszn, tab, $c(j, 1), t a b, f(j, 1), t a b, y 2(j, 1)$,

$1 t a b, f \times(j, 1)$

400 format ( $\mathrm{f} 9.4, \mathrm{a} 1, \mathrm{f} 10.5,4$ (a1, $\mathrm{f9} .5$ ))

write $(10,500)$ time, tab, poszn, tab, $\operatorname{ind} 3(j, 1)$, tab,

$1 y 2(j, 1), t a b, y 2 \max (j, i), t a b, \operatorname{cmx} 2(j, 1)$

500 format $(\mathrm{fg}, 4, \mathrm{a} 1, \mathrm{f} 10.5, \mathrm{a} 1, \mathrm{i} 2,3(\mathrm{a} 1, \mathrm{fg} .5)$ )

$j=j+1$

enddo

write $(1,102)$ time, tab, -2, tab, 0, tab, stem $2 c, t a b, s t e m 2 c, t a b$,

$1 \mathrm{stem} 2 \mathrm{c}$

endif

C Find highest temperature.

temch $=0$.

$j=1$

do while (j.le.m)

$i=1$

do while (i.le.n)

if (temch.lt.temc $(j, i)$ ) then

temch $=\operatorname{temc}(j, i)$

endif

$i=i+1$

enddo

$j=j+1$

enddo

if (abs (nint (time/2.)-time/2.).lt.dt/4./60.)

lwrite $(2,301)$ time, tab, temch, tab, pua, tab, puf

301 format ( $\mathrm{f} 11.4, \mathrm{a} 1, \mathrm{f} 10.5, \mathrm{a} 1, \mathrm{f} 11.5, \mathrm{al}, \mathrm{f} 11.5$ )

c Increment transient calculation loop.

$s=s+1$

enda

c Write temperature profile to output file.

write $\left(7,{ }^{\star}\right)$ stemlc

write $\left(7,{ }^{*}\right)$ stem $2 \mathrm{c}$

$j=m$

do while (j.ge.1)

$i=\mathrm{n}$

do while (i.ge.1)

write $(7, *)$ temc $(j, i)$

$i=i-1$

enddo

$i=2$

do while (i.le.n)

write $\left(7,{ }^{*}\right)$ temc $(j, i)$

$i=j+1$

endao

$j=j-1$

endio

c Write total plutonium concentrations to output file.

write $\left(21,{ }^{\star}\right) 1000 .{ }^{\star}$ sy 21

write $\left(21,{ }^{\star}\right) 1000{ }^{\star}$ sy 22

$j=m$

do while (j.ge.1)

$\mathrm{i}=\mathrm{n}$

do while (i.ge.1) 
write $\left(21,{ }^{\star}\right) 1000{ }^{\star} \operatorname{Ex}(j, i)$

$i=i-1$

enddo

$i=2$

do while (i.le.n)

write $\left(21,{ }^{*}\right) 1000 *{ }^{*} \mathrm{Ex}(j, i)$

$i=i+1$

enddo

$j=j-1$

enddo

c Write solution plutonium concentrations to output file.

write $\left(22,{ }^{\star}\right) 1000,{ }^{\star}$ sy 21

write $\left(22,{ }^{\star}\right)$ 1000. ${ }^{\star}$ sy 22

$j=m$

do while (j.ge.1)

$i=\mathrm{n}$

do while (i.ge.1)

write $\left(22,{ }^{*}\right) 1000,{ }^{*} y 2(j, i)$

$i=i-1$

enddo

$i=2$

do while (i.le.n)

write $(22, *) 1000 \cdot{ }^{*} y 2(j, i)$

$i=i+1$

enddo

$j=j-1$

enddo

c Write densities to output file.

write $\left(23,{ }^{*}\right)$ denst

write $\left(23,{ }^{\star}\right)$ densb

$j=\mathrm{m}$

do while (j.ge.1)

$i=n$

do while (i.ge.I)

write $\left(23,{ }^{*}\right)$ dens $(j, i)$

$i=i-1$

enddo

$i=2$

do while (i.le.n)

write $\left(23,{ }^{*}\right) \operatorname{dens}(j, i)$

$i=i+1$

enddo

$j=j-1$

enddo

c Write axial velocities to output file.

$j=m$

do while (j.ge.1)

$i=n$

do while (i.ge.1)

write $\left(16,{ }^{*}\right) 10000 .{ }^{*} \mathrm{vz}(j, i)$

$i=i-1$

enddo

$i=2$

do while (i.le.n)

write $\left(16,{ }^{*}\right) 10000{ }^{\star} \mathrm{vz}(j, i)$

$i=i+1$

enddo

$j=j-1$

enddo

c Write radial velocities to output file.

$j=m$

do while (j.ge.1)

$i=n$ 
do while (i.ge.1)

write $\left(15,{ }^{\star}\right) 10000{ }^{*} \operatorname{vr}(j, i)$

$i=i-1$

endao

$i=2$

do while (i.le.n)

write $\left(15,{ }^{*}\right) 10000{ }^{*} \operatorname{VI}(j, i)$

$i=i+1$

enddo

$j=j-1$

enddo

$c$ Write modified stream function profile to output file. The stream function

$c$ is modified by multiplying by the radius. This modified function gives a

c profile of the velocity multiplied by the radius.

$$
j=m
$$

do while (j.ge.1)

$i=n$

do while (i.ge.1)

write $\left(17,{ }^{*}\right) 10000,{ }^{\star} \mathrm{gzo}(j, i)$

$i=i-1$

enddo

$i=2$

do while (i.le.n)

write $\left(17,{ }^{\star}\right) 10000,{ }^{\star} \mathrm{gzo}(j, i)$

$i=i+1$

enddo

$j=j-1$

enddo

stop

end

subroutine feeder $(j, i, m, d y 2, d c, d f, f f a c)$

$c$ compute changes in the plutonium concentrations during feeding or washing. implicit double precision $(\mathrm{a}-\mathrm{z})$

integer $i, j, m$, ind, ind 3

dimension $c(200,100), \operatorname{cold}(200,100), f(200,100)$, fold $(200,100)$,

$1 \mathrm{x}(200,100), \mathrm{xold}(200,100), y 2(200,100), y 201 d(200,100)$,

$2 \operatorname{den} 1(200,100), \operatorname{ind} 3(200,100), \operatorname{cmx} 2(200,100)$,

$3 \mathrm{y} 2 \max (200,100)$

common /elut1/c, cold, f, fold, $x$, xold, y2, y2old, den 1 .

$2 y 2 \max , y 2 \max 2, \operatorname{cmax} 2$, ind $3, \mathrm{cmx} 2, \mathrm{cfeed}, \mathrm{dt}, \mathrm{tau}, \mathrm{tau} 2$, ffeed, an 1 ,

3 dpart, dz, xg,vfi2, vfo, ind

if $(\operatorname{xold}(j, i) .1 t .1$.$) then$

if $(\operatorname{xold}(j, i) \cdot g t \cdot 1 \cdot d-3)$

$1 x t e=x o l d(j, i)+d t / \operatorname{tau} \star x o l d(j, i) * \star 2 /(\log ((1,+\operatorname{xold}(j, i)) /$

$\left.2(1 .-\operatorname{xold}(j, i)))-2 .{ }^{*} \operatorname{xold}(j, i)\right)$

if $(\operatorname{xold}(j, i) \cdot 1 \mathrm{e} \cdot 1 \cdot d-3$.and. $\operatorname{xold}(j, i) \cdot g t \cdot 1 \cdot d-8)$

$1 x t e=\operatorname{xold}(j, i)+d t / t^{*}{ }^{*} 1.5 / \operatorname{xol} d(j, i)$

if (xte.gt.1.) xte=1.

if (xte.lt.xold $(j, i)$ ) $x$ te $=\operatorname{xold}(j, i)$

df $=f f e e d *(x t e-x o l d(j, i))$

endif

if $(\operatorname{xold}(j, i) . g e .1$.$) then$

$\mathrm{d} f=0$.

endif

$\mathrm{df}=\mathrm{f} f \mathrm{ac}{ }^{\star} \mathrm{df}$

$d y 2=d y 2-d f$

if $\left(y^{2}(j, i)+d y 2.1 t .0.\right)$ then

$\mathrm{dy} 2=-\mathrm{y} 2(j, i)$

$d f=d y^{2}+y 2(j, i)$

endif

$\mathrm{dc}=\mathrm{dc}+4 .{ }^{\star} \mathrm{dy} 22^{*} 63 . / 238 . / \mathrm{vfo} / \mathrm{den} 1(j, i)$

if $(\operatorname{cold}(j, i)+d c .1 t .0) d c=.-\operatorname{cold}(j, i)$ 
return

end

subroutine crite $(j, i, m)$

$c$ Determine if solution is saturated with plutonium.

implicit double precision $(a-z)$

integer $i, j, m$, ind, ind 3

dimension $c(200,100), \operatorname{cold}(200,100), £(200,100)$, fold $(200,100)$,

$1 \mathrm{x}(200,100), \mathrm{xold}(200,100), \mathrm{y} 2(200,100), y 201 \mathrm{~d}(200,100)$,

$2 \operatorname{den} 1(200,100)$, ind3 $(200,100), \operatorname{cm} x 2(200,100)$

$3 y 2 \max (200,100)$

common /elut1/c, cold, f, fold, $x, x o l d, y 2, y 2 o l d$, den 1 ,

$2 y 2 \max , y 2 \max 2, \mathrm{cmax} 2$, ind $3, \mathrm{cmx} 2, \mathrm{cfeed}, \mathrm{dt}, \mathrm{tau}, \mathrm{tau} 2, \mathrm{ffeed}, \mathrm{an} 1$,

3 dpart, dz, xg,vfi2, vfo, ind

$\operatorname{cno} 3=\operatorname{cold}(j, i) * 1000 . / 63 .{ }^{*} \operatorname{den} 1(j, i)$

cpu $=y 201 d(j, i) * 1000 . / 238 . /$ vfo

сpu2 $=0$.

if $(\mathrm{cno} 3 . \mathrm{le} . \mathrm{cmax} 2)$ then

cpu $2=y 2 \max 2$

else

aa $=1$.

$k=1$

do while (k.le.8)

$a a=a a-\left(2.9 * a a * * 3 *(1 .-a a) * \operatorname{cno} 3-2.9 * * 4 * 0.26^{\star}(1 .-a a) \star \star 4-a a^{\star \star} 4\right)$

$1 /\left(3 . * 2.9 * a a^{\star \star} * 2 *(1 .-a a) * \operatorname{cno} 3-2.9 * a a * * 3 * \operatorname{cno} 3\right.$

$\left.2+4 .{ }^{\star} 2.9 * \star 4 * 0.26 *(1 .-\mathrm{aa}) \star \star 3-4 .{ }^{\star} \mathrm{a} a * \star 3\right)$

$\mathrm{k}=\mathrm{k}+1$

enddo

cpu $2=$ cno $3 / a a-1 . / 2 \cdot 9 /(1 .-a a)$

endif

$y 2 \max (j, i)=v f o 0^{\star} 0.238^{\star} \mathrm{cpu} 2$

if (cpu.ge.cpu2) then

$\operatorname{ind} 3(j, i)=1$

else

ind $3(j, i)=0$

endif

$a b=1$.

if (cpu.gt.1.d-8) then

$k=1$

do while (k.le.5)

$\mathrm{ab}=\left(1 / 3{ }^{*} \mathrm{ab}^{\star \star}(4 . / 3.){ }^{*} \mathrm{Cpu}{ }^{*}(1 . / 3)+.0.26 * *(1 . / 3) * 2.9.\right) /$

$1\left(4 . / 3 .{ }^{\star} \mathrm{ab}^{\star \star}(1 . / 3.){ }^{*} \mathrm{cpu} * *(1 . / 3)+.0.26^{\star \star}(1 . / 3) * 2.9.\right)$

$\mathrm{k}=\mathrm{k}+1$

enddo

endif

if $(1,-a b \cdot g t \cdot 1 \cdot d-8)$

$1 \mathrm{cno} 32=a b^{\star} \mathrm{cpu}+\mathrm{ab} / 2.9 /(1 .-\mathrm{ab})$

if (cno32.gt. cmax2. and.cpu.gt.y2max2) $\operatorname{cno} 32=\mathrm{cmax} 2$ $\operatorname{cmx} 2(j, i)=1 .-\operatorname{cno} 3 / \operatorname{cno} 32$

if $(\mathrm{cmx} 2(j, i) .1 t .0.) \quad \mathrm{cm} 2(j, i)=0$.

if $(\operatorname{cmx} 2(j, i) . g t .1.) \quad \operatorname{cm} 2(j, i)=1$.

return

end

\section{Sample Input Listing for Thermal Analysis during a Flow Stoppage}

25.

1.

34.1

2.54

2.54 
3.73

0.04

0.0000012

0.0000012

0.33

0.05

0.13384

0.274

48,24

0

56

1.0

1.0

36000

36000

Sample Output Listing for Thermal Analysis during a Flow Stoppage

TIME (MIN)
0.0000
2.0000
4.0000
6.0000
8.0000
10.0000
12.0000
14.0000
16.0000
18.0000
20.0000
22.0000
24.0000
26.0000
28.0000
30.0000
32.0000
34.0000
36.0000
38.0000
40.0000
42.0000
44.0000
46.0000
48.0000
50.0000
52.0000
54.0000
56.0000
58.0000
60.0000
62.0000
64.0000
66.0000
68.0000
70.0000
72.0000
74.0000
76.0000
78.0000
80.0000
82.0000

TMAX $\left.{ }^{\circ} \mathrm{C}\right)$
25.22047
26.93949
28.46193
29.86569
31.28179
32.68002
34.04205
35.36350
36.65562
37.89207
39.08942
40.23867
41.32405
42.37786
43.37710
44.31755
45.20343
46.06065
46.86528
47.61947
48.32548
48.98560
49.60221
50.19265
50.74232
51.25312
51.72684
52.16518
52.56972
52.94194
53.28325
53.59492
53.87821
54.13431
54.36438
54.56974
54.75289
54.91620
55.07611
55.22506
55.35980
55.48226

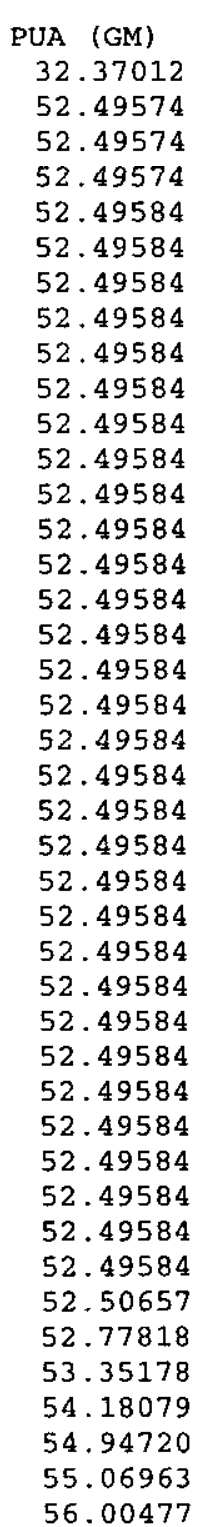

PUT (GM) 92.77193 92.77060 92.77031 92.77018 92.77034 92.77021 92.77013 92.77006 92.76999 92.76994 92.76988 92.76983 92.76979 92.76975 92.76970 92.76967 92.76963 92.76960 92.76956 92.76953 92.76950 92.76947 92.76944 92.76941 92.76938 92.76935 92.76932 92.76929 92.76925 92.76921 $92: 76916$ 92.76911 92.76905 92.76899 92.76891 92.77111 92.77528 92.77915 92.77872 92.77121 92.77535 92.77889 

84.0000
86.0000
88.0000
90.0000
92.0000
94.0000
96.0000
98.0000
100.0000
102.0000
104.0000
106.0000
108.0000
110.0000
112.0000
114.0000
116.0000
118.0000
120.0000
122.0000
124.0000
126.0000
128.0000
130.0000
132.0000
134.0000
136.0000
138.0000
140.0000
142.0000
144.0000
146.0000
148.0000
150.0000
152.0000
154.0000
156.0000
158.0000
160.0000
162.0000
164.0000
166.0000
168.0000
170.0000
172.0000
174.0000
176.0000
178.0000
180.0000
182.0000
184.0000
186.0000
188.0000
190.0000
192.0000
194.0000
196.0000
198.0000
200.0000
202.0000
204.0000
206.0000
208.0000

55.59502

55.70022

55.79999

55.89599

55.98986

56.08296

56.18058

56. 28321

56.37576

56.45868

56.53382

56.60308

56.66752

56.72871

56.78715

56.84271

56.89453

56.94245

56.98685

57.02833

57.07485

57.12701

57.17706

57.22449

57.26885

57.30976

57.34691

57.38007

57.40907

57.43374

57.45418

57.47221

57.50065

57.52513

57.54589

57.56310

57.57700

57.58789

57.59607

57.60179

57.60531

57.60684

57.61338

57.62201

57.62887

57.63411

57.63785

57.64022

57.64134

57.64131

57.64022

57.63816

57.63522

57.63370

57.63642

57.63826

57.63929

57.63958

57.63918

57.63814

57.63650

57.63431

57.63161
56.97047

58.04878

59.11180

60.11682

61.15192

62.01746

62.24486

62.79764

62.79794

62.79827

62.89013

63.24992

63.75953

64.34706

64.99140

65.61835

65.73035

65.73035

65.73044

65.88174

66.18198

66.49636

66.82122

67.15398

67.47528

67.82819

68.18432

68.53554

68.89245

69.00623

69.17869

69.35574

69.53382

69.70978

69.88289

69.91868

69.91882

69.92985

69.92999

69.93014

69.93028

69.94465

69.98084

70.00483

70.02252

70.04470

70.04484

70.06215

70.06229

70.07895

70.10754

70.13509

70.15646

70.17413

70.19333

70.21095

70.22822

70.23483

70.25028

70.25861

70.26763

70.28337

70.30200
92.77800

92.77972

92.77893

92.77780

92.77700

92.77119

92.77112

92.77110

92.77104

92.77099

92.77522

92.77102

92.77515

92.77488

92.77465

92.77118

92.77019

92.76997

92.77122

92.77423

92.77272

92.77272

92.77393

92.77268

92.77380

92.77365

92.77355

92.77350

92.77339

92.77239

92.77236

92.77234

92.77232

92.77291

92.77226

92.77167

92.77167

92.77168

92.77168

92.77168

92.77169

92.77169

92.77171

92.77172

92.77173

92.77172

92.77173

92.77174

92.77175

92.77177

92.77178

92.77179

92.77180

92.77181

92.77183

92.77184

92.77185

92.77186

92.77187

92.77188

92.77189

$92 . \% 1190$

92.77190 
WSRC-TR-99-00027

Revision 0

210.0000

212.0000

214.0000

216.0000

218.0000

220.0000

222.0000

224.0000

226.0000

228.0000

230.0000

232.0000

234.0000

236.0000

238.0000

240.0000

242.0000

244.0000

246.0000

248.0000

250.0000

252.0000

254.0000

256.0000

258.0000

260.0000

262.0000

264.0000

266.0000

268.0000

270.0000

272.0000

274.0000

276.0000

278.0000

280.0000

282.0000

284.0000

286.0000

288.0000

290.0000

292.0000

294.0000

296.0000

298.0000

300.0000

302.0000

304.0000

306.0000

308.0000

310.0000

312.0000

314.0000

316.0000

318.0000

320.0000

322.0000

324.0000

326.0000

328.0000

330.0000

332.0000

334.0000
57.62841

57.62475

57.62352

57.62399

57.62391

57.62331

57.62221

57.62064

57.61860

57.61612

57.61323

57.60993

57.60625

57.60220

57.59782

57.59536

57.59334

57.59092

57.58815

57.58503

57.58162

57.57792

57.57398

57.56981

57.56546

57.56095

57.55630

57.55155

57.54673

57.54187

57.53757

57.53473

57.53188

57.52900

57.52606

57.52308

57.52007

57.51702

57.51394

57.51085

57.50774

57.50462

57.50150

57.49841

57.49652

57.49536

57.49427

57.49326

57.49234

57.49154

57.49086

57.49033

57.49019

57.49182

57.49360

57.49553

57.49762

57.49988

57.50332

57.50765

57.51211

57.51671

57.52243
70.31383

70.31397

70.31410

70.31423

70.31436

70.31450

70.31463

70.31476

70.31489

70.31503

70.31516

70.32303

70.32470

70.35917

70.36313

70.36642

70.40199

70.40212

70.40225

70.40238

70.40251

70.43023

70.43652

70.44252

70.44831

70.45388

70.45931

70.50665

70.51685

70.52716

70.52883

70.52896

70.52909

70.52921

70.52934

70.52947

70.52959

70.52972

70.52985

70.52997

70.53010

70.53023

70.53036

70.53048

70.53212

70.53306

70.53390

70.53462

70.53525

70.53557

70.53570

70.53583

70.53596

70.53665

70.53677

70.53690

70.53703

70.53715

70.53728

70.53741

70.53753

70.53766

70.53779
92.77191

92.77192

92.77192

92.77193

92.77193

92.77193

92.77194

92.77194

92.77194

92.77194

92.77193

92.77193

92.77193

92.77191

92.77191

92.77191

92.77189

92.77189

92.77189

92.77189

92.77189

92.77188

92.77188

92.77187

92.77187

92.77187

92.77186

92.77185

92.77184

92.77184

92.77184

92.77184

92.77184

92.77184

92.77184

92.77184

92.77184

92.77184

92.77184

92.77183

92.77183

92.77183

92.77183

92.77183

92.77182

92.77182

92.77182

92.77182

92.77182

92.77181

92.77181

92.77181

92.77181

92.77181

92.77181

92.77181

92.77181

92.77180

92.77180

92.77180

92.77180

92.77180

92.77180 
WSRC-TR-99-00027

Revision 0

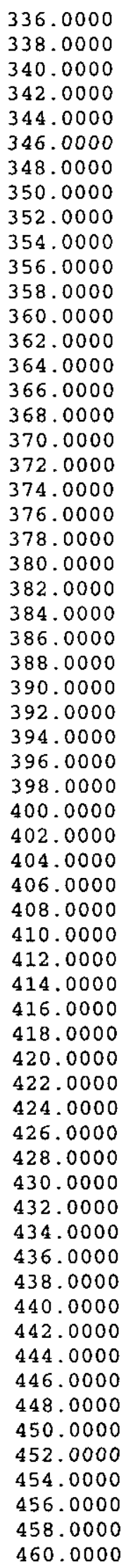

57.52889

57.53545

57.54289

57.55110

57.55936

57.56892

57.57863

57.58882

57.59985

57.61083

57.62252

57.63467

57.64674

57.65905

57.67219

57.68521

57.69813

57.71093

57.72469

57.73842

57.75202

57.76549

57.77883

57.79204

57.80587

57.81985

57.83368

57.84735

57.86088

57.87426

57.88750

57.90059

57.91354

57.92636

57.93939

57.95270

57.96585

57.97884

57.99168

58.00436

58.01689

58.02927

58. 04151

58.05359

58.06554

58.07734

58.08901

58.10054

58.11194

58.12320

58.13434

58.14535

58.15623

58.16699

58.17762

58.18813

58.19853

58.20880

58.21896

58.22900

58.23897

58.24907

58.25906
70.53792

70.53804

70.53817

70.53830

70.53842

70.53855

70.53868

70.53880

70.54088

70.54525

70.54621

70.54633

70.54646

70.54659

70.54671

70.54684

70.54697

70.54709

70.54722

70.54735

70.54747

70.54760

70.54773

70.54785

70.54798

70.54811

70.54823

70.54836

70.54848

70.54861

70.54874

70.54886

70.54899

70.54912

70.54924

70.54937

70.54950

70.54962

70.54975

70.54988

70.55000

70.55013

70.55026

70.55038

70.55051

70.55064

70.55400

70.55413

70.55425

70.55438

70.55451

70.55463

70.55476

70.55489

70.55501

70.55514

70.55526

70.55539

70.55552

70.55564

70.55577

70.55590

70.55602
92.77180

92.77180

92.77180

92.77179

92.77179

92.77179

92.77179

92.77179

92.77179

92.77179

92.77179

92.77179

92.77179

92.77179

92.77179

92.77179

92.77178

92.77178

92.77178

92.77178

92.77178

92.77178

92.77178

92.77178

92.77178

92.77178

92.77178

92.77178

92.77178

92.77178

92.77178

92.77178

92.77178

92.77178

92.77178

92.77178

92.77178

92.77178

92.77178

92.77178

92.77178

92.77178

92.77178

92.77178

92.77178

92.77178

92.77178

92.77178

92.77178

92.77178

92.77178

92.77178

92.77178

92.77178

92.77178

92.77177

92.77177

92.77177

92.77177

92.77177

92.77177

92.77177

92.77177 
WSRC-TR-99-00027

Revision 0

462.0000

464.0000

466.0000

468.0000

470.0000

472.0000

474.0000

476.0000

478.0000

480.0000

482.0000

484.0000

486.0000

488.0000

490.0000

492.0000

494.0000

496.0000

498.0000

500.0000

502.0000

504.0000

506.0000

508.0000

510.0000

512.0000

514.0000

516.0000

518.0000

520.0000

522.0000

524.0000

526.0000

528.0000

530.0000

532.0000

534.0000

536.0000

538.0000

540.0000

542.0000

544.0000

546.0000

548.0000

550.0000

552.0000

554.0000

556.0000

558.0000

560.0000

562.0000

564.0000

566.0000

568.0000

570.0000

572.0000

574.0000

576.0000

578.0000

580.0000

582.0000

584.0000

586.0000
58.26892

58.27867

58.28830

58.29781

58.30722

58.31651

58.32569

58.33477

58.34375

58.35262

58.36139

58.37006

58.37864

58.38711

58.39550

58.40379 .

58.41199

58.42011

58.42813

58.43607

58.44392

58.45169

58.45938

58.46699

58.47451

58.48196

58.48934

58.49664

58.50386

58.51101

58.51809

58.52510

58.53204

58.53891

58.54571

58.55245

58.55912

58.56573

58.57228

58.57876

58.58519

58.59155

58.59785

58.60410

58.61029

58.61643

58.62250

58.62853

58.63450

58.64041

58.64627

58.65209

58.65785

58.66355

58.66921

58.67482

58.68038

58.68590

58.69136

58.69678

58.70215

58.70748

58.71276
70.55615

70.55628

70.55640

70.55653

70.55665

70.55678

70.55691

70.55703

70.55716

70.55729

70.55741

70.55754

70.55767

70.55779

70.55792

70.55804

70.55817

70.55830

70.55842

70.55855

70.55868

70.55880

70.55893

70.55905

70.55918

70.55931

70.55943

70.55956

70.55969

70.55981

70.55994

70.56006

70.56019

70.56032

70.56044

70.56057

70.56070

70.56082

70.56095

70.56107

70.56120

70.56133

70.56145

70.56158

70.56171

70.56183

70.56296

70.56208

70.56221

70.56234

70.56246

70.56259

70.56271

70.56284

70.56297

70.56309

70.56322

70.56335

70.56347

70.56360

70.56372

70.56385

70.56398
92.77177

92.77177

92.77177

92.77177

92.77177

92.77177

92.77177

92.77177

92.77177

92.77177

92.77177

92.77177

92.77177

92.77177

92.77177

92.77177

92.77177

92.77177

92.77177

92.77177

92.77177

92.77177

92.77177

92.77177

92.77177

92.77177

92.77177

92.77177

92.77177

92.77177

92.77177

92.77177

92.77177

92.77177

92.77177

92.77177

92.77177

92.77177

92.77177

92.77177

92.77177

92.77177

92.77177

92.77177

92.77177

92.77177

92.77177

92.77177

92.77177

92.77177

92.77177

92.77177

92.77177

92.77177

92.77177

92.77177

92.77177

92.77177

92.77177

92.77177

92.77177

92.77177

92.77177 
WSRC-TR-99-00027

Revision 0

588.0000

590.0000

592.0000

594.0000

596.0000

598.0000

600.0000
58.71799

58.72318

58.72833

58.73343

58.73850

58.74351

58.74849
70.56410

70.56423

70.56435

70.56448

70.56461

70.56473

70.56486
92.77177

92.77177

92.77177

92.77177

92.77177

92.77177

92.77177 
$\underline{\text { Savannah River Technology Center }}$

M. L. Crowder, 773-24A

F. R. Graham, 773-A

J. R. Knight, 773-A

J. E. Laurinat, 773-A

M. C. Thompson, 773-A

C. R. Wolfe, 773-A

SRTC Records, 773-52A

Nuclear Materials Technology Division

Power Source Technologies

M. E. Pansoy-Hjelvik, MS E502

K. B. Ramsey, MS E502 